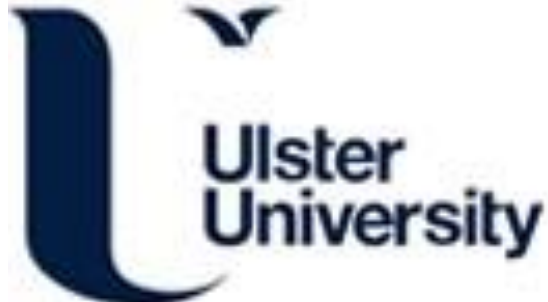

\section{The transcription factor HIF-1a mediates plasticity of NKp46+ innate lymphoid cells in the gut}

Krzywinska, E., Sobecki, M., Nagarajan, S., Zacharjasz, J., Tambuwala, M. M., Pelletier, A., Cummins, E., Gotthardt, D., Fandrey, J., Kerdiles, Y. M., Peyssonnaux, C., Taylor, C. T., Sexl, V., \& Stockmann, C. (2022). The transcription factor HIF-1 a mediates plasticity of NKp46+ innate lymphoid cells in the gut. Journal of Experimental Medicine, 219(2), [e20210909]. https://doi.org/10.1084/jem.20210909

Link to publication record in Ulster University Research Portal

\section{Published in:}

Journal of Experimental Medicine

Publication Status:

Published (in print/issue): 13/01/2022

DOI:

10.1084/jem.20210909

\section{Document Version}

Publisher's PDF, also known as Version of record

\section{General rights}

Copyright for the publications made accessible via Ulster University's Research Portal is retained by the author(s) and / or other copyright owners and it is a condition of accessing these publications that users recognise and abide by the legal requirements associated with these rights.

\section{Take down policy}

The Research Portal is Ulster University's institutional repository that provides access to Ulster's research outputs. Every effort has been made to ensure that content in the Research Portal does not infringe any person's rights, or applicable UK laws. If you discover content in the Research Portal that you believe breaches copyright or violates any law, please contact pure-support@ulster.ac.uk. 


\title{
ARTICLE
}

\section{The transcription factor HIF-1a mediates plasticity of NKp46+ innate lymphoid cells in the gut}

\author{
Ewelina Krzywinska ${ }^{1 *}$ (D) Michal Sobecki ${ }^{*}$ (D), Shunmugam Nagarajan ${ }^{1}$ D, Julian Zacharjasz ${ }^{1}$ (D), Murtaza M. Tambuwala ${ }^{2}$ (D), Abigaelle Pelletier ${ }^{1}$ (D), \\ Eoin Cummins ${ }^{3}$ (D), Dagmar Gotthardt ${ }^{4}$ D , Joachim Fandrey ${ }^{5}$ (D), Yann M. Kerdiles ${ }^{6}$ (D), Carole Peyssonnaux ${ }^{7,8}$ (D), Cormac T. Taylor ${ }^{3}$ (D), Veronika Sexl ${ }^{4}$ (D), \\ and Christian Stockmann ${ }^{1} \mathbb{D}$
}

Gut innate lymphoid cells (ILCs) show remarkable phenotypic diversity, yet microenvironmental factors that drive this plasticity are incompletely understood. The balance between NKp46+, IL-22-producing, group 3 ILCs (ILC3s) and interferon (IFN)-y-producing group 1 ILCs (ILC1s) contributes to gut homeostasis. The gut mucosa is characterized by physiological hypoxia, and adaptation to low oxygen is mediated by hypoxia-inducible transcription factors (HIFs). However, the impact of HIFs on ILC phenotype and gut homeostasis is not well understood. Mice lacking the HIF-1a isoform in NKp46+ ILCs show a decrease in IFN-y-expressing, T-bet ${ }^{+}$, NKp46 ${ }^{+}$ILC1s and a concomitant increase in IL-22-expressing, RORyt ${ }^{+}, \mathrm{NKp}^{2} 6^{+}$ILC3s in the gut mucosa. Single-cell RNA sequencing revealed HIF-1a as a driver of ILC phenotypes, where HIF-1a promotes the ILC1 phenotype by direct up-regulation of T-bet. Loss of HIF-1a in NKp46+ cells prevents ILC3-to-ILC1 conversion, increases the expression of IL-22-inducible genes, and confers protection against intestinal damage. Taken together, our results suggest that HIF-1a shapes the ILC phenotype in the gut.

\section{Introduction}

In the small intestine (SI), the single-cell layer of epithelial cells with a rather porous mucus layer on top allows efficient nutrient absorption, at the risk of compromised barrier function and bacterial penetration (Johansson and Hansson, 2016). Therefore, these processes have to be tightly coordinated and balanced against each other, and innate lymphoid cells (ILCs) play a crucial role in intestinal adaptation to microenvironmental challenges (Diefenbach et al., 2020; Colonna, 2018). ILCs are a heterogeneous population of non- $B$, non- $T$ lymphocytes with critical function for gut homeostasis (Diefenbach et al., 2014; Eberl et al., 2015; Klose and Artis, 2016). The three major groups of ILCs are defined by the secretion of distinct cytokines, the expression of lineage-defining transcription factors that define the phenotype, and distinctive surface markers. T-box expressed in T cell-positive (T-bet ${ }^{+}$) ILCls, which include the natural killer (NK) cell subset, produce proinflammatory IFN- $\gamma$; GATA3 ${ }^{+}$ILC2s secrete IL-5, IL-9, IL-13, and amphiregulin; and retinoic acid receptor-related orphan receptor $\gamma$-positive $\left(\mathrm{ROR}_{\mathrm{t}} \mathrm{t}^{+}\right)$ILC3s produce IL-22 and IL-17. In addition to NKp46ILC3s, murine ROR $\gamma \mathrm{t}^{+}$ILC3s make up a NKp46 ${ }^{+}$ILC3 subset that is specialized in IL-22 secretion, which induces the expression of prohomeostatic factors in gut epithelial cells to maintain barrier integrity and homeostasis (Diefenbach et al., 2014; Eberl et al., 2015; Klose and Artis, 2016; Sanos et al., 2011). Moreover, ILC3derived IL-22 is involved in the regulation of fat absorption in the SI (Mao et al., 2018; Talbot et al., 2020; Seillet et al., 2020; Wang et al., 2014, 2017).

ILCs are highly plastic, and ILC subsets can interconvert in response to cytokines (Colonna, 2018). Notably, ILC3 plasticity has been demonstrated in mice and humans, and NKp46+ ILC3s can convert into IFN- $\gamma$-producing NKp46 ${ }^{+}$ILCls in response to IL-12 (Vonarbourg et al., 2010; Bernink et al., 2015; Forkel and Mjösberg, 2016). This process requires a coordinate decrease in ROR $\gamma t$ and increase in T-bet (Klose et al., 2013; Rankin et al., 2013; Sciumé et al., 2012). Moreover, it has been recently demonstrated that loss of T-bet in NKp46+ ILC3s results in accumulation of CCR6- NKp46- ILC3s (Schroeder et al., 2021). Of note, ILC3 to ILC1 skewing in response to the cytokine IL-12 with reduced IL-22 expression and increased levels of IFN- $\gamma$ has been recognized as a pathogenic event during

${ }^{1}$ Institute of Anatomy, University of Zurich, Zurich, Switzerland; ${ }^{2}$ School of Pharmacy \& Pharmaceutical Sciences, Ulster University, Coleraine, UK; ${ }^{3}$ School of Medicine, University College Dublin, Conway Institute, Dublin, Ireland; ${ }^{4}$ Institute of Pharmacology and Toxicology, University of Veterinary Medicine, Vienna, Austria; 5 Institut für Physiologie, Universitätsklinikum Essen, Universität Duisburg-Essen, Essen, Germany; ${ }^{6}$ Centre d'Immunologie de Marseille-Luminy, Aix Marseille Université UM2, Institut National de la Santé et de la Recherche Médicale, U1104, Centre National de la Recherche Scientifique UMR7280, Marseille, France; 7Université de Paris, Institut Cochin, Institut National de la Santé et de la Recherche Médicale, Centre National de la Recherche Scientifique, Paris, France; ${ }^{8}$ Laboratory of Excellence GR-Ex, Paris, France.

${ }^{*}$ E. Krzywinska and M. Sobecki contributed equally to this paper; Correspondence to Christian Stockmann: christian.stockmann@anatomy.uzh.ch.

(c) 2022 Krzywinska et al. This article is distributed under the terms of an Attribution-Noncommercial-Share Alike-No Mirror Sites license for the first six months after the publication date (see http://www.rupress.org/terms/). After six months it is available under a Creative Commons License (Attribution-Noncommercial-Share Alike 4.0 International license, as described at https://creativecommons.org/licenses/by-nc-sa/4.0/). 
inflammatory bowel disease (Forkel and Mjösberg, 2016; Bernink et al., 2015).

The gut mucosa is characterized by physiological hypoxia in the healthy state, because of its juxtaposition with the oxygendepleted lumen of the gut (Colgan and Taylor, 2010; Fagundes and Taylor, 2017; Campbell et al., 2014). Cellular adaptation to low oxygen is mediated by hypoxia-inducible transcription factors (HIFs), with HIF-1 and HIF-2 being the most extensively studied isoforms (Semenza, 2012; Kaelin and Ratcliffe, 2008). HIFs are basic helix-loop-helix transcription factors that consist of a constitutively expressed $\beta$-subunit and an oxygen-labile $\alpha$-subunit. In the presence of oxygen, the $\alpha$-subunit is hydroxylated by prolyl hydroxylases and subsequently degraded through the ubiquitin proteasome pathway via interaction with its negative regulator von Hippel-Lindau (VHL) protein (Kaelin, 2008; Schofield and Ratcliffe, 2004). In inflammatory bowel disease, the degree of hypoxia found in the intestinal mucosa is exacerbated, leading to a more extensive and severe hypoxia. Designated inflammatory hypoxia, it can contribute to disease development through the regulation of mucosal immune cell function (Fagundes and Taylor, 2017; Taylor and Colgan, 2017; Taylor et al., 2016; Scholz and Taylor, 2013). A recent study by Fachi et al., (2021) investigated a deletion of HIFla in ILCs under the ROR $\gamma$ t promoter. The loss of HIF-1a led to impaired ILC3 activation and proliferation, as well as reduced IL-17 and IL-22 production by ILC3 in vitro and in vivo. This resulted in reduced expression of IL-17 and IL-22 target genes in the gut and an increased susceptibility to Clostridiodes difficile infection. Although the RORYt promoter does not distinguish $\mathrm{NKp} 46^{-}$and NKp46 ${ }^{+}$ ILCs, this finding demonstrates a critical role of microenvironmental factors such as hypoxia for phenotype and function of different ILC subsets and warrants further elucidation (Colonna, 2018; Diefenbach et al., 2014). Therefore, we examined the role of HIF-1a in NKp46+ ILCs in steady-state gut function and murine models of inflammatory bowel disease.

\section{Results}

\section{HIF-1a in NKp46 ${ }^{+}$cells favors an ILC1 phenotype in the SI}

To test the role of HIF-1a in NKp46 $6^{+}$gut ILCs, we created an in vivo, targeted deletion of HIF-1 $\alpha$ via crosses of the loxPflanked HIF-1 $a$ allele to the Ncrl (NKp46) promoter-driven Cre recombinase, specific to NKp46-expressing ILC1s and ILC3s $\left(\mathrm{Ncrl}^{\mathrm{cre}+}\right.$ Hif- $1 \alpha^{\mathrm{fl}+/ \mathrm{fl}+}$ mice, termed HIF-1 $\alpha$ knockout (KO; Eckelhart et al., 2011; Krzywinska et al., 2017).

The distribution of ILCs differs along the gastrointestinal tract, with a progressive increase of total ILCs from the proximal SI to the distal colon (Krämer et al., 2017). First, we analyzed the abundance of the different NKp46+ ILC subsets in the lamina propria of the SI by means of flow cytometry. While the frequency and absolute number of NKp46 ${ }^{+}$ILCs (defined as $\mathrm{CD}_{4} 5^{+}, \mathrm{Lin}^{-}, \mathrm{CD} 127^{+}$, NKp46 $6^{+}$; see Fig. S1 B for detailed gating

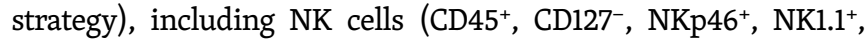
Eomes ${ }^{+}$), were similar across genotypes (Fig. S1 A), we noted a drastic increase in the NKp46 ILC3/ILC1 ratio in the SI of HIF$1 a \mathrm{KO}$ mice, owing to a $50 \%$ reduction in NKp46+ $\mathrm{ILCl}$ (defined as NKp46 ${ }^{+}$ROR $\gamma t^{-}$T-bet ${ }^{+}$NK1.1 $1^{+}$CD49a ${ }^{+}$) and a 1.5-fold increase in
NKp46+ ILC3 (NKp46+ ROR $\gamma \mathrm{t}^{+}$CD49a-) frequencies, as well as absolute cell numbers compared with WT littermates (Fig. $1 \mathrm{~A}$ ). Besides a reduction in $\mathrm{CD} 4^{+} \mathrm{T}$ cells, other immune cell populations, including neutrophils, macrophages, eosinophils, dendritic cells, and B cells, were similarly abundant across genotypes (Fig. S1 C; see Fig. S1 B for detailed gating strategy). The ability of intestinal CD4 ${ }^{+} \mathrm{T}$ cells to produce IFN- $\gamma$ and IL-22, however, is not affected by the deletion of HIF- $1 \alpha$ in NKp46 $6^{+}$ cells (Fig. S1 D). Next, we analyzed NKp46 ${ }^{+}$cells for intracellular levels of the signature cytokines IFN- $\gamma$ in ILC1s and IL-22 in ILC3s. In addition to the increased ILC3-to-ILC1 ratio (Fig. 1 A), HIF-1 $\alpha$ deficiency in NKp46 cells led to a decrease in IFN- $\gamma$ expression in ILC1s and increased expression of IL-22 in ILC3s (Fig. 1 B). Consistently, we also observed a decrease in Ifng transcripts but increased expression of Il22 in the SI mucosa of HIF-1a KO mice (Fig. $1 \mathrm{C}$ ), highlighting the physiological relevance of HIF-1a in NKp46 cells at the whole-organ level. Given the importance of IL-22 for gut homeostasis and defense, we evaluated the expression of IL-22-inducible genes in the SI. As depicted in Fig. 1 D, the gene expression of critical guthomeostatic factors, including regenerating islet-derived protein $3 \alpha, \beta$, and $\gamma$ (Reg3a, Reg3b, Reg3g), defensin a 21 (Defa21), and Mucin 2 (Muc2), was increased in the SI from HIF-1a KO mice (Sanos et al., 2011; Diefenbach et al., 2020). Taken together, these results demonstrate that loss of HIF-1 $1 \alpha$ in gutassociated NKp $46^{+}$ILCs favors the IL-22-driven expression of prohomeostatic defense genes in the SI.

\section{Single-cell RNA sequencing (scRNA-seq) suggests HIF-1a as a driver of NKp46+ ILC phenotypes}

To unequivocally identify NKp $46^{+}$cells in vivo for subsequent sorting, we generated WT and HIF-1a KO fluorescent reporter mouse lines by crossing the Ncrl (NKp46) Cre (Eckelhart et al., 2011) with mice that harbor the B6.Cg-Gt(ROSA)26Sortml(EYFP) Cos-Tg (Srinivas et al., 2001) or the B6.Cg-Gt(ROSA)26Sort$\mathrm{ml}$ (EYFP)Cos-HIF-1 $\mathrm{a}^{\mathrm{l}+/ \mathrm{ll}+}$ fluorescent reporter constructs, resulting in WT (B6.Cg-Gt(ROSA)26Sortm1(EYFP)Cos-Tg(NCR1-Cre), termed EYFP-WT) and HIF-1a null (B6.Cg-Gt(ROSA)26Sortm1(EYFP)Cos-Tg(NCR1-Cre)-HIF-1 $\alpha^{\mathrm{fl}+\mathrm{fl}+1}$, termed EYFP-HIF-1a KO) reporter mice. Of note, this reporter approach has been described to label up to $30 \%$ of former NKp46+ ILC3s that lost NKp46 expression with EYFP (Viant et al., 2016; Verrier et al., 2016). We verified NKp46 expression with an additional staining on EYFP-sorted cells (see Fig. S3 A). In our hands, the percentage of NKp46- cells within the EYFP-sorted cells was 10\% across genotypes.

To determine the transcriptional profiles of sorted NKp46 cells from the SI of WT and HIF-1a KO mice in an unbiased approach, we performed scRNA-seq (10X Genomics). We analyzed 12,974 single cells (6,826 WT and 6,148 HIF-1a KO cells) and detected a median of 1,939 gene transcripts per cell in WT and 2,101 in HIF-1a KO. This readily allowed us to distinguish the ILC1 and ILC3 populations (Fig. 2 A). Unsupervised clustering of all sequenced cells across both genotypes revealed 14 distinct clusters based on transcript signatures (Fig. $2 \mathrm{~A}$ ), with 3 subclusters in the ILC1 population (clusters 4, 7, and 9, of which cluster 9 represents conventional NK cells) and 11 subclusters (clusters $0,1,2,3,5,6,8,10,11,12$, and 13) in the ILC3 subset 
A
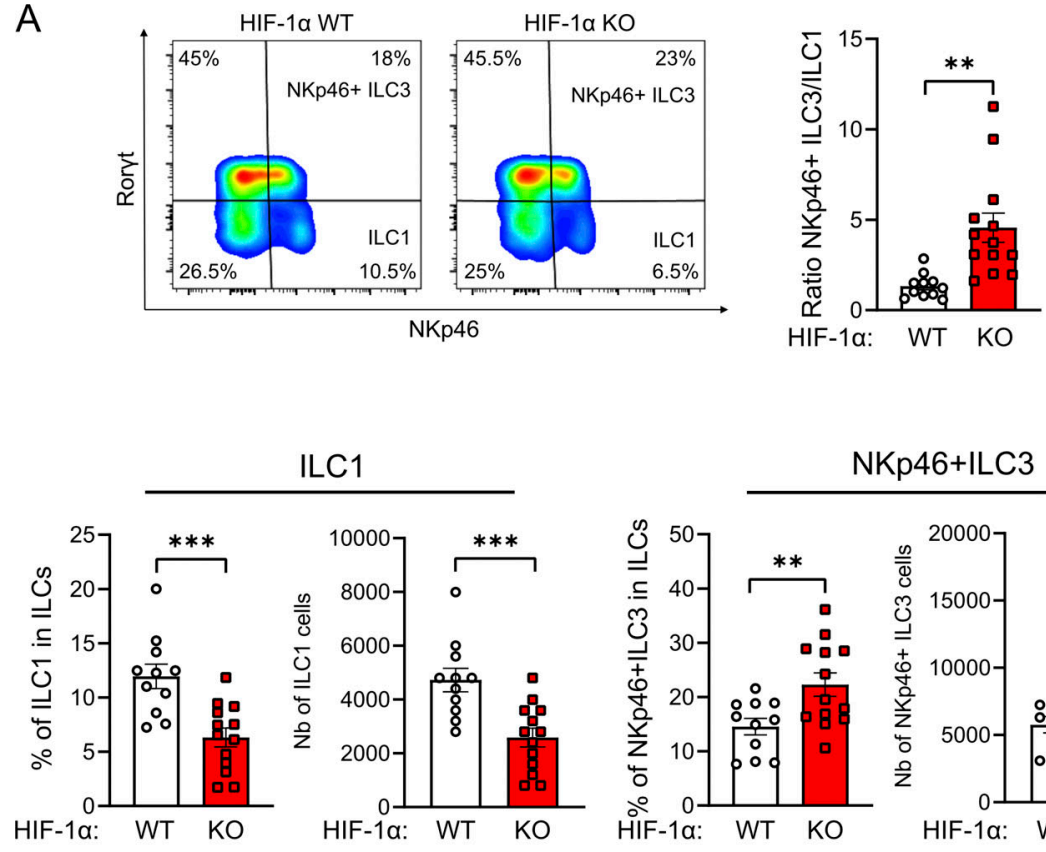

ILC1

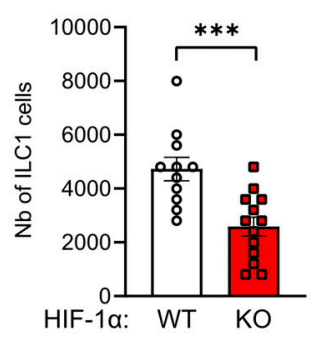

HIF-1a: WT KO

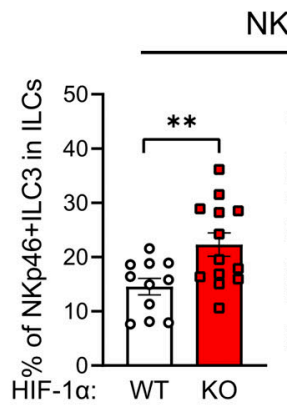

NKp46+ILC3

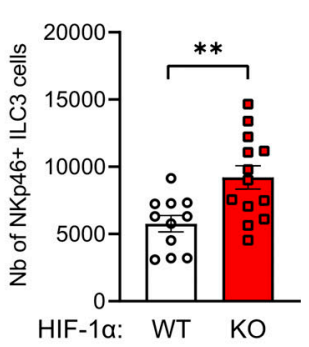

B

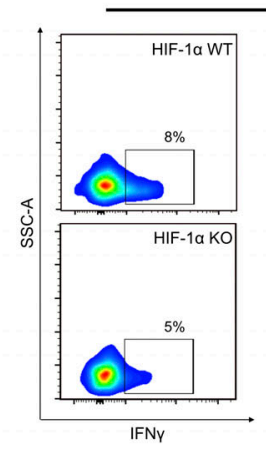

ILC1

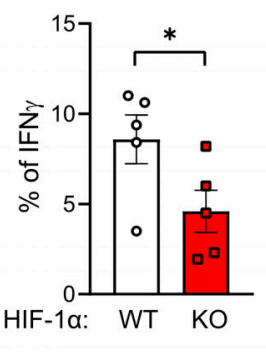

C

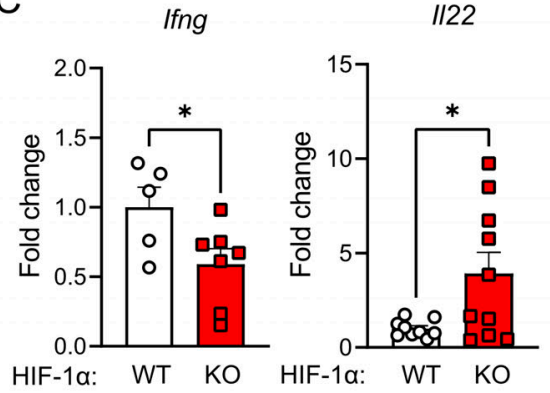

Figure 1. HIF-1a in NKp46+ cells favors an ILC1 phenotype in the SI. (A) Top: Representative FACS plots showing the frequency of small intestinal ILCls, NKp46+ ILC3s in the alive $\mathrm{Lin}^{-}$ $\mathrm{CD}_{127^{+}}$cells from HIF-1a KO and HIF-1a WT mice, and the ratio of NKp46+ ILC3 to ILC1 from HIF-la KO and HIF-la WT mice. Bottom: Quantitative analysis of frequency and absolute number of small intestinal ILCls and NKp46 (pooled data of three independent experiments, $n \geq 11)$; data are mean values $\pm S E M$; ${ }^{* *}, P<0.01$; ${ }^{* * *}, \mathrm{P}<0.001$ by two-tailed Student's $t$ test. (B) Left: Representative FACS plots showing the frequency of IFN- $y$-expressing small intestinal ILCls from HIF-la KO and HIF-la WT mice stimulated with PMA/ionomycin and corresponding quantitative analysis (pooled data of two independent experiments, $n=5$ ); data are mean values \pm SEM; ${ }^{*}, \mathrm{P}<0.05$ by two-tailed Student's $t$ test. Right: Representative FACS plots showing the frequency of IL-22-expressing small intestinal NKp46+ ILC3s from HIF-1a KO and HIF-la WT mice stimulated with PMA/ionomycin and corresponding quantitative analysis (pooled data of two experiments, $n=5$ ), twotailed Student's $t$ test. SSC, side scatter. (C) Gene expression of 1122 and Ifng in small intestinal tissues from HIF-la KO and HIF-la WT mice, as fold-change to the WT samples (pooled data of three independent experiments, $n=8$ ); data are mean values \pm SEM; ${ }^{*}, \mathrm{P}<0.05$ by twotailed Student's $t$ test. (D) Gene expression analysis of IL-22-dependent gut-homeostatic factors such as Reg3a, Reg3b, Reg $3 g$, Defa21, and Muc2 in small intestinal tissues from HIFla KO and HIF-la WT mice (pooled data of three independent experiments, $n=10$ ); data are mean values $\pm \mathrm{SEM} ;{ }^{*}, \mathrm{P}<0.05 ;{ }^{* *}, \mathrm{P}<0.01$ by multiple two-tailed Student's $t$ test.
(Fig. 2 A). WT and HIF-1a KO NKp46 ${ }^{+}$cells showed a distinct distribution across the clusters as displayed in contour plots of the Uniform Manifold Approximation and Projection (UMAP) representation in Fig. 2 B. WT NKp46 ${ }^{+}$ILCs clustered differentially in the ILC3 clusters 1 (16.1\% versus $8.9 \%$ in HIF-1a KO) and the ILC1 cluster 4 ( $9.7 \%$ versus $6.8 \%$ in HIF-1 $\alpha \mathrm{KO}$ ), whereas HIF1a KO NKp $46^{+}$ILCs were predominantly represented in the ILC3 clusters $3(12.4 \%$ versus $5.4 \%$ in WT) and 8 ( $8.6 \%$ versus $5.3 \%$ in WT; Fig. 2 C). The distinct distribution of both genotypes within the ILC3 cluster was further corroborated by a differential abundance analysis based on differential expression of clusterdefining genes (Zhao et al., 2021; Fig. 2 D). Next, we analyzed differential expression of relevant genes that encode for surface markers, intracellular proteins and transcription factors between the different clusters. Of note, clusters 3 and 8 within ILC3s are characterized by high Rorc (the gene that encodes for the transcription factor ROR $\mathrm{t}$ ) and low Tbx21 (the gene that encodes for the transcription factor T-bet) expression, relative 


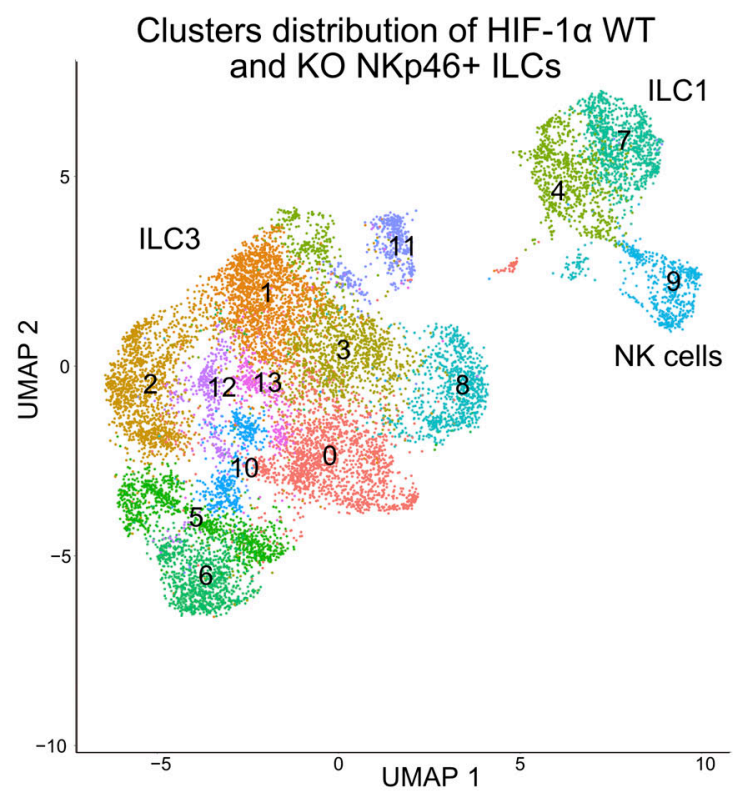

B

Cells distribution within clusters HIF-1aWT HIF-1a KO
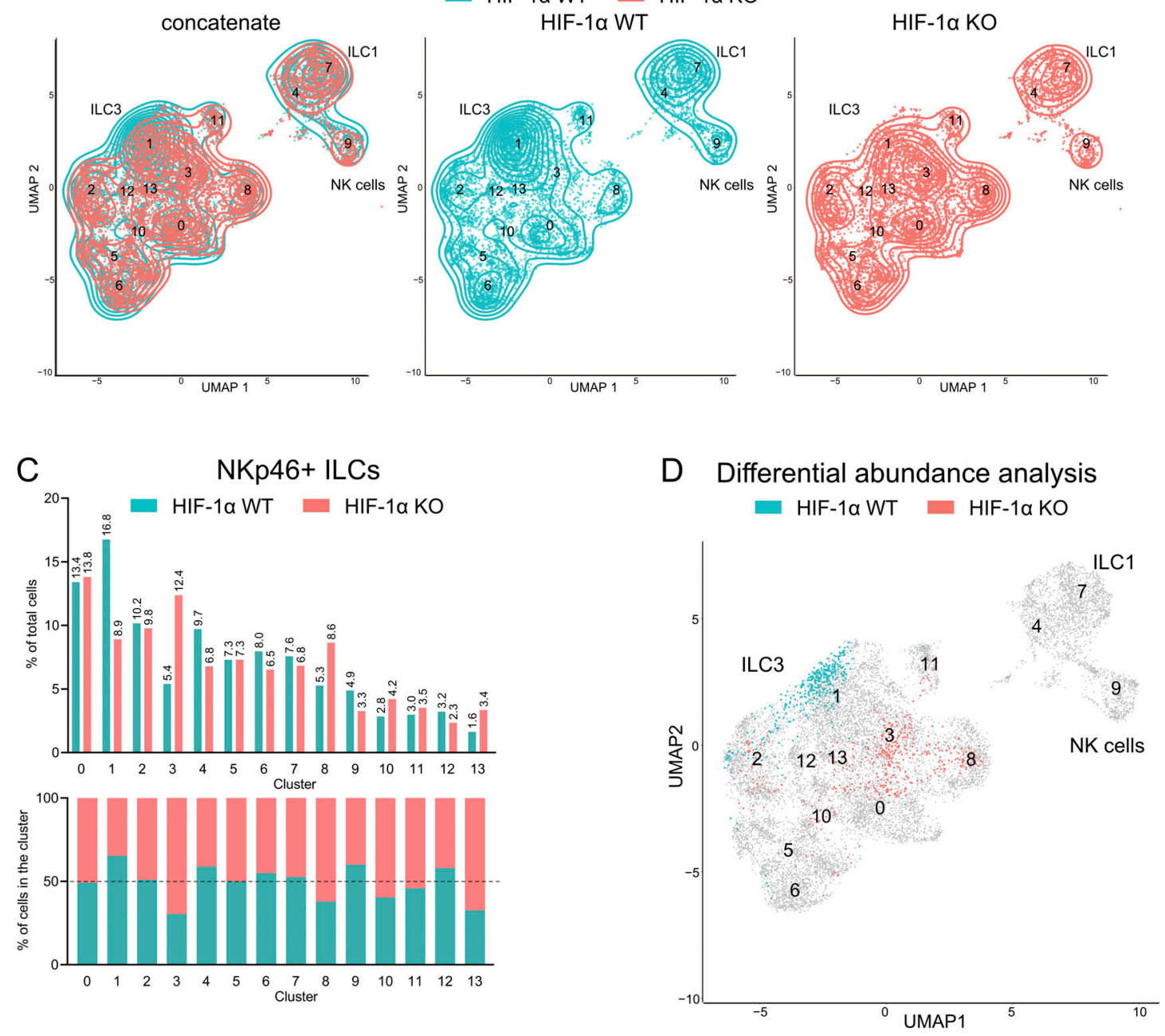

Figure 2. Deletion of HIF-1a alters the transcriptional landscape of NKp46+ ILCs. (A) UMAP plot showing the 12,974 single small-intestinal NKp46 ILCs (6,826 of HIF-1a WT cells and 6,148 of HIF-1a KO cells) defining 14 clusters. (B) Contour plot of the UMAP representation showing the distribution of HIFla WT and HIF-1a KO NKp46+ ILCs across all clusters, displayed as concatenated and separated samples. (C) Quantitative analysis of HIF-la WT and HIF-1a KO cells across all clusters. Percentages of HIF-1a WT and HIF-1a KO NKp46+ ILCs within each cluster among total NKp46 ILC cells (top) and percentage of occupancy within each cluster (bottom). (D) UMAP plot showing differential abundance analysis of HIF-1a WT and HIF-1a KO NKp46 ILCs representing two distinct subpopulations. 
to most other ILC3 clusters, including cluster 1 (Fig. 3 A). This was furthermore associated with increased expression of the ILC3 signature genes (Gury-BenAri et al., 2016), Zfp36, Jun, Batf, Il22, and Csf2 in clusters 3 and 8 , respectively (Fig. 3 A). A comparison of gene expression between the two genotypes within each cluster revealed higher expression of Rorc, Zfp36, Jun, Batf, Il22, and Csf2 in HIF-1a KO NKp46+ cells in the majority of clusters (Fig. $3 \mathrm{~A}$ ). Hence, loss of HIF-1 $\alpha$ in NKp $46^{+}$cells resulted in an enrichment and expansion of cells in clusters with an ILC3 gene signature. To investigate the relationship between these clusters, we performed a trajectory analysis rooted in cluster 6 using PAGA tree (Fig. 3 B). This revealed two main trajectories, along which WT and HIF-1a KO NKp46+ progressed differentially. Trajectory 1 led through the ILC cluster 1 toward ILC1 clusters 4, 7, and 9 and was dominated by WT NKp46+ ILCs. In contrast, trajectory 2, which showed an abundance of HIF-1a KO NKp46+ ILCs, led to the ILC3 clusters 3 and 8 (Fig. 3 B). Progression along trajectory 1 was associated with loss of Rorc expression and the up-regulation of Hifla and Tbx21, whereas cells on trajectory 2 exhibited a decrease in Hifla and Tbx21 expression along with an up-regulation of Rorc (Fig. $3 \mathrm{C}$ ). Therefore, we concluded that loss of HIF-1a in $\mathrm{NKp}^{+} 6^{+}$promotes an ILC3 phenotype, which eventually renders HIF-1a KO NKp46+ ILC3s less prone to conversion into ILC1s. This further suggests a role for HIF-1a in modulating the phenotype of NKp46+ ILCs.

\section{HIF-1a contributes to ILC3-to-ILC1 conversion in NKp46+ cells} Prompted by the scRNA profiling and the observation that HIF1a KO mice harbor increased ILC3 and reduced ILC1 frequencies in the gut, we wanted to test whether HIF-1a is instrumental in the conversion of NKp46 ILC3s to ILC1s. The balanced expression and relative gradients of the transcription factors ROR $\gamma t$ (encoded by the gene Rorc) and T-bet (encoded by Tbx21) control the ILC phenotype and the transition between the ILC3 and ILC1 states (Klose et al., 2013; Vonarbourg et al., 2010; Diefenbach et al., 2014; Colonna, 2018). As shown in Fig. 4 A, ILC1s and NKp46 ${ }^{+}$ILC3s from the SI of HIF-1a KO mice exhibited lower levels of T-bet, and in HIF-1a-deficient NKp46 ${ }^{+}$ILC3s, this was associated with increased ROR $\gamma$ t expression (Fig. 4 A). To investigate potential transcriptional control of Tbx21 by HIF-1a, we sought to analyze the relative mRNA expression of Tbx21 and its counterpart Rorc in sorted WT and HIF-1a KO NKp46+ ILC3s and ILC1s. To do so, we took advantage of our EYFP-expressing reporter mouse lines and performed gene expression analysis on sorted $\mathrm{EYFP}^{+}, \mathrm{NKp}^{+} 6^{+}, \mathrm{CD} 45^{\text {low }}, \mathrm{CD} 90^{\text {high }}$ ILC3s and EYFP ${ }^{+}$, NKp46 ${ }^{+}$, CD45 high, CD90low ILC1s (Li et al., 2016) from the SI of EYFP-WT and EYFP-HIF-1a KO mice (Fig. 4 B). This approach also allowed us to determine the deletion efficiency for HIF$1 a$ defined by reduced expression of Hifla mRNA, which was $\sim 95 \%$ in both NKp46+ ILC3s and ILC1s (Fig. 4 C). As shown in Fig. $4 \mathrm{D}$, the loss of HIF-1a resulted in a decrease in Tbx21 transcripts in HIF-1a KO ILCls, and this was associated with lower expression of Ifng. HIF-1a-deficient NKp46+ ILC3s showed increased Rorc and Il22 expression, with unchanged levels of Tbx21 and Ifng transcripts. HIFs control the transcription of target genes by binding to hypoxia-responsive elements (HREs) with the highly conserved consensus sequence $5^{\prime}$-RCGTG-3' within the promoter and enhancer regions (Wenger et al., 2005; Schödel et al., 2011). We thus performed an in silico search for the most frequent HIF binding motifs, 5'-ACGTG-3' and 5'GCGTG-3' (while excluding the common Ebox motif 5' -CACGTG3'; Wenger et al., 2005; Schödel et al., 2011) in the promoter region of Tbx21. We identified three potential HIF-binding sites in the promoter of Tbx21 (Fig. 4 E). Finally, we performed Cut \& Run for HIF-1a, an alternative method to chromatin immunoprecipitation for low-abundance cell types that allows mapping of protein-DNA interactions, with $\mathrm{EYFP}^{+} \mathrm{NKp}^{4} 6^{+}$ILCs from the SI of EYFP-WT and EYFP-HIFla KO mice after $8 \mathrm{~h}$ of normoxic incubation with IL-12, a cytokine that induces ILC3-to-ILC1 conversion (Bernink et al., 2015). As shown in Fig. 4 F, IL-12 induces the recruitment of HIF-1a to Tbx21 promoter. These findings suggest that HIF-1a drives T-bet expression.

The cytokine IL-12 induces ILC3-to-ILC1 conversion, whereas a cocktail of IL-1 $\beta / \mathrm{IL}-23$ reverses this process (Bernink et al., 2015). To test whether HIF-1 $\alpha$ is involved in ILC conversion in vitro, we made use of EYFP ${ }^{+} \mathrm{NKp} 46^{+}$ILCs from the SI of EYFPWT and EYFP-HIF-1a KO mice. We sorted EYFP ${ }^{+}, \mathrm{NKp}^{+} 6^{+}$, CD45 ${ }^{\text {low }}, \mathrm{CD} 0^{\text {high }}$ ILC3s and EYFP ${ }^{+}, \mathrm{NKp} 46^{+}, \mathrm{CD} 45^{\text {high }}$, CD90 low ILC1s (Li et al., 2016) from the SI of EYFP-WT and EYFP-HIFla KO mice (Fig. 4 B). Next, we challenged sorted ILC3s and ILC1s with IL-12 and IL-1 $/$ IL-23, respectively, in the presence of the ILC-maintaining cytokine IL-7 for $20 \mathrm{~h}$ to monitor changes in the expression of ROR $\gamma \mathrm{t}$ and T-bet (relative to time point $0 \mathrm{~h}$, as prestimulation condition). As expected, IL-7 and IL-7/IL-1 $\beta / \mathrm{IL}-$ 23 induced RORYt and decreased T-bet expression in ILC1s (Fig. $5 \mathrm{~A}$ ); however, there was a trend toward increased RORYt expression and significantly reduced T-bet expression in HIF1a-deficient ILC1s after cytokine challenge (Fig. 5 A). Likewise, IL-7 and IL-7/IL-12 of ILC3s led to a decrease in ROR $\gamma$ t expression and an up-regulation of T-bet, both of which were less pronounced in the absence of HIF-1a (Fig. 5 B).

Next, we sought to evaluate whether HIF-1a is involved in the IL-12-induced conversion of NKp46 ${ }^{+}$ILC3s into ILC1s in vivo. For this purpose, we adoptively transferred sorted $\mathrm{EYFP}^{+}$, NKp46 ${ }^{+}$, CD45 $5^{\text {low }}$, CD90high ILC3s (Li et al., 2016) from the SI of EYFP-WT and EYFP-HIF-1a KO mice, into lymphopenic Rag2 ${ }^{-/-} \mathrm{Yc}^{-/-}$mice and allowed them to home and expand for 5 wk, followed by in vivo stimulation with IL-12 for $48 \mathrm{~h}$ (Fig. $6 \mathrm{~A}$ ). Prior to stimulation with IL-12, the majority of transferred cells showed low T-bet and high ROR $\gamma$ t expression, indicating a preserved ILC3 phenotype across genotypes (Fig. 6 B). Upon IL12 exposure, transplanted EYFP-WT cells up-regulated T-bet expression and decreased ROR $\gamma t$ levels, whereas in EYFP-HIFla KO cells, the up-regulation of T-bet was impaired and ROR $\gamma \mathrm{t}$ expression was preserved (Fig. $6 \mathrm{C}$ ). This suggests that HIFla controls T-bet and subsequently the ILC1 phenotype in response to IL-12 at the transcriptional level. As a consequence, loss of HIF-1a maintains the ILC3 state in gut $\mathrm{NKp} 46^{+}$cells via reduced T-bet expression.

\section{HIF-1a in NKp46 ${ }^{+}$cells mediates intestinal homeostasis}

Next, we evaluated the physiological relevance of HIF signaling in $\mathrm{NKp} 46^{+}$ILCs in steady-state conditions. Although loss of 

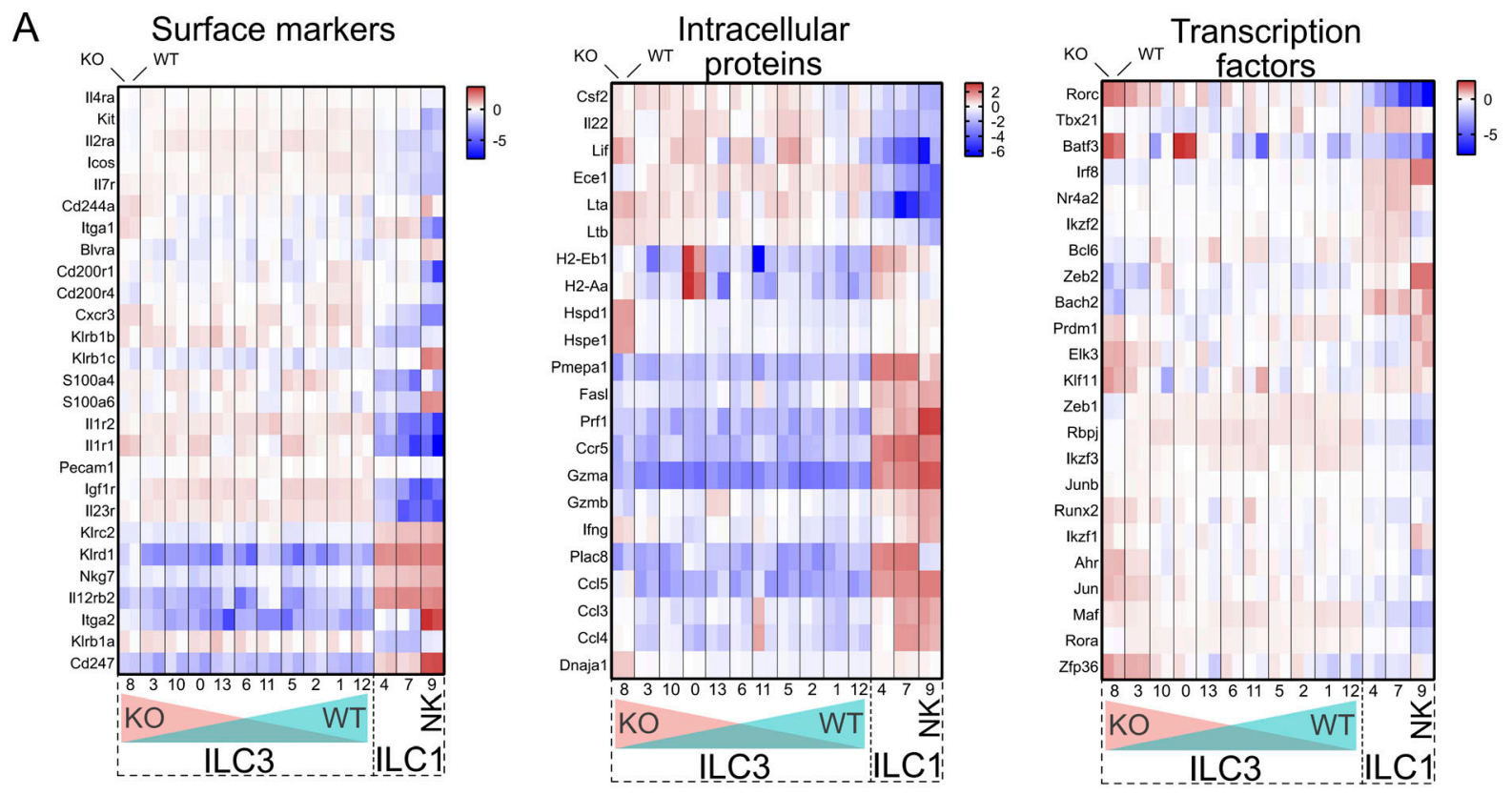

B
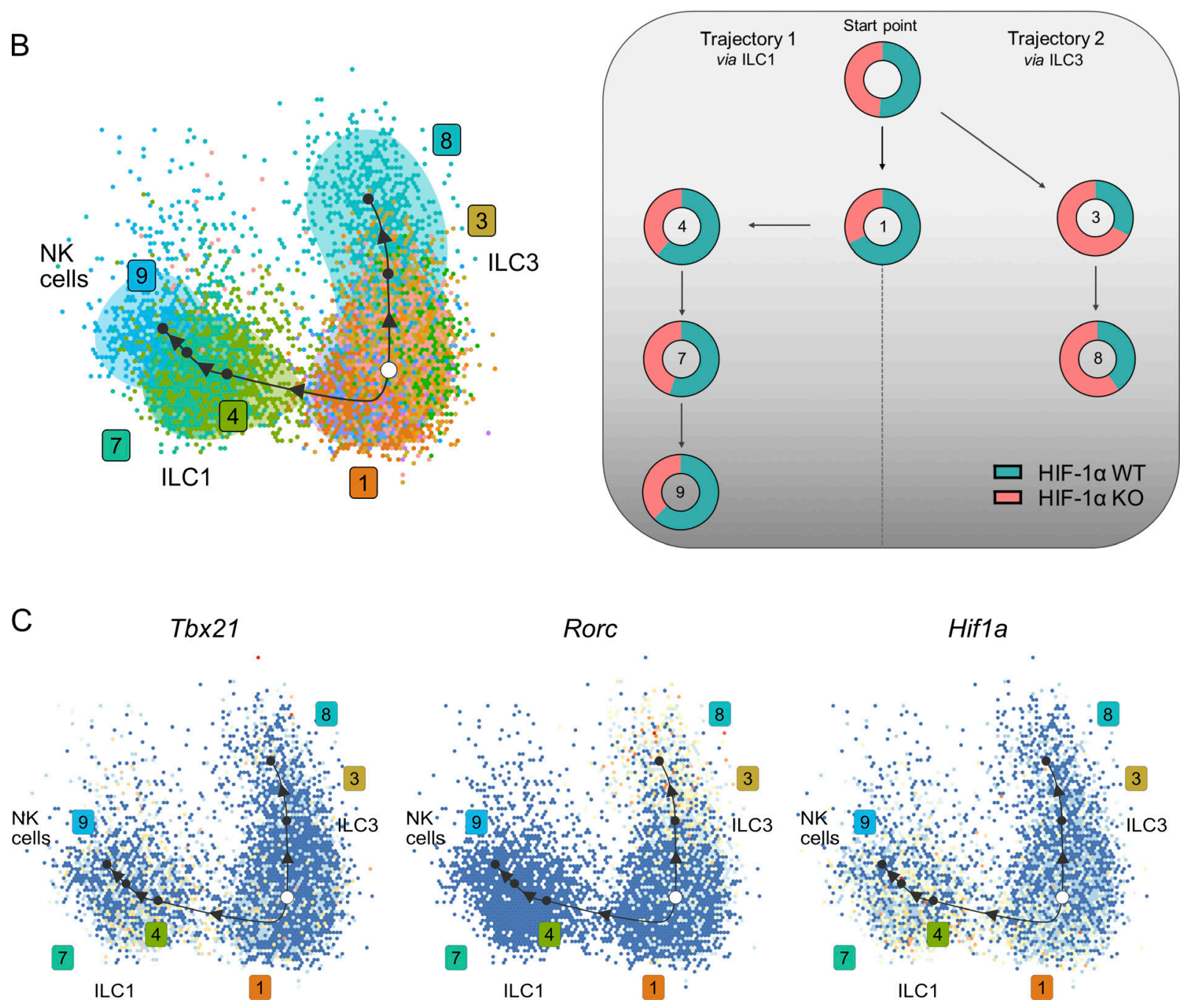

Figure 3. Single-cell RNA-seq suggests HIF-1a as a mediator of NKp46+ ILC phenotypes. (A) Heatmap of the expression of the main ILC markers across all clusters in HIF-1a WT (left cell) and HIF-1a KO (right cell) NKp46+ ILCs divided into three groups: surface markers, intracellular proteins, and transcription 
factors. (B) Trajectory analysis of the 12,974 single small-intestinal NKp46+ ILCs using PAGA tree method together with the composition of clusters along trajectories based on the proportion of contributed cells. (C) Expression of Tbx21, Rorc, and Hif1a along the trajectory analysis.

HIF-1a in NKp46 ${ }^{+}$cells did not cause any obvious changes in SI histology (Fig. S2 A), we wanted to interrogate whether the deletion of HIF-1a in NKp46+ cells translates into global alterations in mucosal gene expression. To this end, we performed whole-tissue RNA-seq on the SI from WT and HIF-1a KO mice at steady state. The absence of HIF-1a in NKp46 ${ }^{+}$cells led to differential gene expression with 686 up- and 549 down-regulated genes in the SI from HIF-1a KO mice (Fig. S2 B). Gene ontology (GO) enrichment analysis revealed that the up-regulated genes are associated with cellular response to fatty acid, steroid biosynthetic process, hormone secretion, and ion transport (Fig. S2, $\mathrm{C}$ and $\mathrm{D}$ ). In contrast, the down-regulated genes are involved in processes such as fructose metabolism, intestinal lipid absorption, positive regulation of triglyceride metabolic process, and lipid homeostasis (Fig. S2, C and D). Using quantitative real-time PCR (qPCR), we confirmed the reduced expression in mRNAs coding for key lipid binding and transport proteins, including the fatty acid translocase, Cd36; intestinal-type fatty acidbinding protein 2, Fabp2; the lipid and cholesterol transporter Niemann-Pick C1-like protein 1, Npclli; and the membraneassociated phospholipase A2, Plazg2, in the SI of cohoused WT and HIF-1a KO mice on a standard chow diet at the age of $8 \mathrm{wk}$ (Fig. S2 E). At the whole-body level, this change was associated with significantly decreased serum levels of triglycerides in HIF1a KO mice, whereas serum cholesterol was similar across genotypes (Fig. S2 F). Although body weight was similar across genotypes at the age of $8 \mathrm{wk}$, HIF-1a KO mice exhibited reduced body weight when the mice reached the age of $12 \mathrm{wk}$ (Fig. S2 G). Next, whole-body magnetic resonance imaging to quantify the fat and lean mass of 12-wk-old cohoused WT and HIF-1a KO mice on a standard chow diet revealed reduced fat mass and a relative increase in lean body mass in HIF-1a KO mice (Fig. S2 H). The reduction in body fat content in HIF-1a KO mice (12 wk) was further corroborated by a decrease in visceral fat, as evidenced by weighing of gonadal adipose depots (Fig. S2 I). This suggests that HIF-1 $1 \alpha$ expression in gut-associated NKp46 ILCs promotes an ILC1 phenotype and intestinal lipid uptake. In contrast, the observed shift in NKp46+ cell populations toward ILC3s and the persistent increase in IL-22 in the absence of HIF-1 1 promote a lean phenotype and, hence, are biologically relevant.

Tissue damage in the gut is associated with profound mucosal hypoxia (Colgan and Taylor, 2010; Fagundes and Taylor, 2017). Considering the critical role of ILC1s and ILC3s as well as IL-22 in gut homeostasis and mucosal protection against injury (Aparicio-Domingo et al., 2015), we sought to investigate the role of HIF-1a in NKp46 ${ }^{+}$cells in a pathologic condition of mucosal injury. We therefore treated WT and HIF-1a KO mice with methotrexate (MTX) to induce small-intestinal damage, characterized by mucosal destruction, inflammation, and body weight loss during $96 \mathrm{~h}$ (Fig. 7 A; Aparicio-Domingo et al., 2015). HIF-1a KO mice were protected against MTX-induced intestinal damage, as evidenced by reduced body weight loss (Fig. $7 \mathrm{~A}$ ) and an ameliorated histological disease score (Fig. 7 B). Next, we aimed to visualize the spatial distribution of NKp46 cells in the SI mucosa by taking advantage of our EYFP-expressing reporter mice (as introduced in Figs. 2 and 3). When we visualized the spatial distribution of NKp46 ${ }^{+}$cells simultaneously with pimonidazole staining to detect hypoxia $\left(<10 \mathrm{mmHg} \mathrm{O}_{2}\right.$; Airley et al., 2003) in the SI mucosa, there was no obvious difference in NKP46 ILC localization across the intestinal wall and relative to hypoxia between EYFP-WT and EYFP-HIF-1a KO mice (Fig. 7 C). However, when we analyzed the abundance of different NKp $46^{+}$ ILC subsets in the SI after MTX treatment by means of flow cytometry, we observed an increased ILC3-to-ILC1 ratio in HIFla KO mice that persisted after injury onset (Fig. $7 \mathrm{D}$ ), as well as a decreased infiltration with neutrophils and macrophages (Fig. S3 B). The fraction of IFN- $\gamma$-expressing ILCls was decreased, while we found a higher frequency of the ILC3 cytokine IL-22 ${ }^{+}$ ILC3s in the SI from HIF-1a KO mice (Fig. 7 E), paralleled by a reduced Ifng-to-Il22 expression ratio at the whole-organ level (Fig. S3 C) even after the onset of injury. Consistently, HIFla deficiency in NKp46 ${ }^{+}$cells led to up-regulation of the IL22-dependent prohomeostatic genes Reg3a, Reg3b, Reg3g, Defa21, and Muc2 (Fig. 7 F). In summary, we show that loss of HIFla confers protection against small intestinal injury by allowing a functional switch to the ILC3 phenotype, with increased expression of the prohomeostatic cytokine IL-22. This suggests that HIF-1 $a$ expression in NKp46 $6^{+}$cells mediates intestinal homeostasis by regulating the balance between prohomeostatic ILC3 and proinflammatory ILC1 at steady state as well as during mucosal injury.

\section{HIF-1a in NKp46 ${ }^{+}$cells alters the microbiome and susceptibility to colitis}

Hypoxia and HIF signaling have also been shown to play a crucial role in the context of colitis (Fagundes and Taylor, 2017). To test the impact of HIFla deficiency in NKp46 cells on colon homeostasis, we first analyzed the abundance of different NKp46+ ILC subsets in the lamina propria of the colon at steady state. Frequency and absolute numbers of total NKp46 ILCs were similar across genotypes (Fig. S4 A). Of note, the colon of HIF-1a KO mice contained twice as many NKp46+ ILC3s, whereas NKp46+ ILCls were similar compared with WT littermates, resulting in a significant increase in the ILC3/ILC1 ratio (Fig. $8 \mathrm{~A}$ ). All other immune cell populations were similar across genotypes (Fig. S4 B). The relative abundance of ILC3s over ILC1s (Fig. $8 \mathrm{~A}$ ) was accompanied by a higher fraction of IL22-expressing NKp46 ${ }^{+}$ILC3s and decreased frequencies of IFN- $\gamma$-expressing ILCls (Fig. 8 B). This resulted in an increased Il22/Ifng expression ratio (Fig. S4 C) and augmented expression of gut-homeostatic genes such as Reg3b, Reg3c, Defa21, Muc2, and Muc5 (Fig. 8 C) in the colon from HIF-1a KO mice. Although the loss of HIF-1 $1 \alpha$ in NKp $46^{+}$cells did not cause any obvious changes in colon histology (Fig. S4 D), we considered that the alterations in ILC subsets and the IL-22-dependent gene signature (Fig. 8, B and $\mathrm{C}$ ) could influence the composition of the microbiome 
A
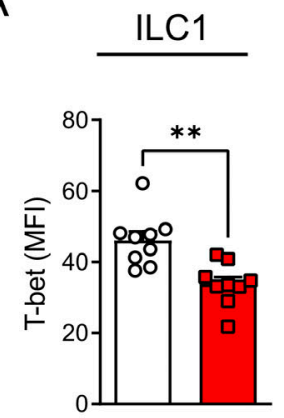

HIF-1a: WT KO

\section{NKp46+ ILC3}

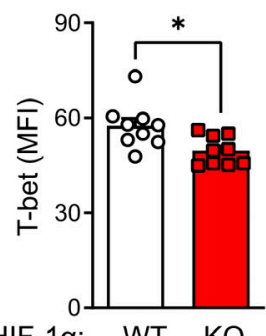

HIF-1a: WT KO

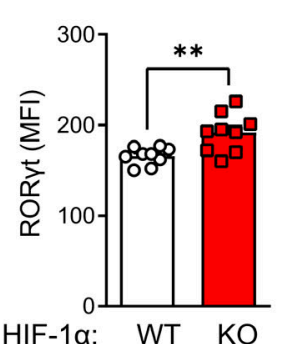

HIF-1a: WT KO
B

EYFP-WT or EYFP-HIF-1 1 KO

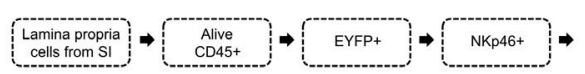

D

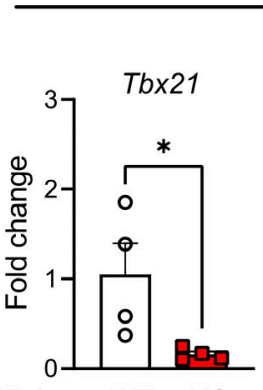

HIF-1a: WT KO

E
ILC1

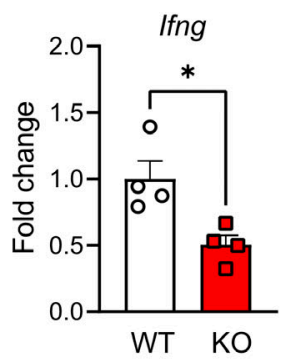

C

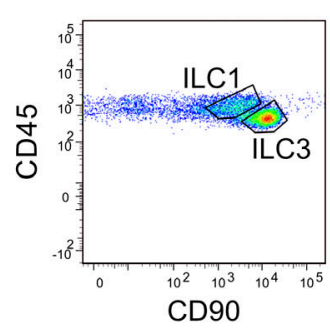

ILC1

NKp46+ ILC3
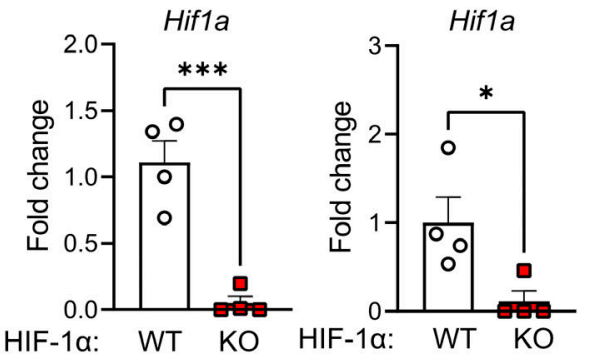

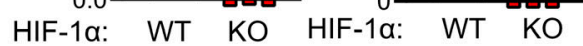

\section{Sorted NKp46+ ILC3}

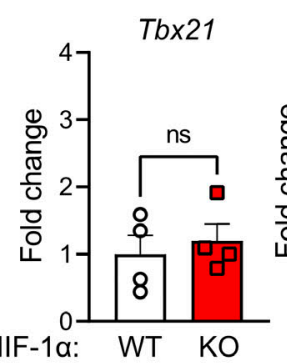

HIF-1a: WT KO
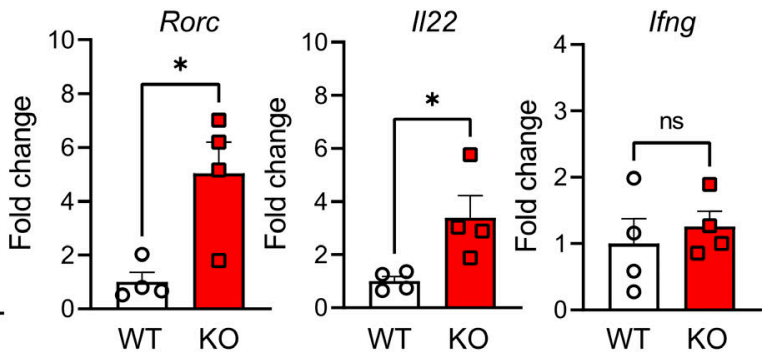

$\mathrm{F}$

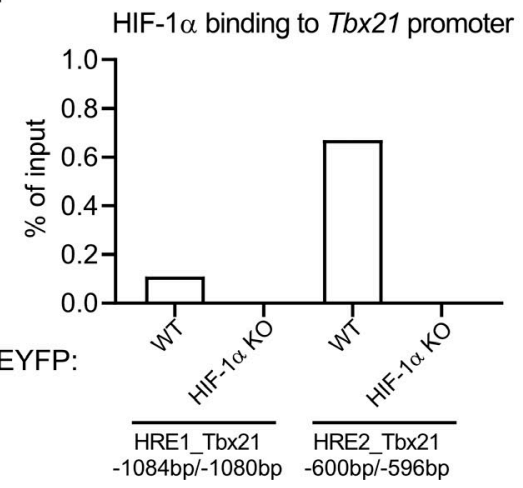

Figure 4. HIF-1a promotes the expression of Tbx21 in NKp46+ cells. (A) Left: T-bet mean fluorescence intensity of HIF-1a KO and HIF-1a WT ILC1s (pooled data of three experiments, $n=9$ ), two-tailed Student's $t$ test. Right: T-bet and RORyt mean fluorescence intensity of HIF-1a KO and HIF-1a WT ILC1s (pooled data of three independent experiments, $n=9$ ); data are mean values $\pm S E M ;{ }^{*}, P<0.05 ; * *, P<0.01$ by two-tailed Student's $t$ test. MFI, mean fluorescence intensity. (B) Sorting strategy for NKp46+ ILCs, ILCls (defined as EYFP + NKp46 $/$ CD45 high/CD90low), and NKp46 ILC3s (defined as EYFP $/ \mathrm{NKp}^{+} 6^{+} / \mathrm{CD}^{+} 5^{\text {low }} /$ CD90 high). (C) Gene expression of Hif1a on sorted ILC1s and NKp46 ${ }^{+}$ILC3s from the SI of EYFP-WT and EYFP-HIF-1a KO mice $(n=4$; each point represents a pool of four mice); data are mean values \pm SEM; ${ }^{*}, P<0.05 ;{ }^{* * *}, P<0.001$ by two-tailed Student's $t$ test. (D) Left: Gene expression of Tbx21 and Ifng on sorted ILC1s from SI of EYFP-WT and EYFP-HIF-1a KO mice ( $n=4$; each point represents a pool of four mice); data are mean values \pm SEM; ${ }^{*}, \mathrm{P}<0.05$ by two-tailed 
Student's $t$ test. Right: The gene expression of Tbx21, Rorc, II22, and Ifng on sorted NKp46+ ILC3s from SI of EYFP-WT and EYFP-HIF-1a KO mice ( $n=4$; each point represents a pool of four mice); data are mean values \pm SEM; ${ }^{*}, \mathrm{P}<0.05$ by two-tailed Student's $t$ test. (E) Schematic diagram of HREs within promoter region of murine Tbx21. (F) HIF-1a binding to HREs ofTbx21 promoter in sorted EYFP+ ILCs upon in vitro IL-12-mediated stimulation.

(Britanova and Diefenbach, 2017; Sanos et al., 2011). Pyrosequencing of feces from cohoused, age- and sex-matched WT and HIF-1a KO littermate mice at steady state revealed significant alterations at the phylum level (Fig. 8 D). We found an increase in homeostatic Bacteroidetes species and a decrease in potentially pathogenic Firmicutes species (Britanova and Diefenbach, 2017) in the feces from HIF-1a KO mice (Fig. 8 D).

A
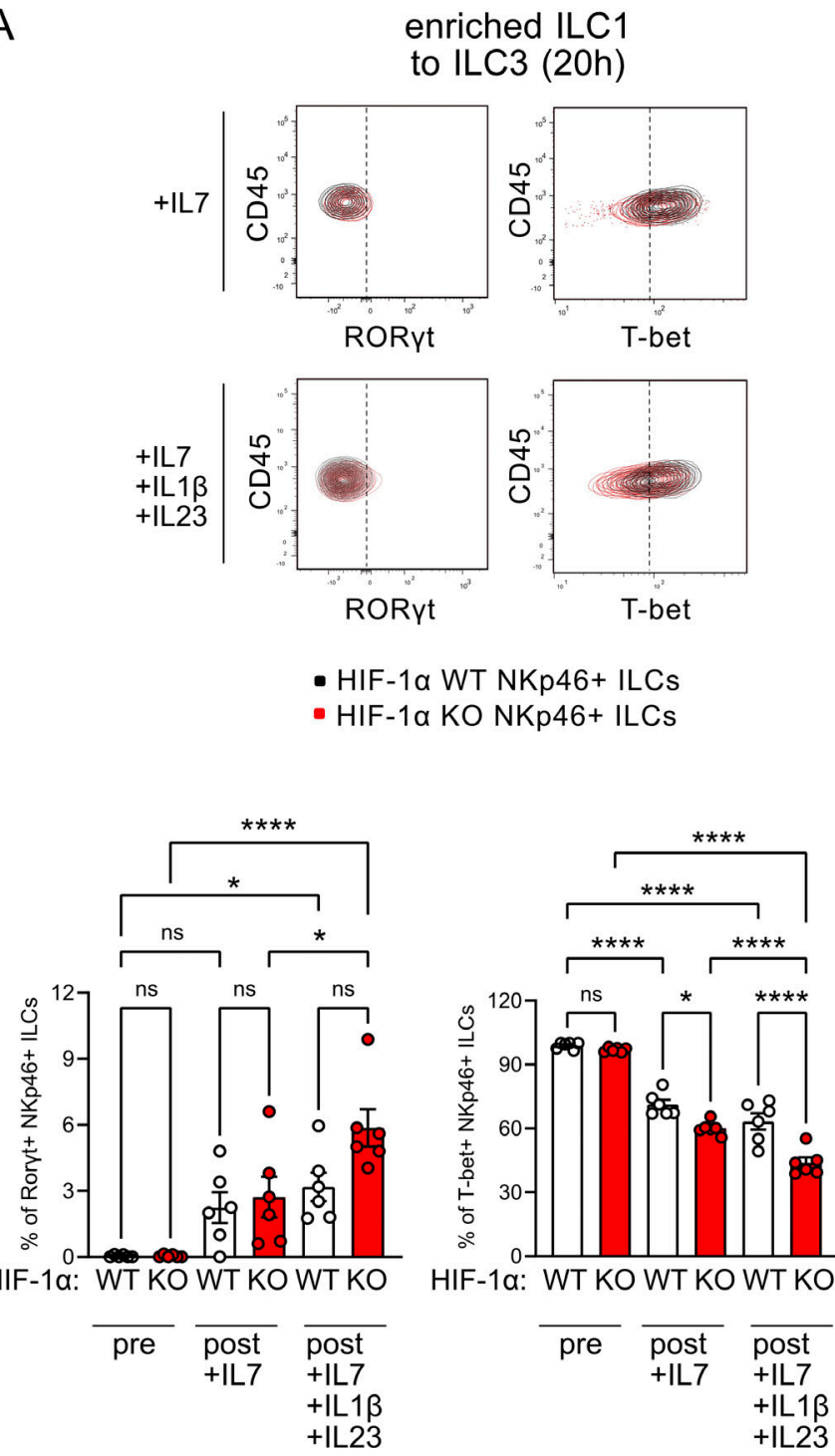

HIF-1a: WT KO WT KO WT KO

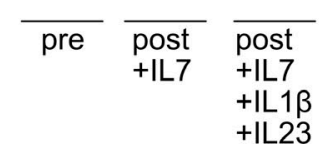

Hence, HIF-1a-dependent regulation of the NKp46+ ILC phenotype influences the colonic microbiome at steady state.

During colitis, ILC3-to-ILC1 conversion is a key pathogenic event (Bernink et al., 2015; Forkel and Mjösberg, 2016), and epithelial damage in the colon further enhances mucosal hypoxia (Taylor and Colgan, 2017; Fagundes and Taylor, 2017). Therefore, we exposed WT and HIF-1a KO mice to dextran

B enriched ILC3 to ILC1 (20h)
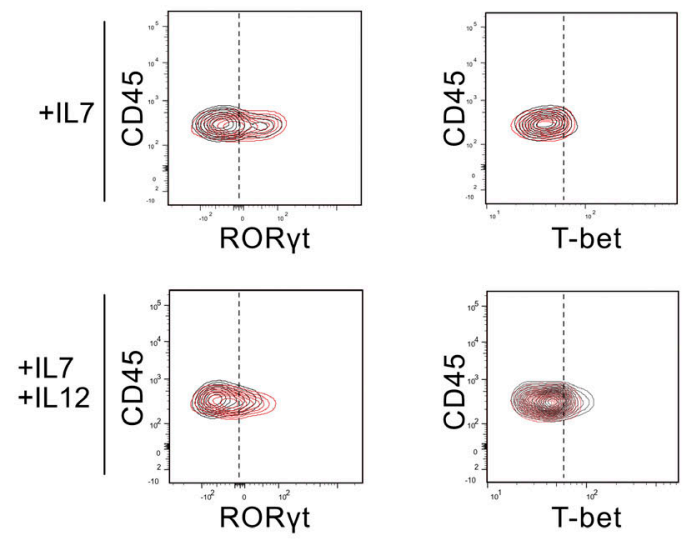

- HIF-1a WT NKp46+ ILCs

- HIF-1a KO NKp46+ ILCs
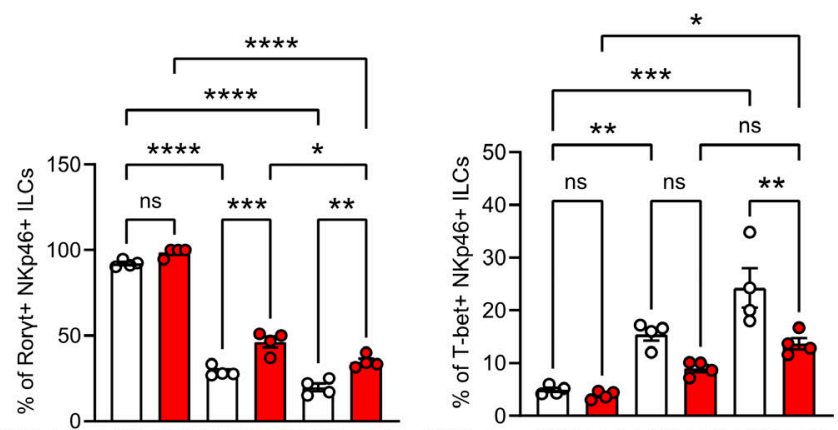

HIF-1a: WT KO WT KO WT KO HIF-1a: WT KO WT KO WT KO
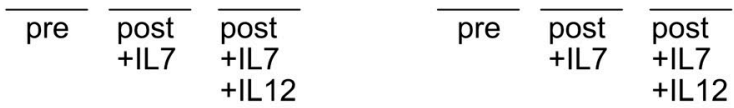

Figure 5. HIF-1a contributes to conversion in NKp46 ${ }^{+}$cells in vitro. (A) In vitro IL-1 $\beta$ - and IL-23-mediated ILC plasticity of sorted ILC1s (defined as EYFP ${ }^{+}$I NKp $46^{+} / \mathrm{CD} 45^{\text {high }} / \mathrm{CD} 90^{\text {low }}$ ) from the SI of EYFP-WT and EYFP-HIF-1a KO mice. ILC1s were challenged with IL-1B, IL-23, and IL-7 (post, +IL7+IL13+IL23) or incubated with IL-7 alone (post, +IL7) as a control for $20 \mathrm{~h}$. Top: Representative contour plots of RORyt and T-bet expression upon stimulation. Bottom: Quantitative analysis of RORyt and T-bet expression upon stimulation relative to the prestimulation (pre; pooled data of two independent experiments, $n=6$ ); data are mean values \pm SEM; ${ }^{*}, \mathrm{P}<0.05 ;^{* * * *}, \mathrm{P}<0.0001$ by two-way ANOVA. (B) In vitro IL-12-mediated ILC plasticity of sorted Nkp46 ${ }^{+}$ILC3s (defined as $\mathrm{EYFP}^{+} / \mathrm{NKp}^{2} 6^{+} / \mathrm{CD} 45^{\text {low }} / \mathrm{CD} 90^{\text {high }}$ ) from the SI of EYFP-WT and EYFP-HIF-1a KO mice. ILC3s were challenged with IL-12 and IL-7 (post, +IL7+IL12) or incubated with IL-7 alone as a control (post, +IL7) for $20 \mathrm{~h}$. Top: Representative contour plots of RORyt and T-bet expression upon stimulation. Bottom: Quantitative analysis of RORyt and T-bet expression upon stimulation relative to prestimulation (pre; pooled data of two independent experiments, $n=4$ ); data are mean values $\pm \mathrm{SEM} ;{ }^{*}, \mathrm{P}<0.05 ;^{* *}, \mathrm{P}<0.01 ;{ }^{* *}, \mathrm{P}<0.001 ;{ }^{* * *}, \mathrm{P}<0.0001$ by two-way ANOVA. 


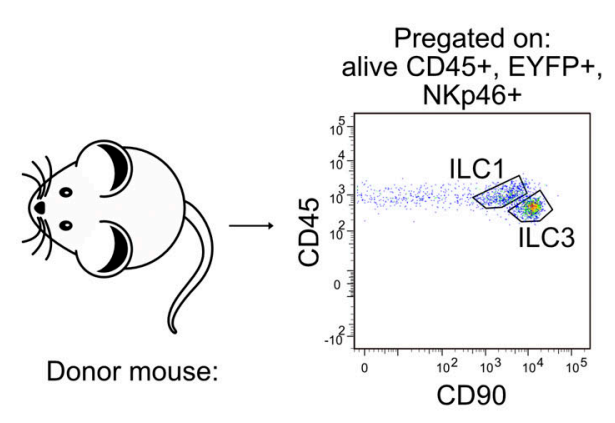

Adoptive transfer of:

1: HIF-1aWT NKp46+ ILC3s

2: HIF-1a KO NKp46+ ILC3s 3: PBS (control)

1. EYFP-WT

2. EYFP-HIF-1 $\alpha \mathrm{KO}$
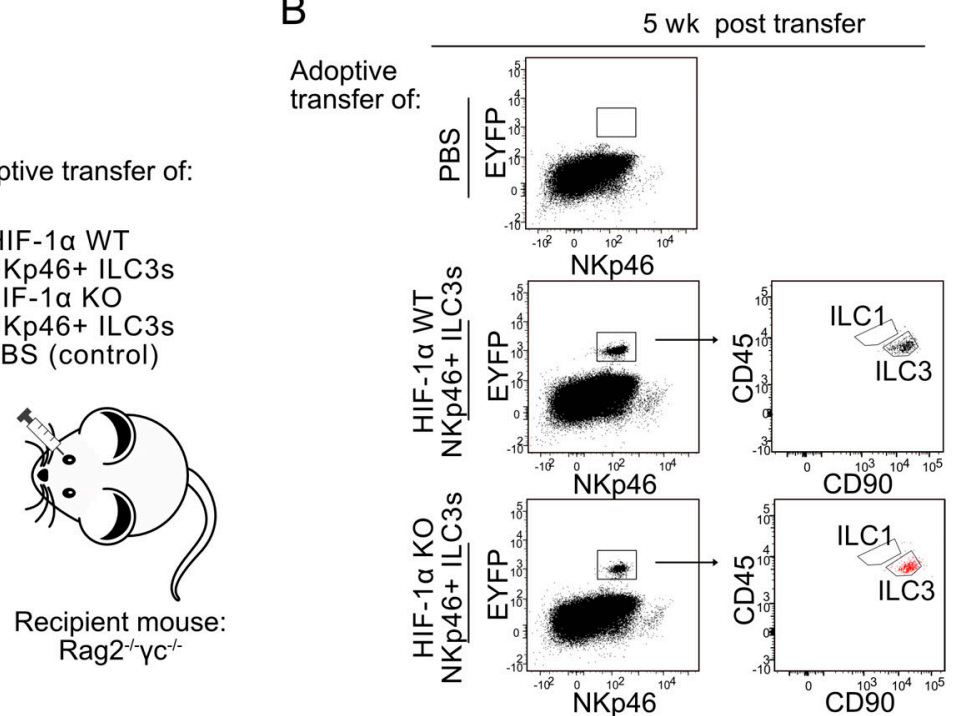

C
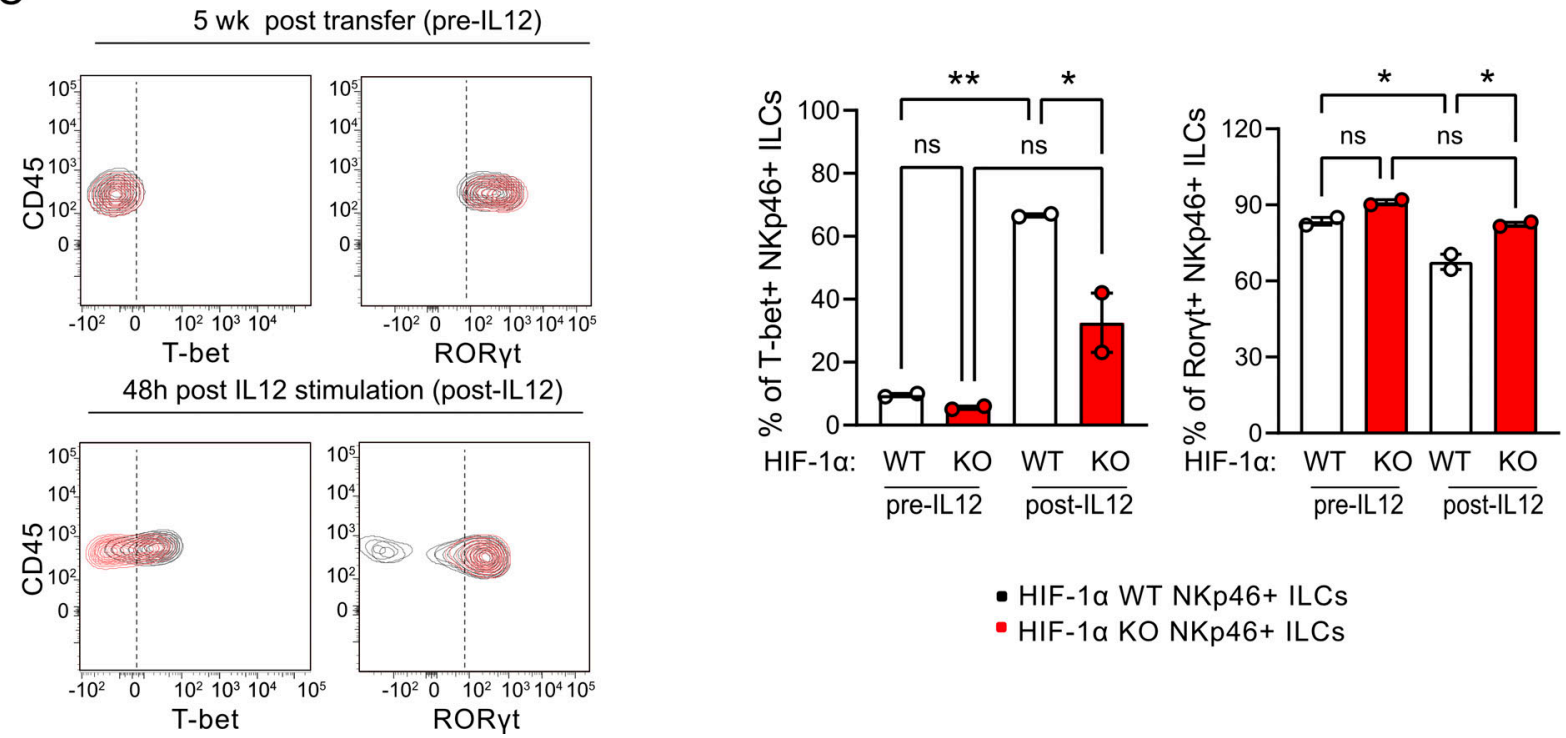

- HIF-1a WT NKp46+ ILCs

- HIF-1a KO NKp46+ ILCs

Figure 6. HIF-1a contributes to ILC3-to-ILC1 conversion in NKp46+ cells in vivo. (A) Scheme of adoptive transfer of purified Nkp46 ${ }^{+}$ILC3s (defined

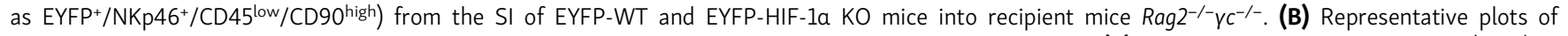
EYFP $^{+} \mathrm{NKp} 6^{+}$ILC fate defined by CD45 and CD90 purified from recipient mice 5 wk after adoptive transfer. (C) In vivo IL-12-mediated plasticity (48 h) of EYFP+NKp46+ ILCs in recipient mice performed 5 wk after adoptive transfer. Left: Representative contour plots of RORyt and T-bet expression before (prelL12) and upon $48 \mathrm{~h}$ in vivo stimulation (post-IL12). Right: Quantitative analysis of RORyt and T-bet expression upon $48 \mathrm{~h}$ in vivo stimulation (post-IL12, $n=2$ ) relative to the prestimulation condition (prelL12, $n=2$ ); data are mean values $\pm \mathrm{SEM} ;{ }^{*}, \mathrm{P}<0.05 ;{ }^{* *}, \mathrm{P}<0.01$ by two-way ANOVA.

sodium sulfate (DSS), which induces colitis characterized by mucosal damage and bacterial translocation, with subsequent inflammation and body weight loss within days (Tambuwala et al., 2010, 2015). In HIF-1a KO mice, DSS-induced colitis was ameliorated, as evidenced by reduced body weight loss and colon shortening (Fig. 8, E and F), as well as an ameliorated histological disease score (Fig. $8 \mathrm{G}$ ) at endpoint (day 7). Again, this was accompanied by an increased ILC3-to-ILC1 ratio in HIF-1a KO at endpoint (Fig. $8 \mathrm{H}$ ), with no genotype-specific differences among other immune cell subsets (Fig. S4 B). Consistently, the percentage of IFN- $\gamma$-expressing ILCls was decreased, while we found a higher frequency of IL-22+ ILC3s in the colon from HIFla KO mice at endpoint (Fig. $8 \mathrm{I})$. Expression of the colitogenic
ILC1 cytokine Ifng was decreased, whereas we found an increased expression of the protective ILC3 cytokine Il22 in the colon from HIF-1a KO mice at endpoint (Fig. $8 \mathrm{~J}$ ). Consistently, HIF-1a deficiency in NKp46 cells led to an up-regulation of the IL-22-dependent gut-protective genes Reg3a, Reg3b, Reg3g, Defa21, and Muc2 (Fig. $8 \mathrm{~K}$ ). This was paralleled by global alterations in gene expression in the damaged colon, triggered by HIF-1 $a$ loss in NKp46 ${ }^{+}$cells, as evidenced by whole-tissue RNAseq. We found 179 up- and 134 down-regulated genes in the colon from HIF-1 $\alpha$ KO mice (Fig. 9, A and B). GO enrichment analysis showed that an up-regulation of genes are involved in Ig production, immune response, defense response to bacterium, epithelium development, and carboxylic acid transport (Fig. 9, A 
A
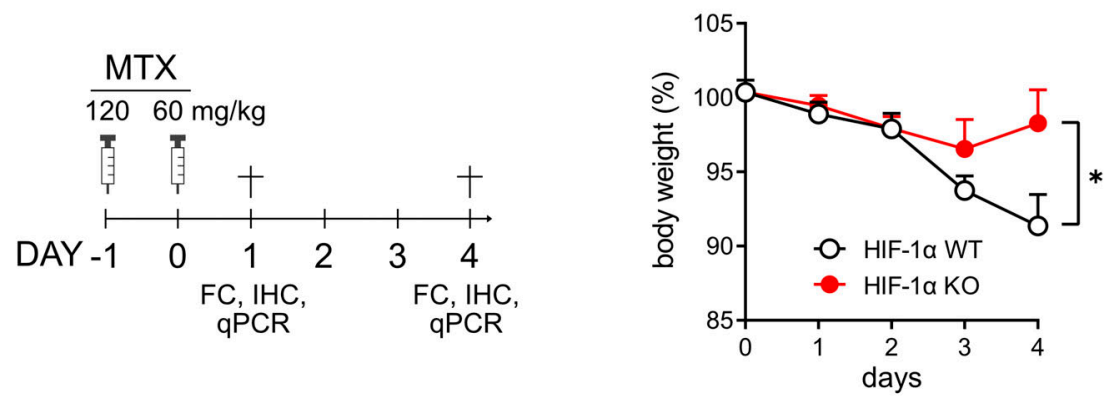

B
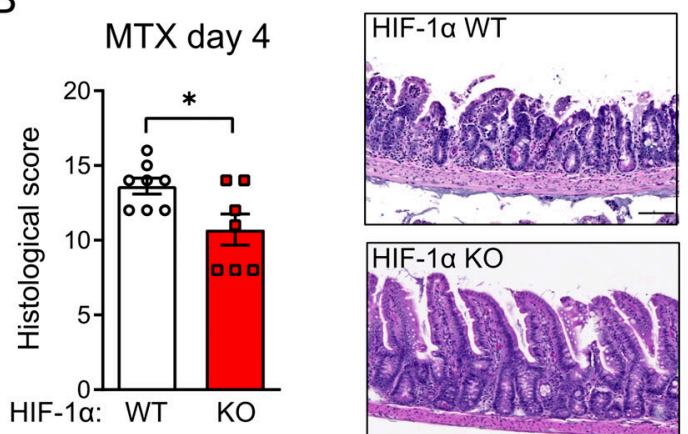

C
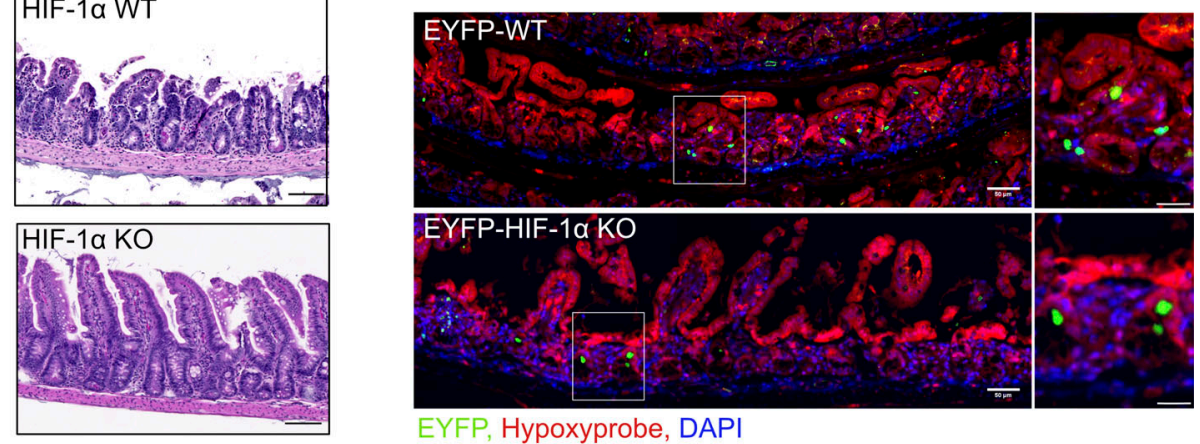

EYFP, Hypoxyprobe, DAPI

D
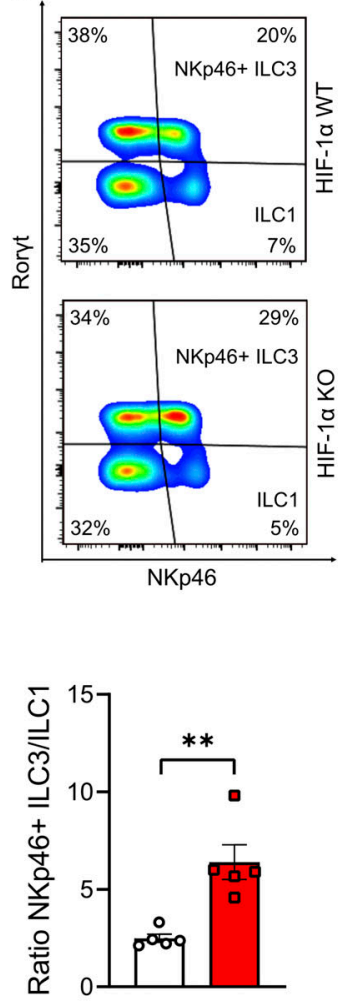

HIF-1a: WT KO
E

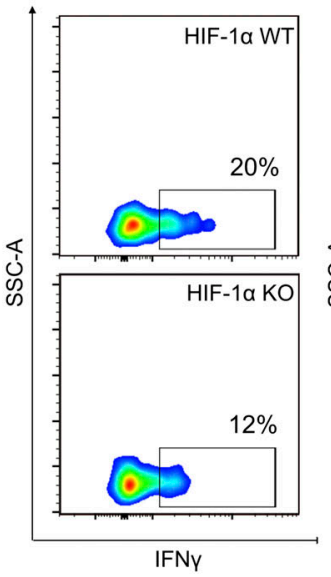

ILC1

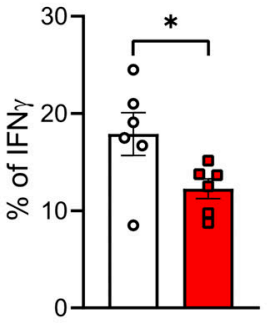

HIF-1a: WT KO
F
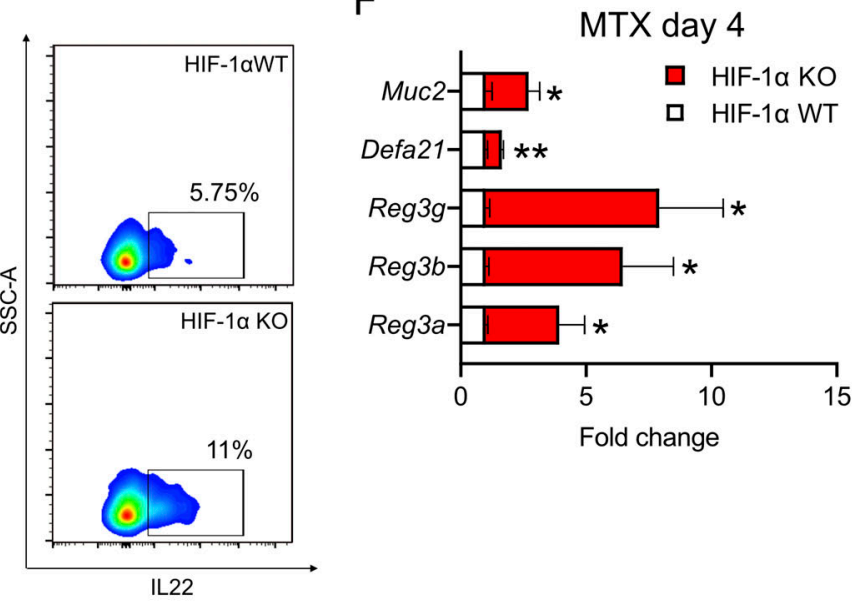

Figure 7. HIF-1a in NKp46+ cells mediates intestinal homeostasis. (A) Left: Scheme of the MTX-induced model of small intestinal damage. Right: Weight curve of HIF-1a KO and HIF-la WT mice treated with MTX (pooled data of three independent experiments, $n=12$ ); data are mean values \pm SEM; ${ }^{*}, \mathrm{P}<0.05$ by multiple two-tailed Student's $t$ test. IHC, immunohistochemistry. (B) Left: MTX-induced pathology analysis of the SI from HIF-1a KO and HIF-1a WT mice as described in Materials and methods (pooled data of two independent experiments, $n \geq 7$ ); data are mean values \pm SEM; ${ }^{*}, P<0.05$ by two-tailed Student's $t$ test. Right: Representative images of H\&E staining on small intestinal tissues from HIF-1a KO and HIF-1a WT mice treated with MTX on day 4 after treatment; scale bar, $100 \mu \mathrm{m}$. (C) Representative images of $\mathrm{NKp} 46^{+}$cells (EYFP) and hypoxic area (Hypoxyprobe-1) immunostaining on small intestinal tissues from EYFPHIF-1a KO and EYFP-WT mice treated with MTX on day 1 after treatment; scale bar, $50 \mu \mathrm{m}$. The enlarged part of the small intestinal tissue (white box) of 
immunostainings is shown. Scale bar, $20 \mu \mathrm{m}$. (D) Top: Representative FACS plots showing the frequency of small intestinal ILC1s and NKp46 ${ }^{+}$ILC3s in the alive $\mathrm{Lin}^{-} \mathrm{CD} 127^{+}$cells from HIF-1a KO and HIF-1a WT mice treated with MTX on day 1 after treatment. Bottom: Ratio of small intestinal NKp46 ${ }^{+}$ILC3 to ILC1 from HIF-1a KO and HIF-1a WT mice treated with MTX on day 1 after treatment (pooled data of two independent experiments, $n=5$ ); data are mean values \pm SEM; **, $\mathrm{P}<0.01$ by two-tailed Student's $t$ test. (E) Top: Representative FACS plots showing the frequency of IFN- $\gamma$-expressing small intestinal ILC1s and the frequency of IL-22-expressing small intestinal NKp46+ ILC3s from HIF-1a KO and HIF-1a WT mice after treatment with MTX and stimulation with PMA/ ionomycin. Bottom: The corresponding quantitative analysis of IFN-y-expressing ILC1- and IL-22-expressing NKp46+ ILC3s (pooled data of two independent experiments, $n=6$ ); data are mean values \pm SEM; ${ }^{*}, P<0.05$ by two-tailed Student's $t$ test. SSC, side Scatter. (F) Gene expression analysis of IL-22-dependent gut-homeostatic genes such as Reg3a, Reg3b, Reg3g, Defa21, and Muc2 in small intestinal tissues from HIF-1a KO and HIF-1a WT mice treated with MTX (pooled data of three independent experiments, $n=12$ ); data are mean values \pm SEM; ${ }^{*}, P<0.05 ;{ }^{*}, P<0.01$ by two-tailed Student's $t$ test.

and $\mathrm{B})$. In contrast, the down-regulated genes in the colon from HIF-1a KO mice are involved in the regulation of cytokine production, regulation of immune effector process, positive regulation of defense, and the regulation of inflammatory responses (Fig. 9, A and B). This led us to conclude that deletion of HIF$1 \alpha$ in $\mathrm{NKp} 46^{+}$cells dampens proinflammatory ILC1-driven immune responses, while maintaining a global ILC3-dependent prohomeostatic transcriptional program in the colon mucosa.

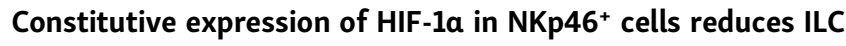 numbers in the $\mathrm{SI}$ and increases the susceptibility to mucosal damage}

Given the effect of HIF-1a deletion on NKp $46^{+}$ILC phenotype and small intestinal homeostasis, we wanted to evaluate the impact of constitutive HIF activation on NKp $46^{+}$ILCs in the SI. To do so, we generated mice with an $\mathrm{NKp} 46^{+}$cell-specific deletion of the negative HIF regulator VHL by crossing the loxPflanked VHL allele (Rankin et al., 2006) to the Ncrl (NKp46) promoter-driven Cre recombinase (Eckelhart et al., 2011), termed VHL KO (Sobecki et al., 2021). Analysis of the abundance of NKp46+ ILC subsets in the lamina propria of the jejunum revealed a reduced frequency of total NKp $46^{+}$ILCs in VHL KO mice (Fig. S5 A). This was caused by decreased levels of NKp46 ${ }^{+}$ ILC3s and NKp46 ${ }^{+}$ILC1s in VHL KO mice (Fig. 10 A). All other immune subsets were present at comparable ratios across genotypes, except for a decrease in CD4 T cells (Fig. S5 B). Despite a similar ILC3/ILC1 ratio across genotypes (Fig. $10 \mathrm{~A}$ ), VHL deficiency in $\mathrm{NKp}^{4} 6^{+}$cells led to higher percentage of IFN- $\gamma^{+}$ILC1s and a decrease in IL-22+ ILC3s (Fig. 10 B). Consistent with the loss of a typical ILC3/IL-22 signature, VHL deletion in NKp46+ cells lowered the expression of IL-22-inducible and prohomeostatic genes Reg3a, Reg3b, Reg3g, Defa21, Muc2, Muc3, Muc5, and Mucl3 (Fig. $10 \mathrm{C}$ ) in the SI of VHL KO mice in the absence of any obvious changes in SI histology (Fig. S5 C). RNA-seq on the jejunum from WT and VHL KO mice at steady state revealed global changes in the mucosal gene expression pattern, with 151 upand 165 down-regulated genes in the SI from VHL KO mice (Fig. 10 D). GO analysis of the down-regulated genes indicated, besides innate immune response in mucosa, which was due to a down-regulation of several Defensins, an involvement in regenerative processes including mitosis, DNA synthesis and replication, stem cell proliferation, and metabolic processes (Figs. $10 \mathrm{D}$ and S5 D). The up-regulated genes were assigned to positive regulation of immune system process, defense to other organism, vesicle-mediated transport, and response to external stimulus (Figs. $10 \mathrm{D}$ and S5 D). These observations are in line with a concept where constitutive activation of HIF-1a in
NKp $46^{+}$cells counteracts a global prohomeostatic transcriptional program in the SI while favoring proinflammatory immune responses.

Next, the impact of constitutive of HIF-1a expression in NKp46 ${ }^{+}$cells on small intestinal damage was tested by exposing WT and VHL KO mice to the MTX model (as in Fig. 7 A; AparicioDomingo et al., 2015). VHL KO mice developed severe MTXinduced intestinal damage, as evidenced by increased body weight loss (Fig. $10 \mathrm{E}$ ) and an aggravated histological disease score (Fig. 10 F) at endpoint. This was associated with a decrease in NKp46+ ILC3s and ILC1s in VHL KO mice after the onset of injury (Fig. $10 \mathrm{G}$ ), as well as a decrease in CD8 T cells (Fig. S5 B). Again, despite a reduction of both ILC subsets (Fig. $10 \mathrm{G}$ ), VHL deficiency in NKp $46^{+}$cells resulted in higher intracellular levels of IFN- $\gamma$ in ILC1s and a decrease of IL-22 in ILC3s (Fig. $10 \mathrm{H}$ ). This translated into an increased expression ratio of the ILC1 cytokine Ifng and a reduction of the ILC3 cytokine Il22 in the SI from VHL KO mice (Fig. S5 E), along with a down-regulation of the IL22-dependent gut-homeostatic genes Reg3a, Reg3g, Defa21, Defa21, and Muc2 (Fig. $10 \mathrm{I}$ ). This is in line with our concept that HIF$1 a$ activation fosters an ILC1 signature and counteracts the ILC3 phenotype in $\mathrm{NKp} 46^{+}$cells to facilitate mucosal injury and inflammation in the intestine.

\section{Discussion}

We provide evidence that HIF-1a modulates the NKp46+ ILC phenotype in the intestinal mucosa. In gut-resident $\mathrm{NKp} 46^{+}$ cells, HIF-1 $\alpha$ fosters an ILC1 phenotype and intestinal lipid uptake as well as inflammation upon intestinal damage. This is mirrored by the observation that loss of HIF-1a confers protection against intestinal damage by allowing a functional ILC3 phenotype in NKp46+ cells in the hypoxic gut, with increased expression of the prohomeostatic cytokine IL-22 and impaired lipid uptake. Conceptually, this suggests a HIF-1a-dependent trade-off in ILCs between ILC3/IL-22-dependent mucosal repair and ILC1-mediated proinflammatory response in the gut. In contrast, enhanced ILC3-driven regenerative properties in the absence of HIF-1a come with impaired intestinal lipid uptake. In summary, our data demonstrate the pivotal role of the transcription factor HIF-1a in controlling ILC phenotype and function during gut homeostasis.

The intestinal mucosa is characterized by low oxygen at steady state, which becomes even more severe upon intestinal injury and inflammation. The dynamics in $\mathrm{pO}_{2}$ directly impact on the function of mucosal immune cells, which fueled the concept of "inflammatory hypoxia" (Karhausen et al., 2005). 


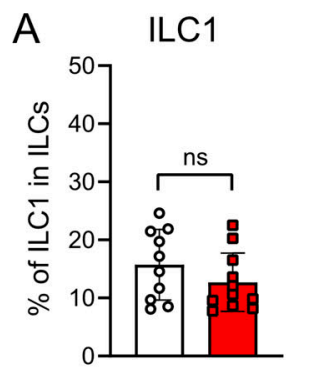

HIF-1a: WT KO
NKp46+ILC3

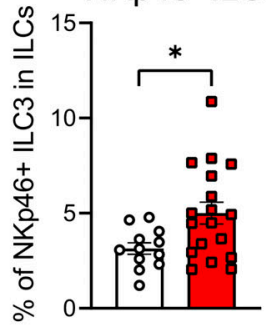

HIF-1a: WT KO

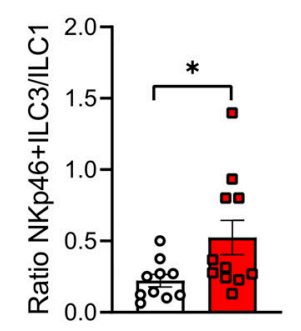

HIF-1a: WT KO
B

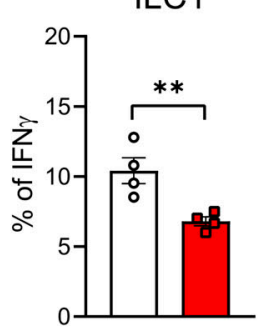

HIF-1a: WT KO
C
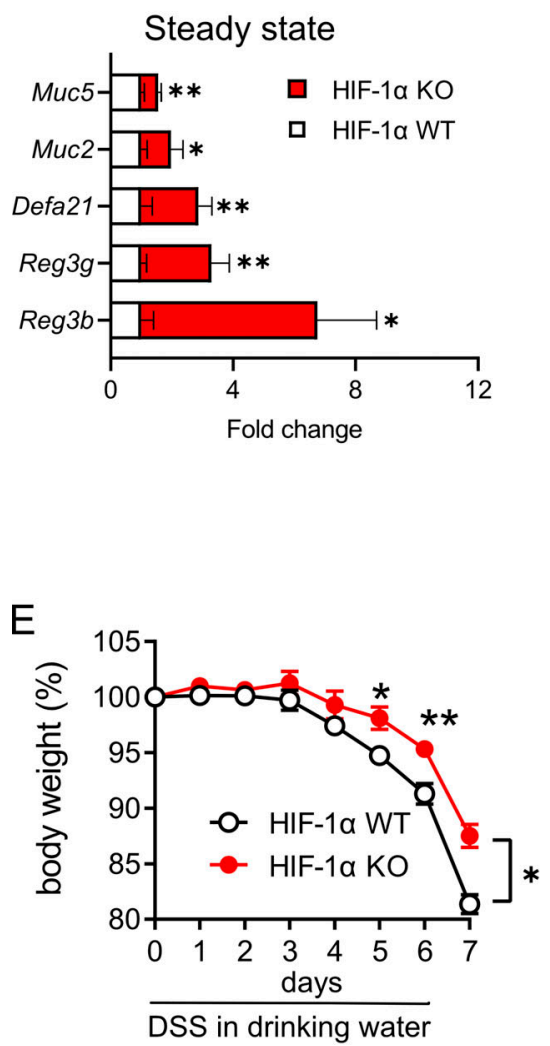

D Taxa in phylum level

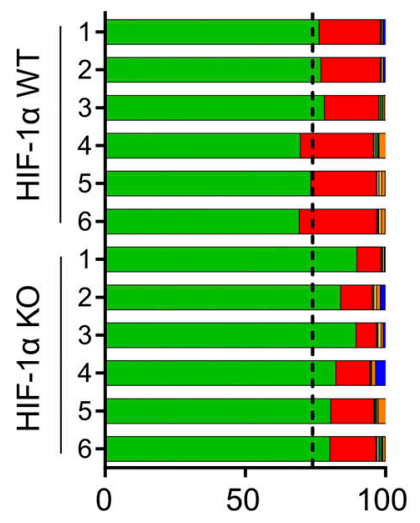

Relative abundance (\%)

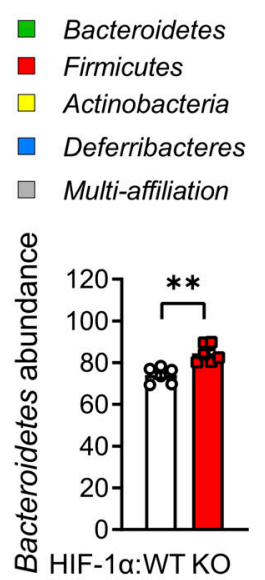

๑ HIF-1a:WT KO
NKp46+ILC3

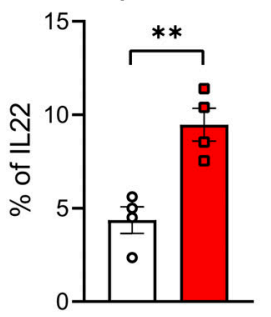

HIF-1a: WT KO
F

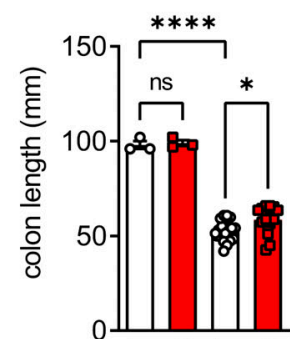

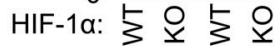
Steady DSS state day 7
G

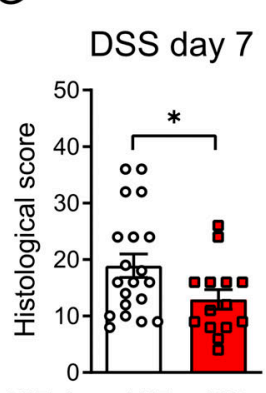

HIF-1a: WT KO

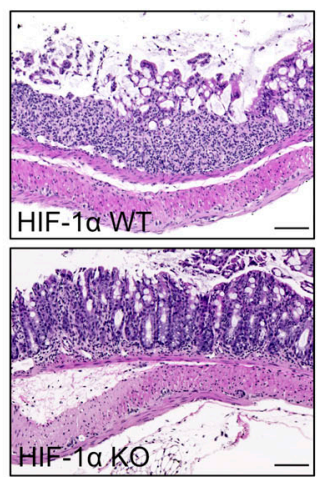

$\mathrm{K}$

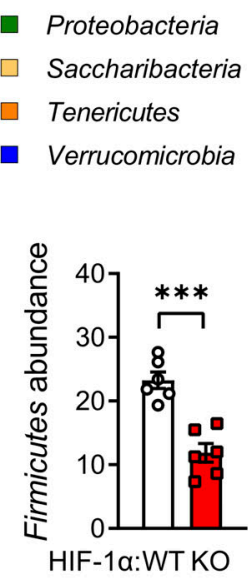

$\mathrm{J}$

$\begin{array}{llll}H & \text { DSS day } 7 & \text { I } & \text { DSS day } 7\end{array}$

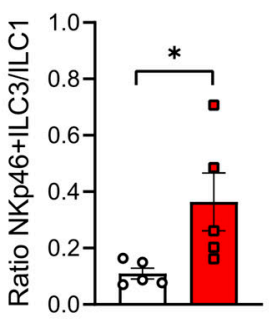

HIF-1a: WT KO
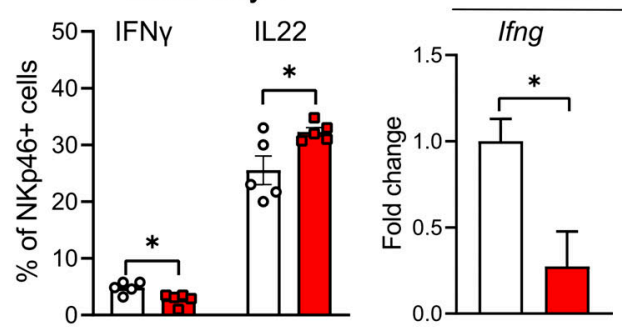

DSS day 7

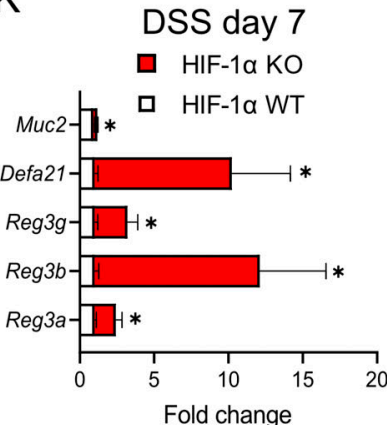

Figure 8. HIF-1a in NKp46+ cells alters the microbiome and susceptibility to colitis. (A) Flow cytometric analysis of large intestinal ILC1s, NKp46 ${ }^{+}$ILC3s, and ratio of NKp46+ ILC3 to ILC1 from HIF-1a KO and HIF-la WT mice (pooled data of three independent experiments, $n \geq 10$ ); data are mean values \pm SEM; *, $\mathrm{P}<0.05$ by two-tailed Student's $t$ test. (B) Flow cytometric analysis of colonic NKp46 ILC3s stimulated with PMA/ionomycin and stained for intracellular IL-22 from HIF-la KO and HIF-la WT mice $(n=4)$; data are mean values \pm SEM; ${ }^{* *}, P<0.01$ by two-tailed Student's $t$ test. (C) The gene expression of IL22-dependent gut-homeostatic genes such as Reg3b, Reg3g, Defa21, Muc2, and Muc5 in large intestinal tissues from HIF-1a KO and HIF-1a WT mice (pooled data of two independent experiments, $n=8$ ); data are mean values $\pm S E M ;{ }^{*}, \mathrm{P}<0.05 ;{ }^{*}{ }^{*}, \mathrm{P}<0.01$ by multiple two-tailed Student's $t$ test. (D) Left: Taxon-based 
analysis at phylum level of fecal samples among the groups from cohoused HIF-1a KO and HIF-1a WT mice (pooled data of two independent experiments, $n=$ 6). Right: Relative abundance of Bacteroidetes and Firmicutes in fecal samples from cohoused HIF-1a KO and HIF-1a WT mice (pooled data of two independent experiments, $n=6$ ); data are mean values $\pm S E M ;{ }^{* *}, P<0.01 ;{ }^{* *}, P<0.001$ by two-tailed Student's $t$ test. (E) Weight curve of HIF-1a KO and HIF-1a WT mice treated with DSS (pooled data of four independent experiments, $n=20$ ); data are mean values \pm SEM; ${ }^{*}, P<0.05 ;{ }^{* *}, P<0.01$ by multiple two-tailed Student's $t$ test. (F) Colon length of HIF-la KO and HIF-la WT mice treated with DSS (pooled data of four independent experiments, $n \geq 17$ ); data are mean values \pm SEM; ${ }^{*}, \mathrm{P}<0.05 ;{ }^{* * *}, \mathrm{P}<0.0001$ by two-tailed Student's $t$ test. (G) Left: DSS-induced pathology analysis of the large intestinal tissues from HIF-1a KO and HIFla WT mice as described in Materials and methods (pooled data of three independent experiments, $n \geq 14$ ); data are mean values $\pm S E M ;{ }^{*}, P<0.05$ by twotailed Student's $t$ test. Right: Representative images of H\&E staining on large intestinal tissues from HIF-1a KO and WT mice treated with DSS; scale bar, 100 $\mu \mathrm{m}$. (H) Ratio of colonic NKp46 ILC3s to ILCls from HIF-1a KO and HIF-1a WT mice treated with DSS (pooled data of two independent experiments, $n=5$ ); data are mean values \pm SEM; ${ }^{*}, \mathrm{P}<0.05$ by two-tailed Student's $t$ test. (I) Flow cytometric analysis of colonic ILC1s and NKp46+ ILC3s stimulated with PMA/ ionomycin and stained for intracellular IFN- $y$ and IL-22 from HIF-1a KO and HIF-1a WT mice treated with DSS (pooled data of two independent experiments, $n=5$ ); data are mean values $\pm S E M ; ~ *, P<0.05$ by two-tailed Student's $t$ test. (J) Gene expression of Il22 and Ifng in large intestinal tissues from HIF-1a KO and HIF-1a WT mice after DSS treatment at day 4 post treatment, as fold-change to the WT samples (pooled data of two independent experiments, $n=8$ ); data are mean values $\pm \mathrm{SEM} ;{ }^{*}, \mathrm{P}<0.05$ by two-tailed Student's $t$ test. (K) The gene expression of IL-22-dependent gut-homeostatic genes such as Reg3a, Reg3b, Reg3g, Defa21, and Muc2 in large intestinal tissues from HIF-1a KO and HIF-1a WT mice (pooled data of three independent experiments, $n=12$ ); data are mean values \pm SEM; ${ }^{*}, \mathrm{P}<0.05$ by multiple two-tailed Student's $t$ test.

We here show that the gut environment and the cytokine IL-12 promote a proinflammatory ILC1 phenotype in NKp46 cells in a HIF-1 $\alpha$-dependent manner. Loss of HIF-1 $\alpha$ engages a prohomeostatic program in the gut by favoring IL-22-expressing ILC3s.

The biological impact of HIF-1 $\alpha$ on the NKp46+ ILC phenotype and IL-22 expression is demonstrated by a reduction of fatty acid transporter expression in the SI of HIF1 KO mice, along with lower serum triglycerides and a reduction of total body fat and body weight in these animals. Hence, although ILCs constrain the microbiome, persistent activation results in abnormal lipid handling and tissue homeostasis. Previous studies suggested a role for IL-22 in lipid metabolism, with recent reports indicating that IL-22 promoted lipid transporter expression in the SI (Wang et al., 2017; Seillet et al., 2020) as acute response to feeding. It is likely that transient IL-22 production has a different impact on intestinal epithelial cells than the persistently enhanced IL-22 expression that we observe in mice lacking the HIF-1 $\alpha$ isoform in NKp $46^{+}$ILCs. In line with this, a recent study in newborn mice revealed that high ILC3 activity and IL-22 release result in increased expression of antimicrobial molecules and a decrease in lipid transporters. Consequently, these mice were leaner and had lower serum triglyceride levels (Mao et al., 2018). Likewise, a feeding-regulated neuroimmune circuit in the intestine has been shown to transiently balance the efficiency of nutrient absorption versus immune protection mediated by IL-22 (Talbot et al., 2020). Our results demonstrate that in the absence of hypoxic adaptation in NKp46+ ILCs, the host persistently trades off intestinal lipid absorption for enhanced epithelial defense and repair properties.

ILC3-derived IL-22 plays a crucial role in epithelial repair in the context of inflammatory bowel disease (Diefenbach et al., 2020). Consistently, mice lacking the HIF-1a isoform in NKp46 ${ }^{+}$ILCs and increased IL-22 expression are protected against intestinal damage and inflammation. In contrast, in a recent study by Fachi et al. (2021), the deletion of HIFla in ILCs under the ROR $\gamma$ t promoter led to expansion of IFN- $\gamma$-expressing ILC1s in the SI, impaired ILC3 activation and proliferation, and reduced IL-17 and IL-22 production by ILC3 in vitro and in vivo. Finally, HIFla in ROR $\gamma$ t ILCs was required to promote IL-22 expression and protection against $C$. difficile infection (Fachi et al., 2021). There are several possible biological explanations for this discrepancy, as different model systems were used. The ROR $\gamma t$ promoter used by Fachi et al. (2021) deletes HIFla simultaneously in NKp46- and NKp46+ ILC3s; however, the impact on the NKp46+ ILC population was not analyzed separately. It is therefore imaginable that the deletion of HIFla has distinct impacts on phenotype and function of $\mathrm{NKp} 46^{+}$and NKp46- ILC subsets. Consistently, it has been shown that graded expression of ROR $\gamma \mathrm{t}$ and T-bet is crucial, in particular for the functional fate of Ncr-expressing ILCs (Vonarbourg et al., 2010; Klose et al., 2013; Rankin et al., 2013). Therefore, it is conceivable that the HIF-1 $\alpha / T$-bet signaling axis that we describe is particularly important for the phenotype and functional of NKp46+ ILCls. Moreover, it is important to point out that in contrast to the ROR $\gamma \mathrm{t}$-cre, the Ncrl (NKp46) promoter-driven deletion of HIFla in the ILC3 compartment becomes effective after these cells acquire Ncr expression and an ILC1-like phenotype, with IFN- $\gamma$ production and reduced IL-22 expression (Vonarbourg et al., 2010; Klose et al., 2013; Rankin et al., 2013). Therefore, the discrepancy between our report and the study by Fachi et al. (2021) might also be partially due to the use of different deleter systems that target different cell types and the different time points of HIFla deletion. A strength of both studies is the use of nonlymphopenic, immunocompetent mice. In this setting, the ROR $\gamma \mathrm{t}$ promoter induces deletion of HIFla in ILC3s as well as Th17 CD4 ${ }^{+}$ $\mathrm{T}$ cells, and recently, an important cross-talk between the CD4 and ILC3 compartment for gut homeostasis has been demonstrated (Mao et al., 2018; Zhou et al., 2019). However, the impact of ROR $\gamma$ t promoter-driven deletion of HIFla on the $\mathrm{CD}^{+}$compartment was not addressed in the study by Fachi et al. (2021). Finally, another fundamental point to consider is the use of different in vivo disease models in the two studies. Whereas Fachi et al. (2021) used infection with enteropathogenic $C$. difficile, we induced chemical epithelial damage in the SI and colon by means of MTX and DSS colitis. Finally, the different anatomic localization of $\mathrm{NKP}^{-} 6^{-}$and $\mathrm{NKp} 46^{+}$cells in the intestinal mucosa (e.g., intraepithelial or lamina propria), and hence different microenvironments with distinct oxygen gradients, may contribute to the different findings.

In contrast, in NKp46- ILC3s, HIF1 $\alpha$ promotes IL-22 expression and protection against $C$. difficile infection (Fachi et al., 
A
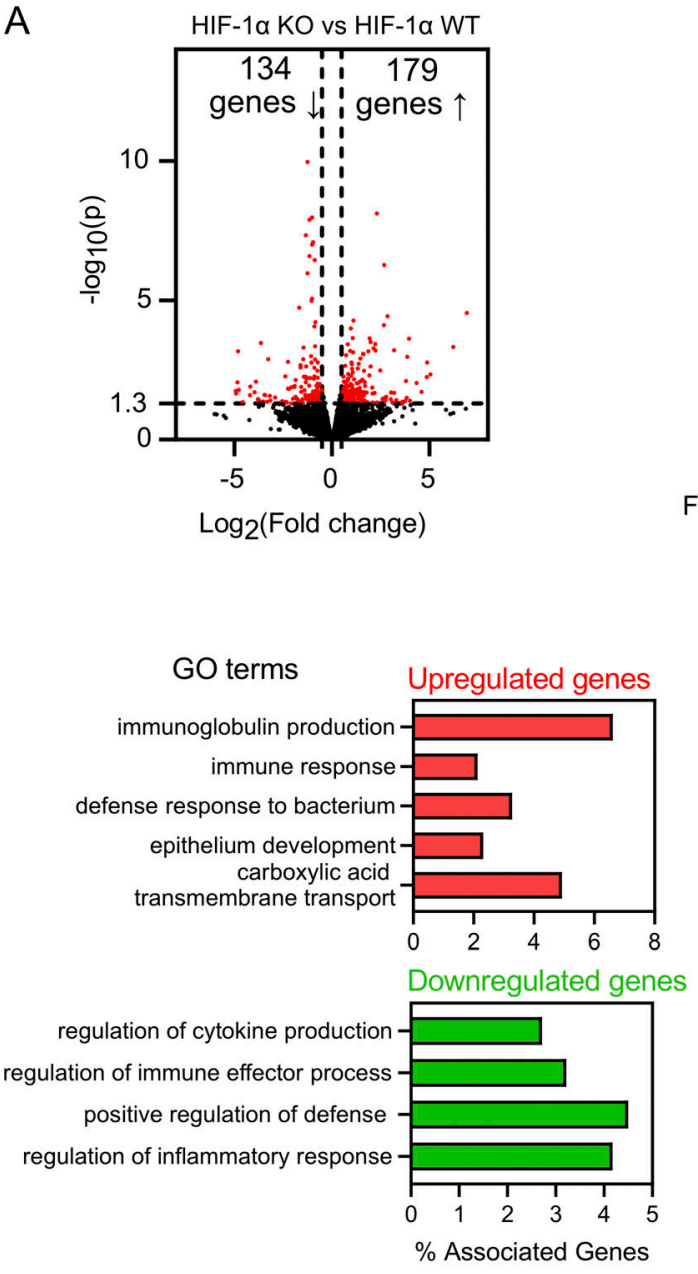

B

Downregulated
genes

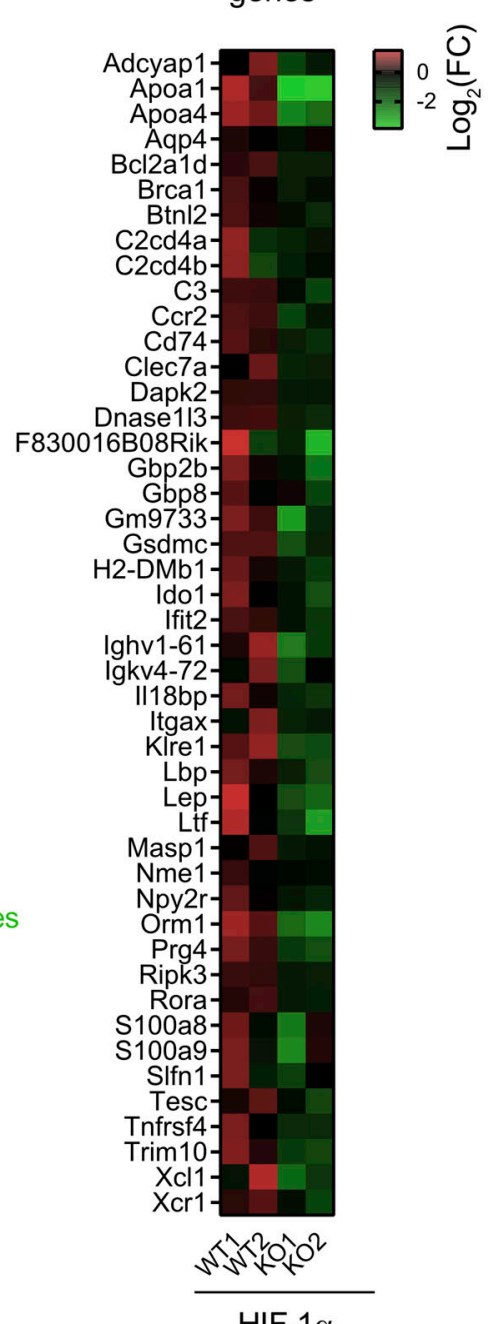

Upregulated genes

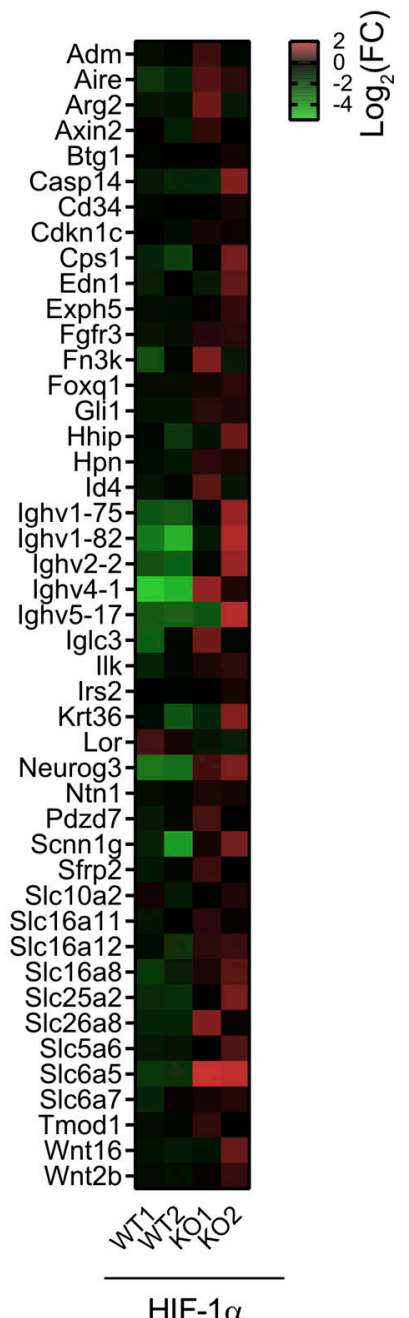

Figure 9. HIF-1a in NKp46+ affects global gene expression during colitis. (A) Top: Volcano plot of the gene expression profile of large intestinal tissues from HIF-1a KO and HIF-1a WT mice after DSS treatment on day 4 after treatment. Red data points meet the thresholds of log2(fold-change [FC]) above 0.5 and less than $-0.5, P$ value $<0.05$. Bottom: GO term enrichment analysis of the up-regulated genes (red bars) and down-regulated genes (green bars). The vertical coordinate is the enriched GO term, and the horizontal coordinate is the percentage of identified and associated genes within a GO term group. Associated genes meet significance of $P \leq 0.001$. (B) Left: Heatmap of down-regulated gene expression of colonic tissues from HIF-la KO mice treated with DSS (day 4 after treatment) significantly associated to identified GO terms. Right: Heatmap of up-regulated gene expression of colonic tissues from HIF-1a KO mice treated with DSS (day 4 after treatment) significantly associated with identified GO terms. Bottom: Heatmap of gene expression of large intestinal tissues from HIF-la KO mice with a significantly differential expression to the large intestinal samples from HIF-la WT mice from the post-filtered (cytokines, chemokines, growth factors) pool of genes. 
A

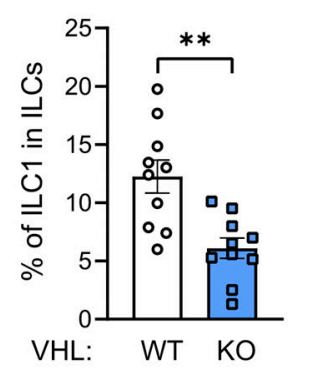

C

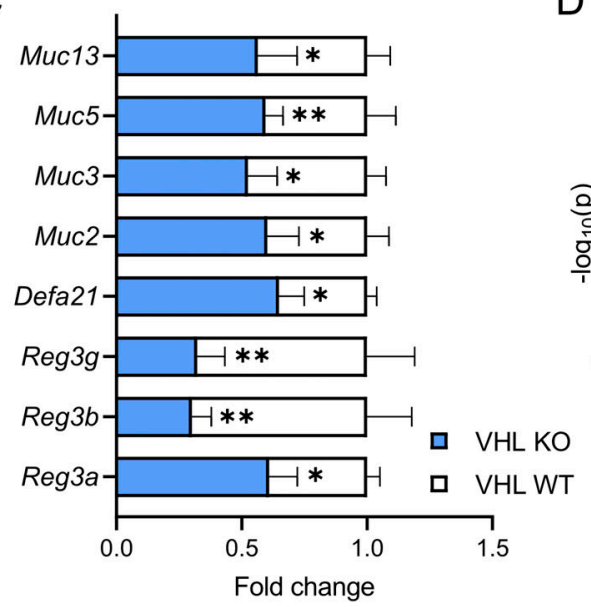

E

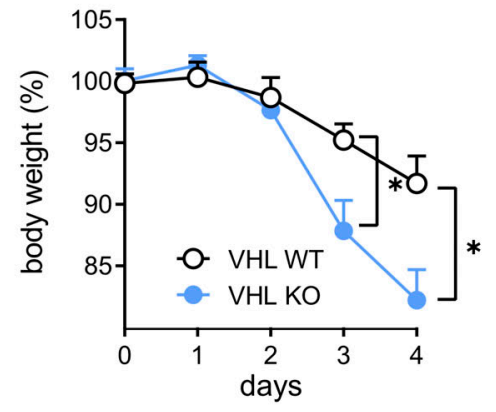

NKp46+ILC3

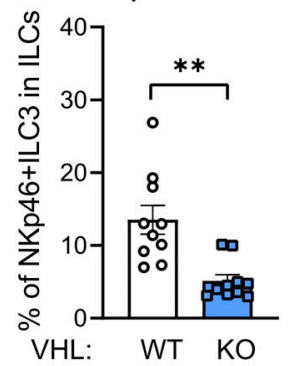

F

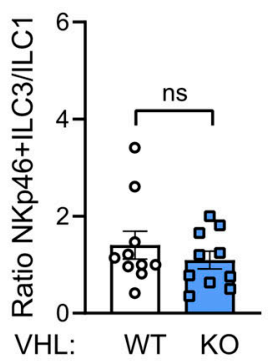

D

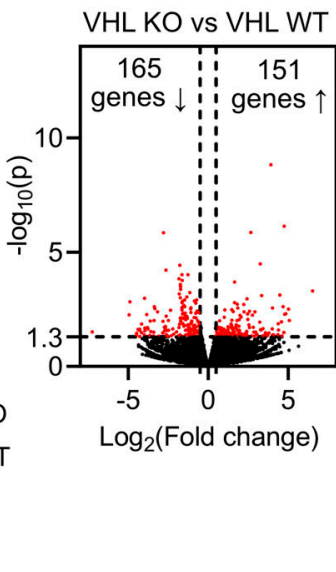

B

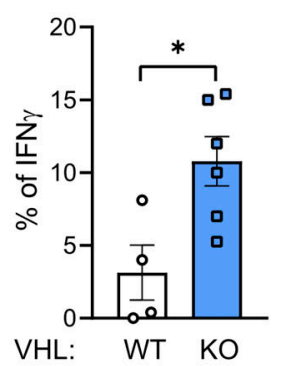

NKp46+ILC3

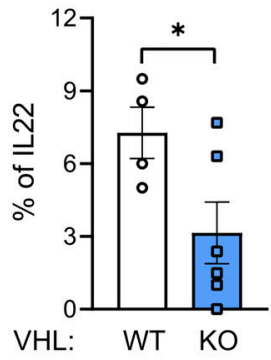

\section{GO terms}

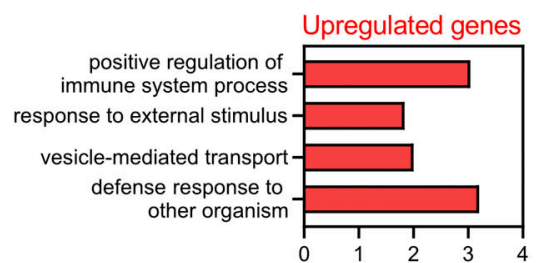

Downregulated genes
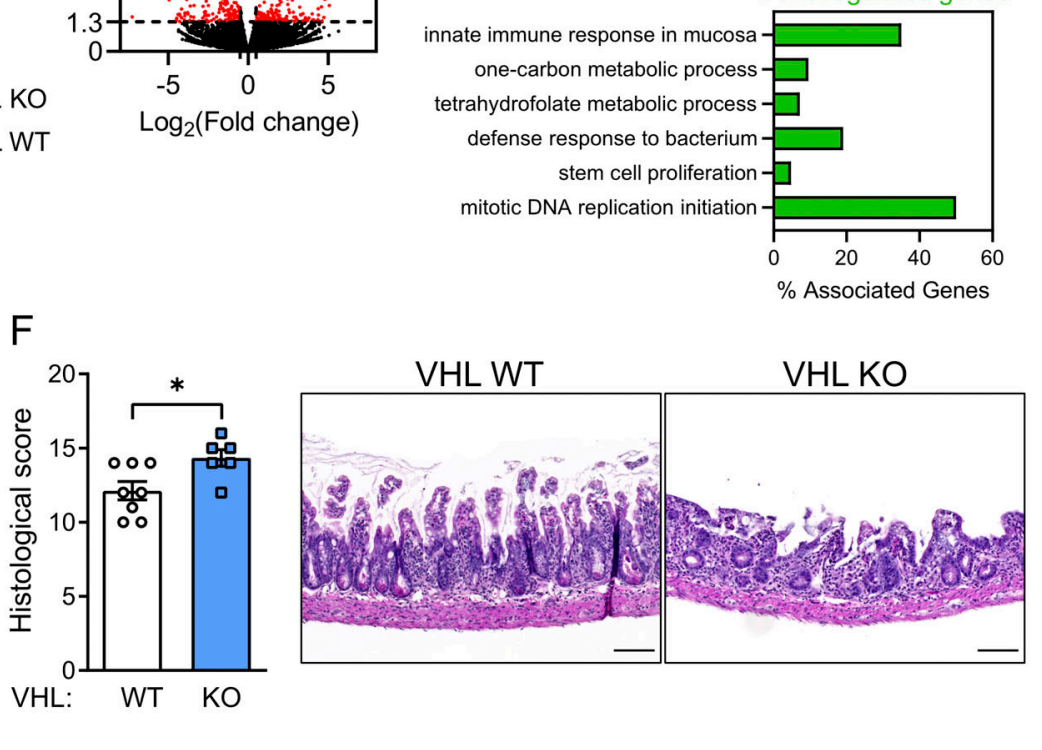

$\mathrm{H}$ ILC1

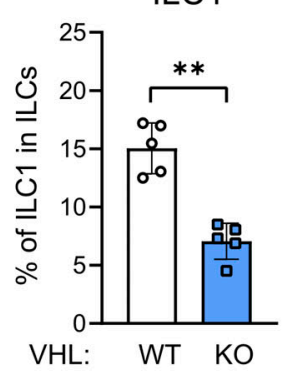

NKp46+ILC3
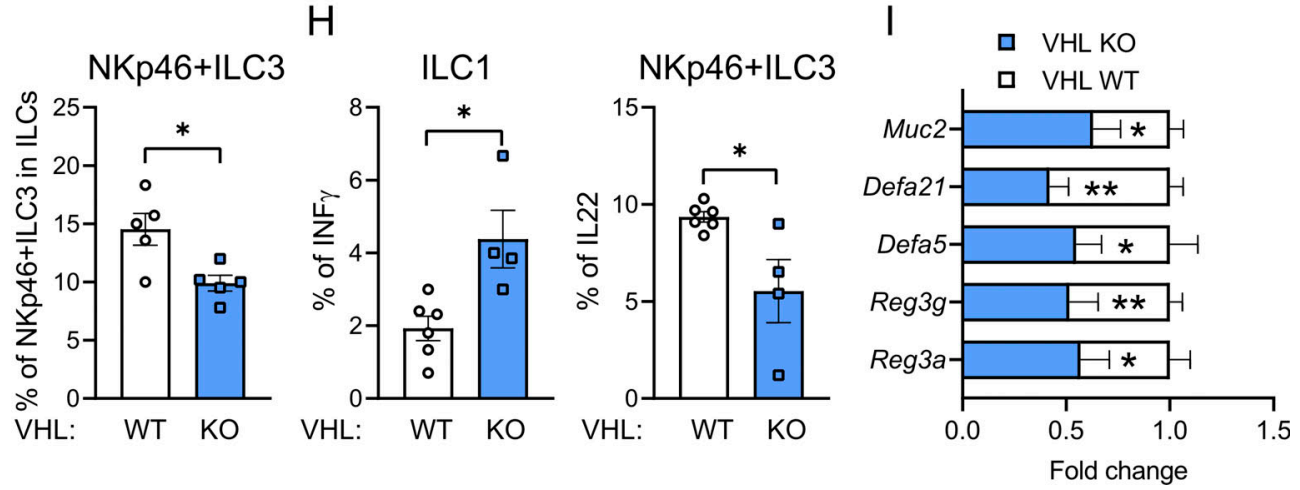

Figure 10. Constitutive expression of HIF-1a in NKp46 cells reduces ILC numbers in the SI and increases the susceptibility to mucosal damage. (A) Flow cytometric analysis of small intestinal ILC1s and NKp46+ ILC3s and the ratio of NKp46+ ILC3 to ILC1 from VHL KO and VHL WT mice (pooled data of three independent experiments, $n=10$ ); data are mean values $\pm S E M$; ${ }^{* *}, P<0.01$ by two-tailed Student's $t$ test. (B) Flow cytometric analysis of small intestinal ILC1s and NKp46+ ILC3s stimulated with PMA/ionomycin and stained for intracellular IFN- $y$ and IL-22 from VHL KO and VHL WT mice (pooled data of two independent experiments, $n \geq 4$ ); data are mean values \pm SEM; ${ }^{*}, P<0.05$ by two-tailed Student's $t$ test. (C) The gene expression analysis of IL-22-dependent gut-homeostatic factors including prohomeostatic genes Reg3a, Reg3b, Reg3g, Defa21, Muc2, Muc3, Muc5, and Muc13 in small intestinal tissues from VHL KO and 
VHL WT mice (pooled data of three independent experiments, $n=10$ ); data are mean values $\pm \mathrm{SEM} ;{ }^{*}, \mathrm{P}<0.05 ;{ }^{* *}, \mathrm{P}<0.01$ by multiple two-tailed Student's $t$ test. (D) Left: Volcano plot of the gene expression profile of small intestinal tissues from VHL KO $(n=3)$ and VHL WT $(n=3)$ mice. Red data points meet the thresholds of $\log 2$ (fold-change [FC]) $>0.5$ and green points less than $-0.5, P$ value $<0.05$. Right: GO term enrichment analysis of the up-regulated genes (red bars) and down-regulated genes (green bars). The vertical coordinate is the enriched GO term, and the horizontal coordinate is the percentage of identified and associated genes within GO term group. Associated genes meet significance P $\leq 0.001$. (E) Weight curve of VHL KO and VHL WT mice treated with MTX (pooled data of three independent experiments, $n=12$ ); data are mean values \pm SEM; ${ }^{*}, P<0.05$ by multiple two-tailed Student's $t$ test. (F) MTX-induced pathology analysis of the small intestinal tissues from VHL KO and VHL WT mice as described in Materials and methods (pooled data of two independent experiments, $n \geq$ $6)$; data are mean values \pm SEM; ${ }^{*}, \mathrm{P}<0.05$ by two-tailed Student's $t$ test. Right: Representative images of H\&E staining on small intestinal tissues from $\mathrm{VHL}$ KO and VHL WT mice treated with MTX on day 4 after treatment; scale bar, $100 \mu \mathrm{m}$. (G) Flow cytometric analysis of small intestinal ILC1s and NKp46 ILC3s from VHL KO and VHL WT mice treated with MTX on day 4 after treatment (pooled data of two independent experiments, $n=5$ ); data are mean values \pm SEM; ${ }^{*}, \mathrm{P}<$ $0.05 ;{ }^{* *}, \mathrm{P}<0.01$ by two-tailed Student's $t$ test. (H) Flow cytometric analysis of small intestinal ILC1s and NKp46+ ILC3s stimulated with PMA/ionomycin and stained for intracellular IFN-y and IL-22 from VHL KO and VHL WT mice treated with MTX at day 4 after treatment (pooled data of two independent experiments, $n \geq 4$ ); data are mean values \pm SEM; *, P < 0.05 by two-tailed Student's $t$ test. (I) The gene expression analysis of IL-22-dependent gut-homeostatic genes Reg3a, Reg3g, Defa5, Defa21, and Muc2 in small intestinal tissues from VHL KO and VHL WT mice treated with MTX on day 4 after treatment (pooled data of three independent experiments, $n=10$ ); data are mean values $\pm \mathrm{SEM} ;{ }^{*}, \mathrm{P}<0.05 ;{ }^{* *}, \mathrm{P}<0.01$ by multiple two-tailed Student's $t$ test.

2021). Campbell et al. (2014) demonstrated that transmigrating neutrophils deplete oxygen from the mucosal microenvironment and consequently stabilize HIF-1 $\alpha$ in intestinal epithelial cells. Likewise, genetic or pharmacologic HIF stabilization in gut epithelial cells is protective against mucosal damage, which appears counterintuitive at first sight (Tambuwala et al., 2010, 2015). However, the protective effect of HIF stabilization in gut epithelial cells was achieved by inducing prohomeostatic genes similar to the ILC3/IL-22-dependent prohomeostatic expression pattern upon deletion of HIF-1a in NKp46+ ILCs. These observations support the concept of cell type-specific effects of HIF transcription factors. Further evidence stems from the observation that deletion of HIF-1 $\alpha$ in myeloid cells ameliorated, whereas HIF-1 $\alpha$ deficiency in dendritic cells aggravated, experimental colitis (Flück et al., 2016; Bäcker et al., 2017).

The ILC phenotype in the gut depends on exogenous cytokines including IL-12 and ILC-intrinsic ROR $\gamma$ t/T-bet gradients. Here, we show that the hypoxic response in $\mathrm{NKp} 46^{+}$cells drives phenotypic ILC changes in a HIF-1 $a$-dependent manner. HIF$1 a$ contributes to T-bet expression and the ILC1 state, whereas loss of HIF-1a favors an increased ROR $\gamma \mathrm{t} / \mathrm{T}$-bet gradient and an ILC3 phenotype, indicating direct transcriptional control of T-bet by HIF-1a. Our findings contrast with observations claiming that mTOR drives activation of ILC3s via a HIF-1a/ RORYt signaling axis, although this study did not use genetic inactivation of HIF-1a but applied pharmacological inhibition of HIF-1 $a$ with potential off-target effects (Di Luccia et al., 2019). HIF-1a was also implicated in fostering the development of Th17 cells through direct transcriptional activation of RORYt (Dang et al., 2011). Likewise, as reported by Fachi et al. (2021) in RORYt-expressing ILC3s, HIFla binds to the Rorc promoter but not the Tbx21 promoter and supports IL-22 and IL-17 expression (Fachi et al., 2021). In contrast to the investigation by Fachi et al. (2021) that analyzed cytokine expression and HIFla binding to the Rorc promoter by ChIP in the ILC3 cell line MNK3 after short-term exposure (up to $3 \mathrm{~h}$ ) to near-anoxic conditions, we assessed Rorc and Tbx21 expression after $20 \mathrm{~h}$ of exposure to IL12 and HIFla binding to the Tbx21 promoter after 8-h incubation with IL-12 by Cut \& Run in primary murine WT and HIFla KO NKp $46^{+}$cells. Therefore, in addition to the different in vitro cell systems, the different stimuli and the duration of stimulation are likely to contribute to the observed discrepancies. Along these lines, different kinetics of HIF binding to the Rorc and Tbx21 promoter, as well epigenetic status of the Rorc and Tbx21 gene that allow or prevent HIF binding in different ILC cell types and subsets, need to be taken into account.

In NKp46+ ILCs, HIF-1a directly increases T-bet expression but does not increase ROR $\gamma t$ expression. Transcriptional control by HIFs requires the presence of HREs within the promoter of target genes (Wenger et al., 2005; Schödel et al., 2011). Consistently, promoter analysis for Rorc revealed 2 HREs located in the promoter region (Fig. S5 A), while we found 3 HREs in the promoter and 14 additional HREs in noncoding regions of the Tbx21 gene, indicating transcriptional control of T-bet by HIF$1 a$ in ILCs. Distinct context-specific transcriptional networks in Th17 cells and ILCs are likely to be responsible for distinct cell type-specific effects (Chang et al., 2020; Colonna, 2018). T-bet is also essential for optimal IFN- $\gamma$ expression (Lugo-Villarino et al., 2003) and consistent with reduced levels of T-bet in the absence of HIF-1a; HIF-1 $\alpha$-null ILCs show impaired IFN- $\gamma$ expression. This further corroborates the existence of a HIF-1a/T-bet/IFN- $\gamma$ signaling axis.

Most studies so far have analyzed ILC functions using Rag-/mice, in which ILCs are the only lymphocyte population (Colonna, 2018). Schroeder et al. (2021) recently demonstrated that loss of T-bet in NKp46 ${ }^{+}$ILC3s results in accumulation of $\mathrm{CCR6}^{-} \mathrm{NKp} 46^{-}$ILC3s in nonlymphopenic mice. We also used immunocompetent mice to be able to understand the impact of HIF-1a on NKp46+ ILC subsets in the presence of T cells and report a decrease in T-bet in NKp46 ${ }^{+}$ILC3s and a decrease in CD4 $\mathrm{T}$ cells in the SI of HIF-1a KO mice under steady-state conditions. The underlying mechanism remains elusive but suggests a cross-talk between ILCs and T cells in the gut (Mao et al., 2018), which is beyond the scope of the current study.

We observe differential outcome of HIF-1a deletion in $\mathrm{NKp} 46^{+}$cells dependent on the gut compartment investigated. In the SI, loss of HIF-1a decreased ILC1s and increased ILC3s in the $\mathrm{NKp} 46^{+}$subset. In contrast, in the colon, the $\mathrm{NKp} 46^{+}$population of HIF-1a KO mice showed an increase in ILC3s, with unaltered ILC1 levels. This is consistent with the concept of varying distributions of ILC across gastrointestinal compartments, with ILC1s enriched in the upper gastrointestinal tract (Krämer et al., 2017). It is conceivable that a reduction in ILCls is most obvious in the ILC1-rich SI. Additional differences between the SI and 
colon include the microbiome composition (Britanova and Diefenbach, 2017; Diefenbach et al., 2020). Moreover, differences in mucosal oxygenation (Fagundes and Taylor, 2017; Flück and Fandrey, 2016) may contribute to the tissue-specific ILC phenotype that we observe in the SI and colon of HIF-1a KO mice. This is in line with the recent discovery that the same ILC subtype may fulfill tissue-specific but different functions in the SI and colon (Zhou et al., 2019).

The important role of HIF-1a in NKp46+ ILCs is further substantiated in a mouse model with constitutive NKp46 cellspecific HIF-1a stabilization (VHL KO). HIF-1a stabilization enhances levels of the ILC1 cytokine IFN- $\gamma$ and decreases expression of the ILC3 cytokine IL-22. This is paralleled by a down-regulation of IL-22-dependent gut-homeostatic genes and accentuated susceptibility to intestinal inflammation. Although forced HIF-1a expression fails to increase the ILC1/ILC3 ratio in the gut, our findings support the concept of a HIF-1a/T-bet/IFN$\gamma$ axis in gut NKp46 ${ }^{+}$ILC1s. VHL negatively regulates both HIF isoforms, and the deletion of VHL results in constitutive expression of HIFl $\alpha$ and HIF-2 $\alpha$. The two HIF isoforms may exert opposing effects regarding immune cell functions (Takeda et al., 2010), which requires study to understand the role of HIF-2 $\alpha$ in gut NKp $46^{+}$cells. At that point, we also cannot exclude that VHL deletion causes HIF-independent effects that contribute to the observed phenotypes (Kurban et al., 2006; Grosfeld et al., 2007).

Conceptually, this suggests a HIF-1 $\alpha$-dependent trade-off in ILCs between enhanced ILC3/IL-22-driven prohomeostatic properties of the gut mucosa and a dampened ILC1 proinflammatory response on the one hand as well as reduced intestinal lipid uptake and weight gain on the other hand. Modulation of the HIF pathway in ILCs may therefore be a therapeutic target in inflammatory bowel disease as well as metabolic disorders. In summary, our data demonstrate the pivotal role of the transcription factor HIF-1a in ILC function, lipid metabolism, and gut defense.

\section{Materials and methods}

\section{Mouse models}

Targeted deletion of HIF-1 $\alpha$ in NKp46-expressing cells was achieved by crossing the loxP-flanked HIF-1 $\alpha$ allele and the loxPflanked VHL allele to the Ncrl (NKp46) promoter-driven cre recombinase (termed HIF-1 $\alpha \mathrm{KO}$ and VHL KO mice). For genetic tracing of NKp46 cells, the B6.Cg-Gt(ROSA)26Sortml(EYFP)Cos $\times$ B6.Cg-Tg(NCR1-Cre) transgenic mouse line was used as an HIF-1a WT, and the B6.Cg-Gt(ROSA)26Sortml(EYFP)Cos $\times$ B6.Cg-Tg(NCR1-Cre) $\times$ C57BL/6-Hifla(loxP) transgenic mouse line was used as an HIF-1 $\alpha \mathrm{KO}$. To mitigate the influence of strain variation, mice were kept in a >99\% C57BL/6J background. Mouse experiments were performed with at least three mice per group, and multiple experiments were combined to assess statistically significant differences as noted. Littermates (between 8 and $12 \mathrm{wk}$ of age) of the same genotype were randomly assigned to experimental groups and were weighed before each experiment. Males and females were used in approximately equal ratios.

For analysis of the SI, the distal half of the jejunum and the entire ileum (without Peyer patches) was used. For analysis of the large intestine, we used the colon (large intestine without the cecum and rectum. Fat tissue explants were obtained from gonadal visceral adipose tissue of WT and HIF-1a KO mice. All animal experiments have been approved by the veterinary authorities of the Canton of Zurich, Switzerland, and were performed in accordance with Swiss law on the care, welfare, and treatment of animals.

\section{Serum triglycerides and cholesterol and body composition measurement}

Serum triglycerides and cholesterol were measured using the UniCel DxC 800 Chemistry Analyzer (Zurich Integrative Rodent Physiology) according to the manufacturer's instructions. Mouse body composition, including fat and lean mass, was measured with EchoMRI at $12 \mathrm{wk}$ of age according to the manufacturer's instructions (Echo Medical Systems, Zurich Integrative Rodent Physiology).

\section{MTX treatment}

8-wk-old mice were injected i.p. with $120 \mathrm{mg} / \mathrm{kg}$ MTX (SigmaAldrich) on day -1 and with $60 \mathrm{mg} / \mathrm{kg}$ on day 0 . Body weight was monitored daily, and tissues were collected on days 1 and 4 after the final MTX injection (Aparicio-Domingo et al., 2015).

\section{DSS colitis model}

The DSS model of colitis was used as described previously (Chassaing et al., 2014). Briefly, acute disease was induced in 8wk-old mice by the treatment with $2.5 \%$ DSS in drinking water for at least $6 \mathrm{~d}$. The disease activity index was determined according to the parameters outlined in Tambuwala et al. (2010).

\section{Isolation of lamina propria lymphocytes}

Isolated SI and colon were washed with cold PBS and turned over, and the Peyer patches were removed. Tissues were cut in 2 -cm pieces and incubated in HBSS containing $2 \% \mathrm{FBS}$ and $5 \mathrm{mM}$ dithiothreitol at $37^{\circ} \mathrm{C}$, two times for 15 min with shaking (200 rpm). Next, tissues were incubated in HBSS containing $2 \%$ FBS and $5 \mathrm{mM}$ EDTA at $37^{\circ} \mathrm{C}$, three times for $15 \mathrm{~min}$ with shaking (200 rpm) to remove intraepithelial lymphocytes. The tissues were digested with $0.4 \mathrm{Wünsch} \mathrm{U} / \mathrm{ml}$ of Liberase TL (Roche) and $200,000 \mathrm{U} / \mathrm{ml}$ of DNaseI (Roche) in HBSS containing $\mathrm{MgCl}_{2}$ and $\mathrm{CaCl}_{2}$ at $37^{\circ} \mathrm{C}$, with horizontal shaking $(200 \mathrm{rpm})$ for $30 \mathrm{~min}$. Supernatants were passed through a $70-\mu \mathrm{m}$ cell strainer and washed three times in HBSS without $\mathrm{MgCl}_{2}$ or $\mathrm{CaCl}_{2}$ and containing $2 \%$ FBS. In the end, the cell pellet was resuspended in complete medium (10\% FBS with penicillin-streptomycin; Goodyear et al., 2014). Lamina propria lymphocytes were stained as in the procedure below (Flow cytometry and cell sorting), and lamina propria lymphocytes were analyzed with a BD FACSymphony Flow Cytometer. Data were analyzed using FlowJo v10 (TreeStar; see Fig. S1 B for full gating strategy).

\section{Flow cytometry and cell sorting}

Single-cell suspensions of small intestinal and colonic tissues were obtained and stained. Anti-mouse CD16/32 antibody was used to block the nonspecific binding to Fc receptors before all surface staining. Cell viability was measured using LIVE/DEAD 
Fixable Aqua Dead Cell Stain Kit (Thermo Fisher Scientific). The following $\mathrm{mAbs}$ from eBioscience, BD Biosciences, or BioLegend were used: anti-F4/80 (BM8; 123107; 123131), anti-CD1lc (N418; 117310; 117306), anti-CD8 (53-6.7; 100730), anti-CD19 (6D5; $115530 ; 152404)$, anti-MHCII (M5/114.15.2; 48-5321; 107616), antiLy6G (1A8; 746448; 127618), anti-Ly6C (HK1.4; 128035), antiCD45 (30-F11; 564225; 103128), anti-CD4 (GK1.5; 565974; 564667), anti-B220 (RA3-6B2; 564662), anti-CD11b (M1/70; 564443; 101206), anti-NK1.1 (PK136; 553165; 563220; 564144), anti-Siglec-F (E502440; 562757), anti-TCR $\beta$ (H57-597; 109210; 109206), anti-TCR $\delta$ (GL3; 118106), anti-NKp46 (29A1.4; 25-3351), anti-TER119/ erythroid cells (TER-119; 116206), anti-CD127 (A7R34; 135027), anti-CCR6 (140706; 747831), anti-CD49b (DX5; 741752), antiCD49a (Ha31/8; 741976), anti-ICOS (C398.4A; 15-9949-82), and relevant isotype controls.

For detection of IL-22 and IFN- $\gamma$, in brief, cells were stimulated by PMA and ionomycin (eBioscience Cell Stimulation Cocktail plus protein transport inhibitors) for $4 \mathrm{~h}$. Cells were stained with surface antibodies and fixed according to the manufacturer's protocol (eBioscience Intracellular Fixation \& Permeabilization Buffer Set; 88-8824-00). Next, cells were stained with anti-IL-22 (il22jop; 17-7222-82) and anti-IFN- $\gamma$ (XMG1.2; 566151).

The nuclear staining for ROR $\gamma \mathrm{t}$ (Q31-378; 562682), T-bet (4b10; 644835), GATA3 (TWAJ; 12-9966-42), and Eomes (Dan11mag; 61-4875-82) was performed according to manufacturer's protocol (eBioscience Foxp3/Transcription Factor Staining Buffer Set; 00-5523-00). Flow cytometry was performed on a BD FACSymphony Flow Cytometer. Data were analyzed using FlowJo v10 (TreeStar; see Fig. S1 B for full gating strategy).

To isolate $\mathrm{EYFP}^{+} \mathrm{NKp}^{+} 6^{+} \mathrm{ILCs}$, EYFP ${ }^{+} \mathrm{NKp} 46^{+} \mathrm{CD} 49^{+}$ILC1s, and $\mathrm{EYFP}^{+} \mathrm{NKp}^{-} 6^{+} \mathrm{CD} 49 \mathrm{a}^{-}$ILC3s by cell sorting, lamina propria lymphocytes from SI were stained with Abs specific for CD49b, CD49a, and Zombie Violet Fixable Viability Kit. The resulting cell populations were sorted using FACSAria III 5L into RLT Buffer and processed with Qiagen RNA extraction kit (RNeasy Micro Kit) following the manufacturer's instructions or into IMDM Glutamax supplemented with 10\% (vol/vol) FBS.

\section{Cell culture and conversion of NKp46 ${ }^{+}$ILC3s}

Freshly sorted small intestinal ILCls (defined as EYFP ${ }^{+} / \mathrm{NKp}^{2} 6^{+} /$ CD45 high/CD90 intermediate) or NKp46 ${ }^{+}$ILC3s (defined as EYFP ${ }^{+} /$ $\left.\mathrm{NKp} 46^{+} / \mathrm{CD} 45^{\text {intermediate}} / \mathrm{CD} 90^{\text {high }}\right)$ were cultured in IMDM Glutamax supplemented with $10 \%$ (vol/vol) FBS, $\beta$-ME ( $55 \mu \mathrm{M})$, and penicillin-streptomycin. ILC1s were grown in the presence of (1) IL-7 (5 ng/ml; Peprotech) or (2) mixed IL-7 ( $5 \mathrm{ng} / \mathrm{ml})$, IL$1 \beta(20 \mathrm{ng} / \mathrm{ml})$, and IL-23 $(20 \mathrm{ng} / \mathrm{ml})$. ILC3s were grown in the presence of (1) IL-7 (5 ng/ml; Peprotech) or (2) mixed IL-7 (5 ng/ $\mathrm{ml})$ and IL-12 $(20 \mathrm{ng} / \mathrm{ml})$. After $20 \mathrm{~h}$, cells were stained as in Flow cytometry and cell sorting.

\footnotetext{
Adoptive transfer

For adoptive transfer experiments, Rag2 ${ }^{-/-} \mathrm{\gamma c}^{-/-}$recipient mice were injected i.v. with 8,000 small intestinal NKp46 ${ }^{+}$ILC3s FACS-sorted on an 56 instrument (BD Biosciences) from EYFPWT and EYFP HIF-1a KO mice defined as EYFP ${ }^{+} / \mathrm{NKp} 6^{+} /$ $\mathrm{CD} 45^{\text {low }} / \mathrm{CD} 90^{\text {high }}$. Mice were analyzed 5 wk after transfer.
}

\section{In vivo plasticity}

Rag2 $2^{-/-} \mathrm{\gamma c}^{-/-}$recipient mice 5 wk after adoptive transfer were injected i.p. with recombinant mIL-12 (Peprotech) at $50 \mu \mathrm{g} / \mathrm{kg}$ body weight. Mice were analyzed $48 \mathrm{~h}$ after injection.

\section{CUT\&RUN; HIF1a binding to the Tbx21 promoter}

30,000 freshly sorted EYFP ${ }^{+}$NKp46 ${ }^{+}$ILCs were cultured in IMDM Glutamax supplemented with 10\% (vol/vol) FBS, $\beta$-ME $(55 \mu \mathrm{M})$, and penicillin-streptomycin and in the presence of mixed IL-7 ( $5 \mathrm{ng} / \mathrm{ml})$ and IL-12 $(20 \mathrm{ng} / \mathrm{ml})$. After $8 \mathrm{~h}$, cells were harvested and processed with the CUT\&RUN (Cleavage Under Targets \& Release Using Nuclease) Assay Kit (86652; Cell Signaling Technology) following the supplier's instructions. HIFla (NB100-479SS; Novus) antibody was used at $5 \mu \mathrm{g}$. DNA was purified using DNA spin columns and eluted in $50 \mu \mathrm{l}$ buffer. Finally, binding of HIFla onto the Tbx21 promoter was quantified by qPCR using the following primers: Tbx21_HRE1_F, 5'-CCA TCTATACAAAGCTGGGGGT-3'; Tbx21_HRE1_R, 5'-AACTGATGG AGTGCCTGCTTA-3'; Tbx21_HRE2_F, 5'-ACTTCCCGTGTCTTT CGCTA-3'; and Tbx21_HRE2_R, 5'-AATGCTCCCACAAAAGCT CG-3'.

\section{scRNA-seq}

For scRNA-seq, lamina propria lymphocytes (pooled from three mice per genotype) from SI of the B6.Cg-Gt(ROSA)26Sort$\mathrm{ml}$ (EYFP) Cos $\times$ B6.Cg-Tg(NCR1-Cre) transgenic mouse line (HIF-1a WT) and the B6.Cg-Gt(ROSA)26Sortml(EYFP)Cos $\times$ B6.Cg- $\mathrm{Tg}(\mathrm{NCR1}-\mathrm{Cre}) \times$ C57BL/6-Hifla(loxP) transgenic mouse line (HIF-1a KO) were stained with Zombie Violet Fixable Viability Kit. Small intestinal EYFP ${ }^{+}$cells from EYFP-WT mice and EYFP-HIF-1 $\alpha$-KO were sorted using FACSAria III $5 \mathrm{~L}$ into ice-cold $0.5 \%$ BSA in PBS and processed on the same day through the Chromium Single Cell 30v2 Library Kit (10X Genomics) according to the manufacturer's protocol on a Functional Genomics Center Zurich platform.

\section{Analysis of scRNA-seq data}

FASTQ files were generated using the Cell Ranger FASTQ (cellranger mkfastq; 10X Genomics) pipeline, through which resulting BCL files from sequencing were de-multiplexed using bcl2fastq (v2.17). The resultant paired-end FASTQ files were aligned using the Cell Ranger Count (cellranger count; 10X Genomics) pipeline, though which FASTQ files were aligned to the mm10 reference transcriptome (Ensembl GRCm38 primary assembly) using STAR, an open-source splicing-aware RNA-seq aligner, and then single-cell gene counts were generated. Outputs from the Cell Ranger Count pipeline were then run through the Cell Ranger Aggregator (cell-ranger aggr) pipeline to combine data from EYFP-WT and EYFP-HIF-1a-KO samples. Further analysis was performed with Loupe 5.0 (10X Genomics).

The sequencing libraries were de-multiplexed and aligned to the mouse transcriptome (mm10), and unique molecular identifiers were counted using Cell Ranger (10X Genomics) v3.0.1 by the Functional Genomics Center Zurich. Further data analysis was performed using the Seurat package v3.1 in R v3.6.2. For in-depth analysis of cell populations, only cells with counts in $1,000-4,000$ genes and $<10 \%$ mitochondrial 
genes were retained, resulting in a final dataset consisting of 12,974 cells.

For dimensionality reduction and clustering of the final datasets, normalization, scaling, and variable gene selection was performed using the SCTransform function in Seurat, with standard settings. After principle component analysis, dimensionality reduction using the UMAP algorithm was performed using 30 principal components. Clusters were then identified using the FindNeighbors and FindClusters functions in Seurat, with resolution parameters of 0.6.

Differential abundance analysis was performed using the differential abundance sequencing (DA-seq) algorithm. DA-seq computes, for each cell, a score vector based on the relative prevalence of cells from both biological states in the cell's neighborhood. This vector is merged into a single DA measure as quantity of differential abundance. The associated prediction probability is then transformed to a DA measure of how much a cell's neighborhood is dominated by cells from one of the biological states. Cells were clustered according to their DA measure. The cells in each region represent cell subpopulations with a significant difference in abundance between biological states (Zhao et al., 2021). We used the Wilcoxon rank sum test, which assesses separation between the expression distributions of different clusters. Genes with an average of at least 0.25 -fold difference (log scale) between the cells in the tested cluster and the rest of the cells and an adjusted $P$ value $<0.05$ were declared significant. For pseudo-time analysis, we applied the PAGA tree method. scRNA-seq of intestinal NKp46 ${ }^{+}$ILCs from HIF1a WT and HIF-1a KO mice have been deposited in the ArrayExpress database under accession no. E-MTAB-11238.

\section{Histological analysis}

10-mm small-intestinal and colonic tissues were removed and fixed in $4 \%$ paraformaldehyde and then embedded in paraffin. Alternatively, 30-50-mm small-intestinal and colonic tissues were fixed in modified Bouin's fixative ( $50 \%$ ethanol/5\% acetic acid in distilled $\mathrm{H}_{2} \mathrm{O}$ ), and the Swiss roll preparation procedure was used. All the samples were embedded in paraffin and sectioned with a microtome. The 7- $\mu \mathrm{m}$ sections were deparaffinized with xylene and rehydrated with graded ethanol. The sections were stained for hematoxylin (Vector Laboratories) and eosin (Sigma-Aldrich; H\&E). The colonic sections were blindly analyzed and scored according to a previously described scoring system (Tambuwala et al., 2010). The four parameters used include (1) severity of inflammation, range 1-3; (2) extent of inflammation, range $0-3,(3)$ crypt damage, range $0-3$, and (4) percentage involvement, range $0-4$. Scores were calculated by multiplying the score for the first three parameters by their percentage involvement, giving a maximum score of 40 . The small intestinal sections were blindly analyzed and scored according to the following four-parameter scoring system (Erben et al., 2014): (1) severity of inflammation, range 0-4; (2) extent of inflammation, range $0-4,(3)$ epithelial changes, range $0-4$, and (4) mucosal architecture, range 0-4, with a maximum score of 16 .

\section{Gene expression by qPCR}

General procedure: The tissue samples were homogenized in RLT buffer (Qiagen). Total RNA was isolated with Qiagen RNA extraction kits following the manufacturer's instructions. For real-time PCR analysis, the isolated RNA was reverse transcribed (High-Capacity cDNA Reverse Transcription Kit; 4368814; Applied Biosystems). For PCR reactions, SYBR Green I Master MIX (LightCycler 480 SYBR Green I Master; 04887352001; Roche) was used. $10 \mathrm{ng}$ cDNA was used as template to determine the relative amount of mRNA by real-time PCR (Roche Detection System). PCR conditions were as follows: $95^{\circ} \mathrm{C}$ for $10 \mathrm{~min}$ followed by 45 cycles of $95^{\circ} \mathrm{C}$ for $15 \mathrm{~s}$ and $60^{\circ} \mathrm{C}$ for $1 \mathrm{~min}$. Data were normalized to $16 \mathrm{~S}$ mRNA levels.

The following primers were used: $16 \mathrm{~s}$ forward primer, $5^{\prime}$-AGA TGATCGAGCCGCGC-3'; reverse primer, 5'-GCTACCAGGGCC TTTGAGATGGA-3'; Muc2 forward primer, 5' -TCGCCCAAGTCG ACACTCA-3'; reverse primer, 5' -GCAAATAGCCATAGTACAGTT ACACAGC-3'; Muc3 forward primer, 5'-TGGTCAACTGCGAGA ATGGA-3'; reverse primer, 5'-TACGCTCTCCACCAGTTCCT-3'; Muc5 forward primer, 5'-GATCCATCCATCCCATTTCTACC-3'; reverse primer, 5'-TTGCTTATCTGACTACCACTTGTTGA3'; Mucl3 forward primer, 5'-GCGGTGGAAGCACAGGTCCC-3'; reverse primer, 5'-TGCTGACCGTGAAGGGGCTG-3'; Reg3a forward primer, $5^{\prime}$-TTACTCСАСТСССАТССАСС-3'; reverse primer, 5'-TGAGGCTTCCTTTGTGTCCT-3'; Reg3b forward primer, 5' TGGGAATGGAGTAACAATGACGTG-3'; reverse primer, $5^{\prime}$-GGC AACTTCACCTCACATGTCAT-3'; Reg $3 g$ forward primer, $5^{\prime}$-GCT CCTATTGCTATGCCTTGTTTAG-3'; reverse primer, 5' -CATGGA GGACAGGAAGGAAGC-3'; Defa5 forward primer, 5'-TATCTCCTT TGGAGGCCAAG-3'; reverse primer, 5'-TTTCTGCAGGTCCCA AAAAC-3'; Defa21 forward primer, 5'-CTGATCCTATCCAAAACA CAGATG-3'; reverse primer, 5'-CAATTTTTCATGAAGAGCAGA TCC-3'; Ifng forward primer, 5'-TCAAGTGGCATAGATGTGGAA GAA-3'; reverse primer, 5'-TGGCTCTGCAGGATTTTCATG-3'; Il22 forward primer, 5'-TCAGCTCAGCTCCTGTCACAT-3'; reverse primer, $5^{\prime}$-TCCCCAATCGCCTTGATCTCT-3'; Hifla forward primer, 5' -GAGCTCACATTGTGGGGAAG-3'; reverse primer, 5' GGCGAGAACGAGAAGAAAAA-3'; Rorc forward primer, 5' -ACA ACAGCAGCAAGTGATGG-3'; reverse primer, 5'-CCTGGATTT ATCCCTGCTGA-3'; Tbx21 forward primer, 5'-GGACGATCATCT GGGTCACAT-3'; reverse primer, 5'-CGCCAGGGAACCGCTTAT ATG-3'; Pla2g2 forward primer, 5'-GCCTGGAGAAAAGTGGAT GTG-3'; reverse primer, 5'-GGCTTTATCGCACTGACACAG-3'; Cd36 forward primer, 5'-GCGACATGATTAATGGCACAG-3'; reverse primer, 5'-GATCCGAACACAGCGTAGATAG-3'; Fabp2 forward primer, 5' -AGCTCGGTGTAAACTTTCCC-3'; reverse primer, 5'-TTCATTACCAGAAACCTCTCGG-3'; and Npcll1 forward primer, 5' -CGGAACTCACAGGACTTTACAG-3'; reverse primer, 5' -TGC TGGTAGAACACATTGGAG-3'.

For gene expression analysis on sorted $\mathrm{EYFP}^{+} \mathrm{NKp} 46^{+} \mathrm{CD} 49 \mathrm{a}^{+}$ CD49b- ILC1 cells and EYFP ${ }^{+} \mathrm{NKp}^{-} 6^{+}$CD49a- CD49b- ILC3 cells, $\sim 5,000$ ILC1 cells and 20,000 NKp46 ${ }^{+}$ILC3 cells were directly lysed using RNeasy Micro Kit (Qiagen) and analyzed according to the previously described procedure.

\section{Bulk RNA-seq}

The small intestinal and colonic tissues, respectively from HIF1a WT, HIF-1a KO, or VHL WT and VHL KO, were directly placed into RNA lysis buffer, homogenized, and processed for subsequent RNA isolation using RNeasy Mini Kit (Qiagen). RNA-seq 
from total RNA was performed by Novogene Europe. Differential gene expression analysis was performed using a minimum fold-change of 1.3 and a $\mathrm{P}$ value $<0.05$. GO network analysis was performed with ClueGO/Cytoscape (Shannon et al., 2003; Bindea et al., 2013, 2009).

The differentially expressed genes from RNA-seq of small intestinal tissues from HIF-1 $\alpha$ KO and VHL KO mice with corresponding WT mice under steady-state conditions have been deposited in the ArrayExpress database under accession nos. E-MTAB-11213 and E-MTAB-11212, respectively. The differentially expressed genes from RNA-seq of steady-state and DSSinduced colitis colonic tissues from HIF-1a WT and HIF-1 $\alpha$ KO mice have been deposited in the ArrayExpress database under accession no. E-MTAB-11215.

\section{Metagenomics study}

The feces of HIF-1a KO and WT mice were collected, and the bacterial populations in the samples were determined using next-generation high-throughput pyrosequencing of variable regions (V3-V4) of the 16S rDNA bacterial gene. The metagenomics workflow was used to identify organisms from a sample by amplifying specific regions in the $16 \mathrm{~S}$ ribosomal RNA gene. This metagenomics workflow is exclusive to bacteria. The main output is a classification of reads at several taxonomic levels: phylum, class, order, family, genus, and species.

\section{Statistical analysis}

Statistical analysis was performed with Prism 8.3 (GraphPad Software). Statistical significance was determined by an unpaired Student's $t$ test or one-way ANOVA, where appropriate. Statistical significance is indicated as ${ }^{*}, \mathrm{P}<0.05$; ${ }^{* *}, \mathrm{P}<0.01$; ***, $\mathrm{P}<0.001$; and ${ }^{* * *}, \mathrm{P}<0.0001$.

\section{Online supplemental material}

Fig. S1 frequencies and absolute numbers of $\mathrm{NKp} 46^{+}$cells, NK cells, and frequencies of other main immune cells populations in the SI of WT and HIF-1a KO mice together with the gating strategy; IFN- $\gamma$ and IL-22 expression in $\mathrm{CD}^{+}$cells in the SI of WT and HIF-1a KO mice. Fig. S2 shows representative histology images of the SI from WT and HIF-1a KO mice at steady state; bulk RNAseq analysis and expression of Cd36, Fabp2, Npcll1, and Pla2g2 in the SI from HIF-1 $\alpha$ KO and WT mice; serum triglyceride and cholesterol levels, body weight, and body composition from HIF-1 $a$ KO and HIF-1 $a$ WT mice. Fig. S3 shows the gating strategy for EYFP ${ }^{+}$cells and NKp46 expression in $\mathrm{EYFP}^{+}$ cells purified from the SI of EYFP-WT and EYFP-HIF-1 $\alpha$ KO reporter mice; frequencies of main immune cell population and the ratio of Il22 expression to Ifng expression in the SI of WT and HIF-1 $\alpha$ KO mice after MTX treatment on day 1 after treatment. Fig. S4 shows frequencies and absolute numbers of $\mathrm{NKp} 46^{+}$cells at the steady state and frequencies of other main immune cells populations in the colon of WT and HIF-1a KO mice at the steady state and on days 4 and 7 after DSS treatment; and the ratio of Il22 to Ifng expression and representative H\&E staining in the colon of WT and HIF-1 $1 \alpha \mathrm{KO}$ mice at the steady state. Fig. S5 frequencies of $\mathrm{NKp} 6^{+}$cells at the steady state and other immune cell populations at the steady state and on day 1 after MTX treatment in the SI of WT and VHL KO mice; representative H\&E staining of the SI from VHL KO and VHL WT mice at the steady state; bulk RNAseq analysis in the SI from VHL KO mice and WT mice at the steady state; and the ratio of Il22 expression to Ifng expression in the SI from VHL KO and VHL WT mice on day 1 after MTX treatment.

\section{Acknowledgments}

We thank the Laboratory Animal Services Center (LASC) for animal care; the UZH Irchel Flow Cytometry core facility and cell sorting core facility for cell sorting, especially Mario Wickert; the Functional Genomics Center Zurich facility for scRNA-seq service, especially Doris Popovic and Daymé Gonzalez Rodriguez; and the Zurich Integrative Rodent Physiology facility, especially Petra Seebeck and Nadine Nägele.

We acknowledge the support of the Swiss National Fund (310030_179235), the Swiss National Centre for Competence in Research "Kidney.CH" (project grant N-403-06-26 HCP), the Swiss Cancer League (KFS-4398-02-2018 and KFS-5402-082021), and support from the SKINTEGRITY.CH collaborative research program. M. Sobecki was supported by the internal postdoc funding program of the University of Zurich (Forschungskredit UZH Postdoc 2019).

Author contributions: E. Krzywinska and M. Sobecki designed and conducted experiments, analyzed data, prepared the figures and wrote the manuscript. S. Nagarajan conducted experiments and analyzed the data. J. Zacharjasz conducted experiments. M.M. Tambuwala and E. Cummins performed histological scoring and edited the manuscript. A. Pelletier harvested and analyzed murine adipose tissue. D. Gotthardt, J. Fandrey, Y.M. Kerdiles, and C. Peyssonnaux interpreted data, provided conceptual input, and edited the manuscript. C.T. Taylor performed histological scoring, provided conceptual input, and edited the manuscript. V. Sexl analyzed and interpreted data, helped to write the manuscript, and provided vital reagents. C. Stockmann designed and conducted experiments, analyzed and interpreted data, wrote the manuscript, and supervised and directed the project.

Disclosures: The authors declare no competing interests exist.

Submitted: 28 April 2021

Revised: 3 November 2021

Accepted: 2 December 2021

\section{References}

Airley, R.E., J. Loncaster, J.A. Raleigh, A.L. Harris, S.E. Davidson, R.D. Hunter, C.M.L. West, and I.J. Stratford. 2003. GLUT-1 and CAIX as intrinsic markers of hypoxia in carcinoma of the cervix: relationship to pimonidazole binding. Int. J. Cancer. 104:85-91. https://doi.org/10.1002/ijc.10904

Aparicio-Domingo, P., M. Romera-Hernandez, J.J. Karrich, F. Cornelissen, N. Papazian, D.J. Lindenbergh-Kortleve, J.A. Butler, L. Boon, M.C. Coles, J.N. Samsom, and T. Cupedo. 2015. Type 3 innate lymphoid cells maintain intestinal epithelial stem cells after tissue damage. J. Exp. Med. 212:1783-1791. https://doi.org/10.1084/jem.20150318

Bäcker, V., F.Y. Cheung, J.T. Siveke, J. Fandrey, and S. Winning. 2017. Knockdown of myeloid cell hypoxia-inducible factor-1 $\alpha$ ameliorates the 
acute pathology in DSS-induced colitis. PLoS One. 12:e0190074. https:// doi.org/10.1371/journal.pone.0190074

Bernink, J.H., L. Krabbendam, K. Germar, E. de Jong, K. Gronke, M. KofoedNielsen, J.M. Munneke, M.D. Hazenberg, J. Villaudy, C.J. Buskens, et al. 2015. Interleukin-12 and -23 Control Plasticity of CD127+ Group 1 and Group 3 Innate Lymphoid Cells in the Intestinal Lamina Propria. Immunity. 43:146-160. https://doi.org/10.1016/j.immuni.2015.06.019

Bindea, G., B. Mlecnik, H. Hackl, P. Charoentong, M. Tosolini, A. Kirilovsky, W.H. Fridman, F. Pagès, Z. Trajanoski, and J. Galon. 2009. ClueGO: a Cytoscape plug-in to decipher functionally grouped gene ontology and pathway annotation networks. Bioinformatics. 25:1091-1093. https://doi .org/10.1093/bioinformatics/btp101

Bindea, G., J. Galon, and B. Mlecnik. 2013. CluePedia Cytoscape plugin: pathway insights using integrated experimental and in silico data. Bioinformatics. 29:661-663. https://doi.org/10.1093/bioinformatics/btt019

Britanova, L., and A. Diefenbach. 2017. Interplay of innate lymphoid cells and the microbiota. Immunol. Rev. 279:36-51. https://doi.org/10.1111/imr.12580

Campbell, E.L., W.J. Bruyninckx, C.J. Kelly, L.E. Glover, E.N. McNamee, B.E. Bowers, A.J. Bayless, M. Scully, B.J. Saeedi, L. Golden-Mason, et al. 2014. Transmigrating neutrophils shape the mucosal microenvironment through localized oxygen depletion to influence resolution of inflammation. Immunity. 40:66-77. https://doi.org/10.1016/j.immuni.2013.11 .020

Chang, D., Q. Xing, Y. Su, X. Zhao, W. Xu, X. Wang, and C. Dong. 2020. The Conserved Non-coding Sequences CNS6 and CNS9 Control CytokineInduced Rorc Transcription during $\mathrm{T}$ Helper 17 Cell Differentiation. Immunity. 53:614-626.e4. https://doi.org/10.1016/j.immuni.2020.07.012

Chassaing, B., J.D. Aitken, M. Malleshappa, and M. Vijay-Kumar. 2014. Dextran sulfate sodium (DSS)-induced colitis in mice. Curr. Protoc. Immunol. 104:15.25.1-15.25.14. https://doi.org/10.1002/0471142735.im1525s104

Colgan, S.P., and C.T. Taylor. 2010. Hypoxia: an alarm signal during intestinal inflammation. Nat. Rev. Gastroenterol. Hepatol. 7:281-287. https://doi .org/10.1038/nrgastro.2010.39

Colonna, M. 2018. Innate Lymphoid Cells: Diversity, Plasticity, and Unique Functions in Immunity. Immunity. 48:1104-1117. https://doi.org/10 .1016/j.immuni.2018.05.013

Dang, E.V., J. Barbi, H.Y. Yang, D. Jinasena, H. Yu, Y. Zheng, Z. Bordman, J. Fu, Y. Kim, H.R. Yen, et al. 2011. Control of $\mathrm{T}(\mathrm{H}) 17 / \mathrm{T}(\mathrm{reg})$ balance by hypoxia-inducible factor 1 . Cell. 146:772-784. https://doi.org/10.1016/j .cell.2011.07.033

Di Luccia, B., S. Gilfillan, M. Cella, M. Colonna, and S.C.C. Huang. 2019. ILC3s integrate glycolysis and mitochondrial production of reactive oxygen species to fulfill activation demands. J. Exp. Med. 216:2231-2241. https:// doi.org/10.1084/jem.20180549

Diefenbach, A., M. Colonna, and S. Koyasu. 2014. Development, differentiation, and diversity of innate lymphoid cells. Immunity. 41:354-365. https://doi.org/10.1016/j.immuni.2014.09.005

Diefenbach, A., S. Gnafakis, and O. Shomrat. 2020. Innate Lymphoid CellEpithelial Cell Modules Sustain Intestinal Homeostasis. Immunity. 52: 452-463. https://doi.org/10.1016/j.immuni.2020.02.016

Eberl, G., M. Colonna, J.P. Di Santo, and A.N.J. McKenzie. 2015. Innate lymphoid cells. Innate lymphoid cells: a new paradigm in immunology. Science. 348:aaa6566. https://doi.org/10.1126/science.aaa6566

Eckelhart, E., W. Warsch, E. Zebedin, O. Simma, D. Stoiber, T. Kolbe, T. Rülicke, M. Mueller, E. Casanova, and V. Sexl. 2011. A novel Ncrl-Cre mouse reveals the essential role of STAT5 for NK-cell survival and development. Blood. 117:1565-1573. https://doi.org/10.1182/blood-2010 $-06-291633$

Erben, U., C. Loddenkemper, K. Doerfel, S. Spieckermann, D. Haller, M.M. Heimesaat, M. Zeitz, B. Siegmund, and A.A. Kühl. 2014. A guide to histomorphological evaluation of intestinal inflammation in mouse models. Int. J. Clin. Exp. Pathol. 7:4557-4576.

Fachi, J.L., L.P. Pral, J.A.C. Dos Santos, A.C. Codo, S. de Oliveira, J.S. Felipe, F.F.F. Zambom, N.O.S. Câmara, P.M.M.M. Vieira, M. Colonna, and M.A.R. Vinolo. 2021. Hypoxia enhances ILC3 responses through HIF-1adependent mechanism. Mucosal Immunol. 14:828-841. https://doi.org/10 $.1038 / \mathrm{s} 41385-020-00371-6$

Fagundes, R.R., and C.T. Taylor. 2017. Determinants of hypoxia-inducible factor activity in the intestinal mucosa. J Appl Physiol (1985). 123: 1328-1334. https://doi.org/10.1152/japplphysiol.00203.2017

Flück, K., and J. Fandrey. 2016. Oxygen sensing in intestinal mucosal inflammation. Pflugers Arch. 468:77-84. https://doi.org/10.1007/s00424 -015-1722-4

Flück, K., G. Breves, J. Fandrey, and S. Winning. 2016. Hypoxia-inducible factor 1 in dendritic cells is crucial for the activation of protective regulatory $\mathrm{T}$ cells in murine colitis. Mucosal Immunol. 9:379-390. https://doi.org/10.1038/mi.2015.67

Forkel, M., and J. Mjösberg. 2016. Dysregulation of Group 3 Innate Lymphoid Cells in the Pathogenesis of Inflammatory Bowel Disease. Curr. Allergy Asthma Rep. 16:73. https://doi.org/10.1007/s11882-016-0652-3

Goodyear, A.W., A. Kumar, S. Dow, and E.P. Ryan. 2014. Optimization of murine small intestine leukocyte isolation for global immune phenotype analysis. J. Immunol. Methods. 405:97-108. https://doi.org/10.1016/j jim.2014.01.014

Grosfeld, A., I.P. Stolze, M.E. Cockman, C.W. Pugh, M. Edelmann, B. Kessler, A.N. Bullock, P.J. Ratcliffe, and N. Masson. 2007. Interaction of hydroxylated collagen IV with the von hippel-lindau tumor suppressor. J. Biol. Chem. 282:13264-13269. https://doi.org/10.1074/jbc.M611648200

Gury-BenAri, M., C.A. Thaiss, N. Serafini, D.R. Winter, A. Giladi, D. LaraAstiaso, M. Levy, T.M. Salame, A. Weiner, E. David, et al. 2016. The Spectrum and Regulatory Landscape of Intestinal Innate Lymphoid Cells Are Shaped by the Microbiome. Cell. 166:1231-1246.e13. https://doi .org/10.1016/j.cell.2016.07.043

Johansson, M.E.V., and G.C. Hansson. 2016. Immunological aspects of intestinal mucus and mucins. Nat. Rev. Immunol. 16:639-649. https://doi.org/ $10.1038 / \mathrm{nri} .2016 .88$

Kaelin, W.G. Jr. 2008. The von Hippel-Lindau tumour suppressor protein: 02 sensing and cancer. Nat. Rev. Cancer. 8:865-873. https://doi.org/10 $.1038 / \mathrm{nrc} 2502$

Kaelin, W.G. Jr., and P.J. Ratcliffe. 2008. Oxygen sensing by metazoans: the central role of the HIF hydroxylase pathway. Mol. Cell. 30:393-402. https://doi.org/10.1016/j.molcel.2008.04.009

Karhausen, J., V.H. Haase, and S.P. Colgan. 2005. Inflammatory hypoxia: role of hypoxia-inducible factor. Cell Cycle. 4:255-257. https://doi.org/10 .4161/cc.4.2.1407

Klose, C.S.N., and D. Artis. 2016. Innate lymphoid cells as regulators of immunity, inflammation and tissue homeostasis. Nat. Immunol. 17: 765-774. https://doi.org/10.1038/ni.3489

Klose, C.S.N., E.A. Kiss, V. Schwierzeck, K. Ebert, T. Hoyler, Y. d'Hargues, N. Göppert, A.L. Croxford, A. Waisman, Y. Tanriver, and A. Diefenbach. 2013. A T-bet gradient controls the fate and function of CCR6-ROR $\gamma \mathrm{t}+$ innate lymphoid cells. Nature. 494:261-265. https://doi.org/10.1038/ nature11813

Krämer, B., F. Goeser, P. Lutz, A. Glässner, C. Boesecke, C. Schwarze-Zander D. Kaczmarek, H.D. Nischalke, V. Branchi, S. Manekeller, et al. 2017. Compartment-specific distribution of human intestinal innate lymphoid cells is altered in HIV patients under effective therapy. PLoS Pathog. 13:e1006373. https://doi.org/10.1371/journal.ppat.1006373

Krzywinska, E., C. Kantari-Mimoun, Y. Kerdiles, M. Sobecki, T. Isagawa, D. Gotthardt, M. Castells, J. Haubold, C. Millien, T. Viel, et al. 2017. Loss of HIF-1a in natural killer cells inhibits tumour growth by stimulating non-productive angiogenesis. Nat. Commun. 8:1597. https://doi.org/10 1038/s41467-017-01599-w

Kurban, G., V. Hudon, E. Duplan, M. Ohh, and A. Pause. 2006. Characterization of a von Hippel Lindau pathway involved in extracellular matrix remodeling, cell invasion, and angiogenesis. Cancer Res. 66:1313-1319. https://doi.org/10.1158/0008-5472.CAN-05-2560

Li, S., J.J. Heller, J.W. Bostick, A. Lee, H. Schjerven, P. Kastner, S. Chan, Z.E. Chen, and L. Zhou. 2016. Ikaros Inhibits Group 3 Innate Lymphoid Cell Development and Function by Suppressing the Aryl Hydrocarbon Receptor Pathway. Immunity. 45:185-197. https://doi.org/10.1016/j.immuni 2016.06.027

Lugo-Villarino, G., R. Maldonado-Lopez, R. Possemato, C. Penaranda, and L.H. Glimcher. 2003. T-bet is required for optimal production of IFN-gamma and antigen-specific T cell activation by dendritic cells. Proc. Natl. Acad. Sci. USA. 100:7749-7754. https://doi.org/10.1073/pnas.1332767100

Mao, K., A.P. Baptista, S. Tamoutounour, L. Zhuang, N. Bouladoux, A.J. Martins, Y. Huang, M.Y. Gerner, Y. Belkaid, and R.N. Germain. 2018 Innate and adaptive lymphocytes sequentially shape the gut microbiota and lipid metabolism. Nature. 554:255-259. https://doi.org/10.1038/ nature25437

Rankin, E.B., J.E. Tomaszewski, and V.H. Haase. 2006. Renal cyst development in mice with conditional inactivation of the von Hippel-Lindau tumor suppressor. Cancer Res. 66:2576-2583. https://doi.org/10.1158/ 0008-5472.CAN-05-3241

Rankin, L.C., J.R. Groom, M. Chopin, M.J. Herold, J.A. Walker, L.A. Mielke, A.N.J. McKenzie, S. Carotta, S.L. Nutt, and G.T. Belz. 2013. The transcription factor T-bet is essential for the development of NKp46+ innate lymphocytes via the Notch pathway. Nat. Immunol. 14:389-395. https://doi.org/10.1038/ni.2545 
Sanos, S.L., C. Vonarbourg, A. Mortha, and A. Diefenbach. 2011. Control of epithelial cell function by interleukin-22-producing ROR $\mathrm{t}+$ innate lymphoid cells. Immunology. 132:453-465. https://doi.org/10.1111/j.1365 $-2567.2011 .03410 . x$

Schödel, J., S. Oikonomopoulos, J. Ragoussis, C.W. Pugh, P.J. Ratcliffe, and D.R. Mole. 2011. High-resolution genome-wide mapping of HIF-binding sites by ChIP-seq. Blood. 117:e207-e217. https://doi.org/10.1182/blood $-2010-10-314427$

Schofield, C.J., and P.J. Ratcliffe. 2004. Oxygen sensing by HIF hydroxylases. Nat. Rev. Mol. Cell Biol. 5:343-354. https://doi.org/10.1038/nrm1366

Scholz, C.C., and C.T. Taylor. 2013. Targeting the HIF pathway in inflammation and immunity. Curr. Opin. Pharmacol. 13:646-653. https://doi .org/10.1016/j.coph.2013.04.009

Schroeder, J.-H., L.B. Roberts, K. Meissl, J.W. Lo, D. Hromadová, K. Hayes, T. Zabinski, E. Read, C. Moreira Heliodoro, R. Reis, et al. 2021. Sustained Post-Developmental T-Bet Expression Is Critical for the Maintenance of Type One Innate Lymphoid Cells In Vivo. Front. Immunol. 12:760198. https://doi.org/10.3389/fimmu.2021.760198

Sciumé, G., K. Hirahara, H. Takahashi, A. Laurence, A.V. Villarino, K.L. Singleton, S.P. Spencer, C. Wilhelm, A.C. Poholek, G. Vahedi, et al. 2012. Distinct requirements for T-bet in gut innate lymphoid cells. J. Exp. Med. 209:2331-2338. https://doi.org/10.1084/jem.20122097

Seillet, C., K. Luong, J. Tellier, N. Jacquelot, R.D. Shen, P. Hickey, V.C. Wimmer, L. Whitehead, K. Rogers, G.K. Smyth, et al. 2020. The neuropeptide VIP confers anticipatory mucosal immunity by regulating ILC3 activity. Nat. Immunol. 21:168-177. https://doi.org/10.1038/s41590 -019-0567-y

Semenza, G.L. 2012. Hypoxia-inducible factors in physiology and medicine. Cell. 148:399-408. https://doi.org/10.1016/j.cell.2012.01.021

Shannon, P., A. Markiel, O. Ozier, N.S. Baliga, J.T. Wang, D. Ramage, N. Amin, B. Schwikowski, and T. Ideker. 2003. Cytoscape: a software environment for integrated models of biomolecular interaction networks. $\mathrm{Ge}$ nome Res. 13:2498-2504. https://doi.org/10.1101/gr.1239303

Sobecki, M., E. Krzywinska, S. Nagarajan, A. Audigé, K. Huỳnh, J. Zacharjasz, J. Debbache, Y. Kerdiles, D. Gotthardt, N. Takeda, et al. 2021. NK cells in hypoxic skin mediate a trade-off between wound healing and antibacterial defence. Nat. Commun. 12:4700. https://doi.org/10.1038/s41467 -021-25065-w

Srinivas, S., T. Watanabe, C.S. Lin, C.M. William, Y. Tanabe, T.M. Jessell, and F. Costantini. 2001. Cre reporter strains produced by targeted insertion of EYFP and ECFP into the ROSA26 locus. BMC Dev. Biol. 1:4. https://doi .org/10.1186/1471-213X-1-4

Takeda, N., E.L. O'Dea, A. Doedens, J.-W. Kim, A. Weidemann, C. Stockmann, M. Asagiri, M.C. Simon, A. Hoffmann, and R.S. Johnson. 2010. Differential activation and antagonistic function of HIF- $\alpha$ isoforms in macrophages are essential for NO homeostasis. Genes Dev. 24:491-501. https://doi.org/10.1101/gad.1881410

Talbot, J., P. Hahn, L. Kroehling, H. Nguyen, D. Li, and D.R. Littman. 2020. Feeding-dependent VIP neuron-ILC3 circuit regulates the intestinal barrier. Nature. 579:575-580. https://doi.org/10.1038/s41586-020-2039-9
Tambuwala, M.M., E.P. Cummins, C.R. Lenihan, J. Kiss, M. Stauch, C.C. Scholz, P. Fraisl, F. Lasitschka, M. Mollenhauer, S.P. Saunders, et al. 2010. Loss of prolyl hydroxylase-1 protects against colitis through reduced epithelial cell apoptosis and increased barrier function. Gastroenterology. 139:2093-2101. https://doi.org/10.1053/j.gastro.2010 .06 .068

Tambuwala, M.M., M.C. Manresa, E.P. Cummins, V. Aversa, I.S. Coulter, and C.T. Taylor. 2015. Targeted delivery of the hydroxylase inhibitor DMOG provides enhanced efficacy with reduced systemic exposure in a murine model of colitis. J. Control. Release. 217:221-227. https://doi.org/10 .1016/j.jconrel.2015.09.022

Taylor, C.T., and S.P. Colgan. 2017. Regulation of immunity and inflammation by hypoxia in immunological niches. Nat. Rev. Immunol. 17:774-785. https://doi.org/10.1038/nri.2017.103

Taylor, C.T., G. Doherty, P.G. Fallon, and E.P. Cummins. 2016. Hypoxiadependent regulation of inflammatory pathways in immune cells. J. Clin. Invest. 126:3716-3724. https://doi.org/10.1172/JCI84433

Verrier, T., N. Satoh-Takayama, N. Serafini, S. Marie, J.P. Di Santo, and C.A.J. Vosshenrich. 2016. Phenotypic and Functional Plasticity of Murine Intestinal NKp46+ Group 3 Innate Lymphoid Cells. J. Immunol. 196: 4731-4738. https://doi.org/10.4049/jimmunol.1502673

Viant, C., L.C. Rankin, M.J.H. Girard-Madoux, C. Seillet, W. Shi, M.J. Smyth, L. Bartholin, T. Walzer, N.D. Huntington, E. Vivier, and G.T. Belz. 2016. Transforming growth factor- $\beta$ and Notch ligands act as opposing environmental cues in regulating the plasticity of type 3 innate lymphoid cells. Sci. Signal. 9:ra46. https://doi.org/10.1126/scisignal.aaf2176

Vonarbourg, C., A. Mortha, V.L. Bui, P.P. Hernandez, E.A. Kiss, T. Hoyler, M. Flach, B. Bengsch, R. Thimme, C. Hölscher, et al. 2010. Regulated expression of nuclear receptor RORYt confers distinct functional fates to NK cell receptor-expressing ROR $\gamma \mathrm{t}(+)$ innate lymphocytes. Immunity. 33:736-751. https://doi.org/10.1016/j.immuni.2010.10.017

Wang, X., N. Ota, P. Manzanillo, L. Kates, J. Zavala-Solorio, C. Eidenschenk, J. Zhang, J. Lesch, W.P. Lee, J. Ross, et al. 2014. Interleukin-22 alleviates metabolic disorders and restores mucosal immunity in diabetes. Nature. 514:237-241. https://doi.org/10.1038/nature13564

Wang, Y., Z. Kuang, X. Yu, K.A. Ruhn, M. Kubo, and L.V. Hooper. 2017. The intestinal microbiota regulates body composition through NFIL3 and the circadian clock. Science. 357:912-916. https://doi.org/10.1126/science .aan0677

Wenger, R.H., D.P. Stiehl, and G. Camenisch. 2005. Integration of oxygen signaling at the consensus HRE. Sci. STKE. 2005:rel2. https://doi.org/10 $.1126 /$ stke.3062005re12

Zhao, J., A. Jaffe, H. Li, O. Lindenbaum, E. Sefik, R. Jackson, X. Cheng, R.A. Flavell, and Y. Kluger. 2021. Detection of differentially abundant cell subpopulations in scRNA-seq data. Proc. Natl. Acad. Sci. USA. 118: e2100293118. https://doi.org/10.1073/pnas.2100293118

Zhou, L., C. Chu, F. Teng, N.J. Bessman, J. Goc, E.K. Santosa, G.G. Putzel, H. Kabata, J.R. Kelsen, R.N. Baldassano, et al. 2019. Innate lymphoid cells support regulatory $\mathrm{T}$ cells in the intestine through interleukin-2. $\mathrm{Na}$ ture. 568:405-409. https://doi.org/10.1038/s41586-019-1082-x 


\section{Supplemental material}




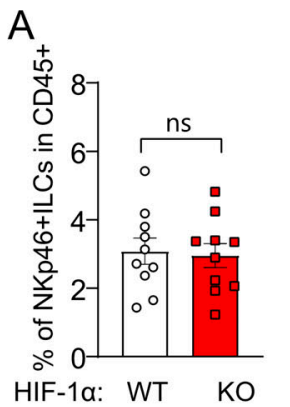

B

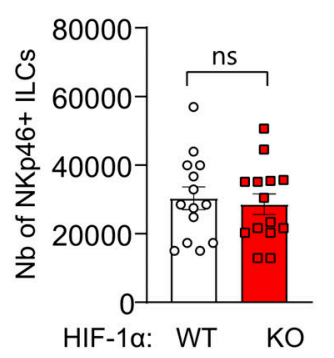

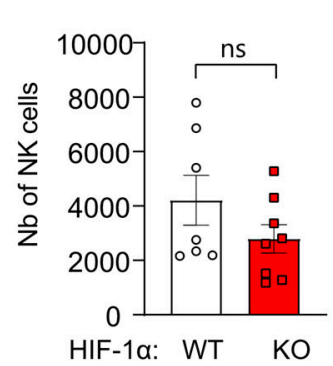

C

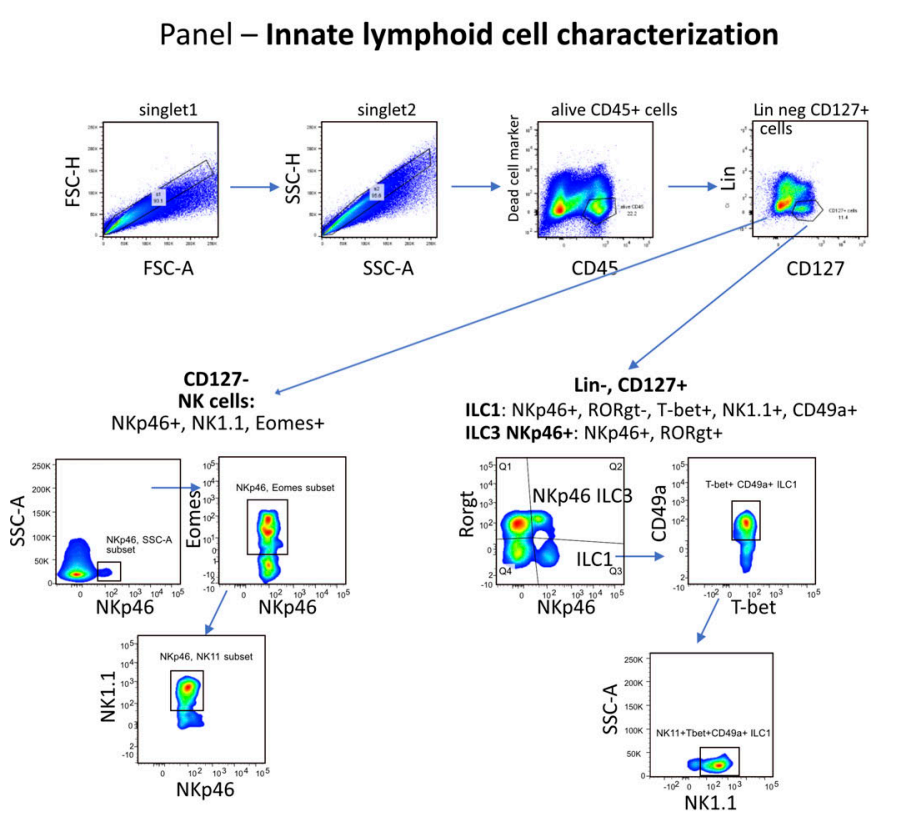

Panel - Lymphoid \& Myeloid cell characterization

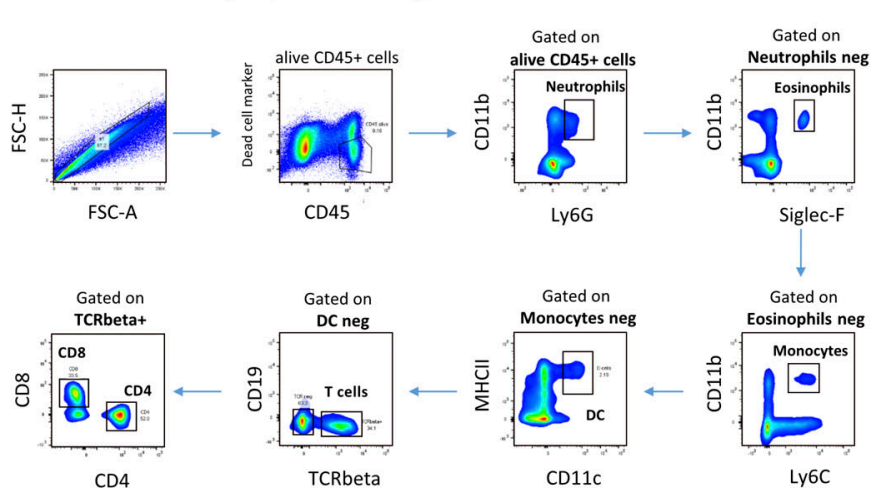

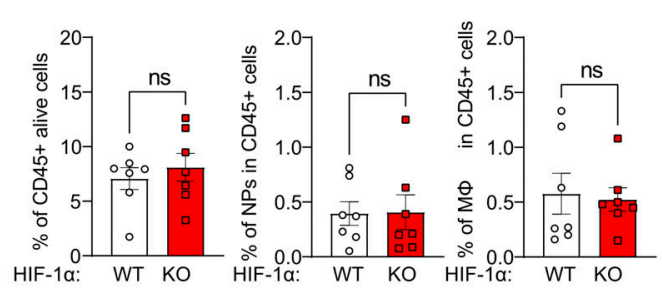
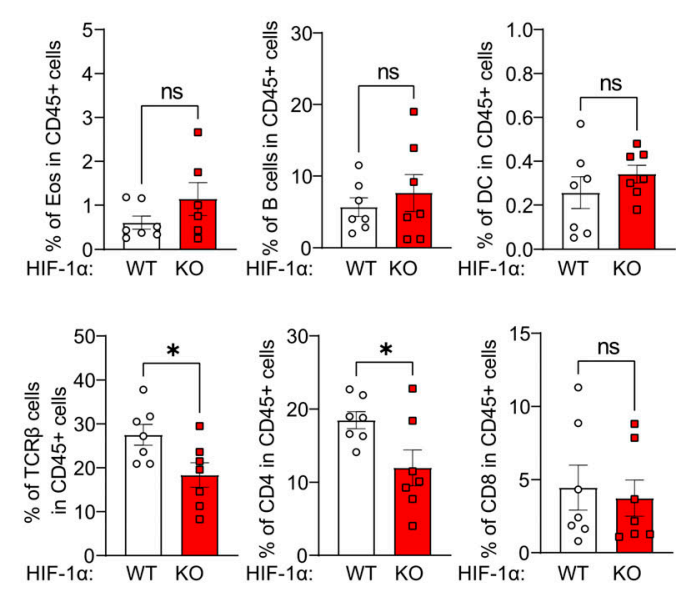

$\mathrm{D}$

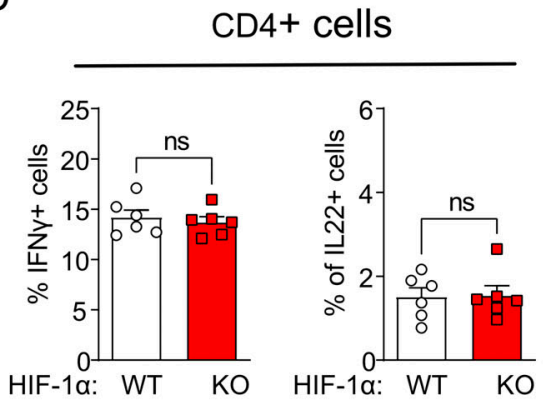

Figure S1. HIF-1a in NKp46+ cells favors an ILC1 phenotype and controls homeostasis in the SI. (A) The frequency and absolute number (Nb) of small intestinal NKp46+ ILCs together with NK cells in CD45 $5^{+}$population, from HIF-1a KO and HIF-la WT mice (pooled data of three independent experiments, $n \geq 7$ ); data are mean values \pm SEM; two-tailed Student's $t$ test. (B) Gating strategy, upper panel: ILC characterization, the analysis of alive CD45+ in $^{-}$CD127 $7^{+}$ILCs; ILC1 (NKp46+ RORyt $^{-}$T-bet $^{+}$NK1.1 $1^{+}$CD49a ${ }^{+}$); NKp46+ ILC3 (NKp46+ RORyt ${ }^{+}$CD49a-). Lower panel: lymphoid and myeloid cell characterization: the analysis of alive $\mathrm{CD}_{4} 5^{+}$cells; neutrophils $\left(\mathrm{CD} 11 \mathrm{~b}^{+} \mathrm{Ly}_{6 \mathrm{G}^{+}}\right)$; eosinophils $\left(\mathrm{CD} 11 \mathrm{~b}^{+}\right.$Siglec- $\left.\mathrm{F}^{+}\right)$; macrophages $\left(\mathrm{CD} 11 \mathrm{~b}^{+} \mathrm{Ly}_{6 \mathrm{C}^{+}} \mathrm{F} 4 / 80^{+}\right)$; dendritic cells $\left(\mathrm{MHClI}^{+} \mathrm{CD} 11 \mathrm{c}^{+}\right)$; B cells

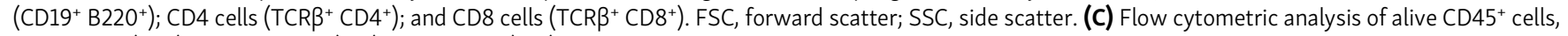
neutrophils (NPs), macrophages (M\$), eosinophils (Eos), B cells, total T cells, CD4 cells, CD8 cells, and dendritic cells from steady-state small intestinal tissues from HIF-1a KO and HIF-la WT mice (pooled data of two independent experiments, $n \geq 7$ ); data are mean values \pm SEM; ${ }^{*}, \mathrm{P}<0.05$ by two-tailed Student's $t$ test. (D) Flow cytometric analysis of CD4+ cells stimulated with PMA/ionomycin and stained for intracellular IFN-y and IL-22 from HIF-la KO and HIF-1a WT mice $(n=6)$; data are mean values \pm SEM; two-tailed Student's $t$ test. 
A

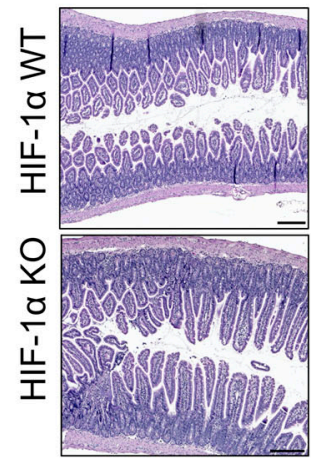

B

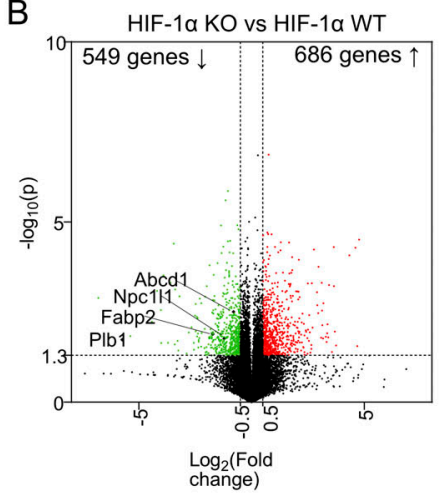

C Top 4 GOs
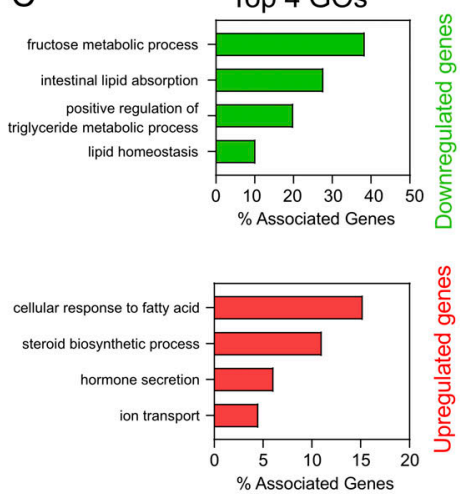

D Downregulated genes

Upregulated genes

from GO enrich. analysis

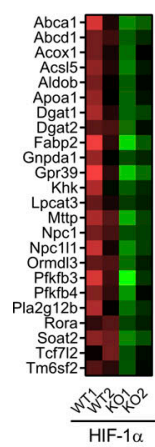

from $\mathrm{GO}$ enrichment analysis

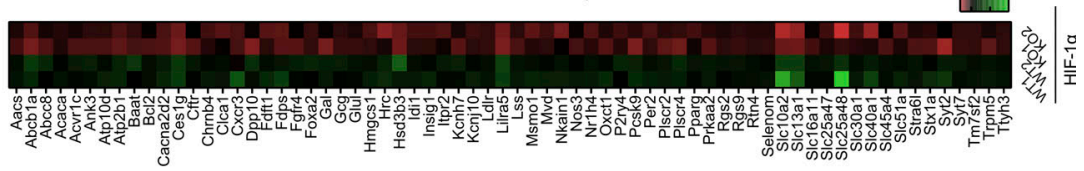

E
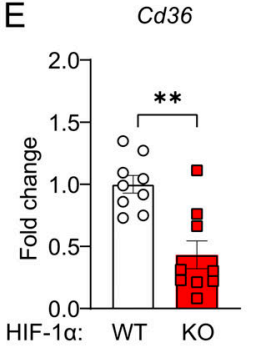

Fabp2

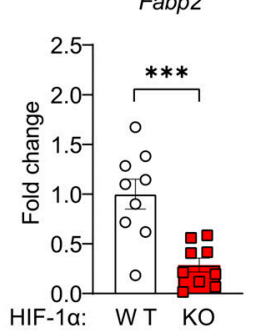

Npc111

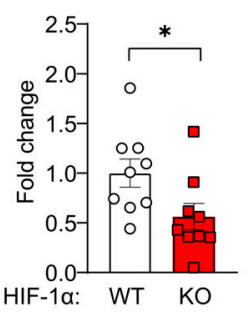

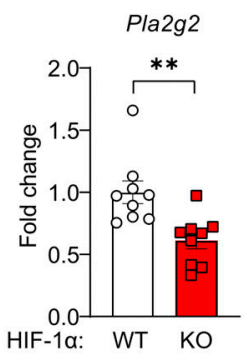

F

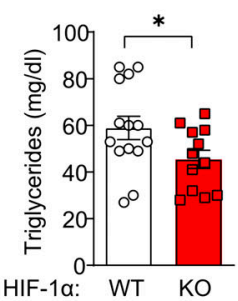

$\mathrm{H}$

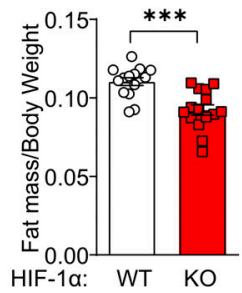

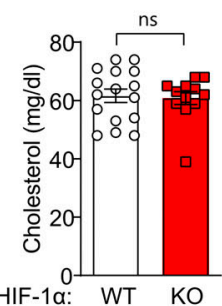

HIF-1a: WT KO

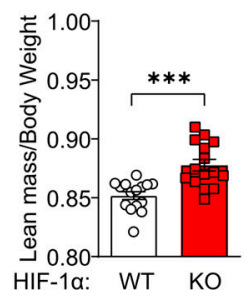

G

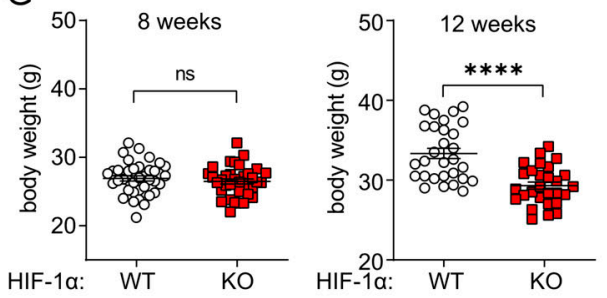

I

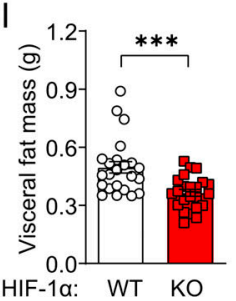

Figure S2. HIF-1a in NKp46+ cells favors an ILC1 phenotype and controls homeostasis in the SI. (A) Representative H\&E staining of small intestinal tissues from HIF-1a KO and HIF-1a WT mice at steady state; scale bar, $100 \mu \mathrm{m}$. (B) Volcano plot of the gene expression profile of small intestinal tissues from HIF-1a KO and HIF-1a WT mice. Red data points meet the thresholds of $\log 2$ (fold-change [FC]) $>0.5$ and green points less than $-0.5 ; P<0.05$. (C) GO term enrichment analysis of the up-regulated genes (red bars) and down-regulated genes (green bars). The vertical coordinate is the enriched $\mathrm{GO}$ term, and the horizontal coordinate is the percentage of identified and associated genes within a $G O$ term group. Associated genes met the significance ( $P \leq 0.001)$. (D) Left: Heatmap of down-regulated gene expression of small intestinal tissues from HIF-1a KO mice significantly associated with identified GO terms. Right: Heatmap of up-regulated gene expression of small intestinal tissues from HIF-1a KO mice significantly associated with identified GO terms. (E) Gene expression analysis of Cd36, Fabp2, Npc1l1, and Pla2g2 in small intestinal tissue from HIF-1a KO and HIF-1a WT mice (pooled data of three independent experiments, $n=9$ ); data are mean values $\pm \mathrm{SEM} ;{ }^{*}, \mathrm{P}<0.05 ;{ }^{* *}, \mathrm{P}<0.01 ;{ }^{* * *}, \mathrm{P}<0.001$ by two-tailed Student's $t$ test. (F) Serum triglyceride and cholesterol levels from HIF-1a KO and HIFla WT mice (pooled data of four independent experiments, $n>12$ ); data are mean values \pm SEM; ${ }^{*}, P<0.05$ by two-tailed Student's $t$ test. (G) Body weight of 8 wk-old (left) and 12-wk-old (right) HIF-1a KO and HIF-1a WT mice (pooled data of four independent experiments, $n>20$ ); data are mean values \pm SEM; ${ }^{* * * *}$, $\mathrm{P}<0.0001$ by two-tailed Student's $t$ test. $(\mathrm{H})$ Ratio of adipose weight to total weight (left) and ratio of lean weight to total weight from HIF-1a KO and HIFla WT mice determined by EchoMRI (pooled data of four independent experiments, $n>16$ ); data are mean values \pm SEM; ${ }^{* * *}, P<0.001$ by two-tailed Student's $t$ test. (I) Visceral fat mass from HIF-1a KO and HIF-1a WT mice (pooled data of four independent experiments, $n=20$ ); data are mean values \pm SEM; ${ }^{* * *}, P<$ 0.001 by two-tailed Student's $t$ test. 


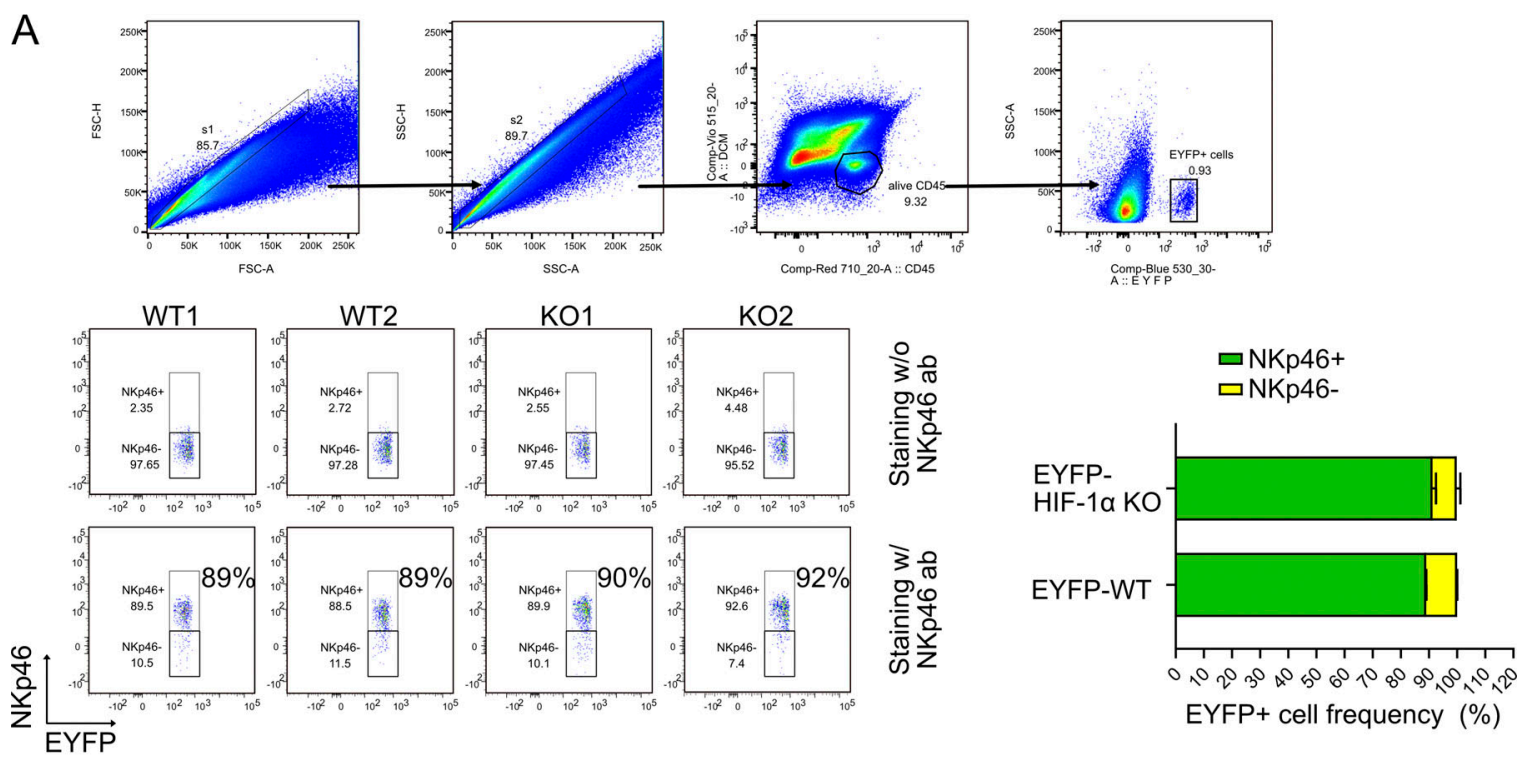

B
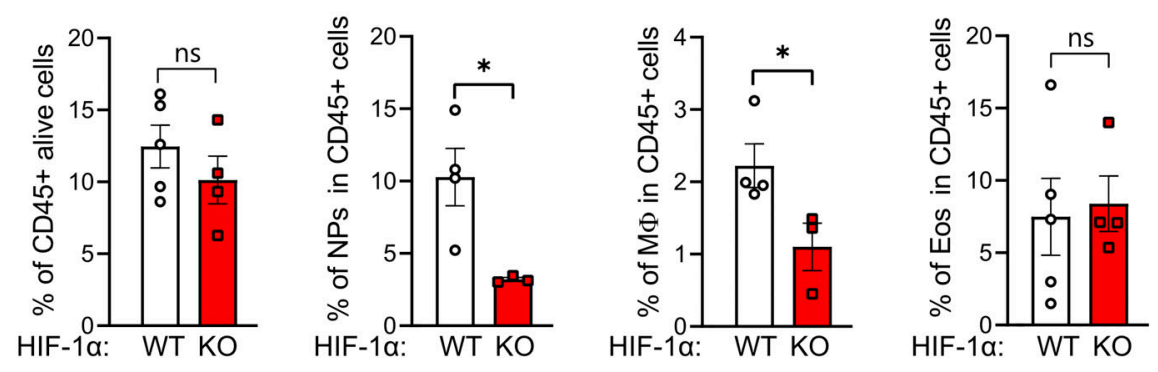

- HIF-1a WT
- HIF-1a KO
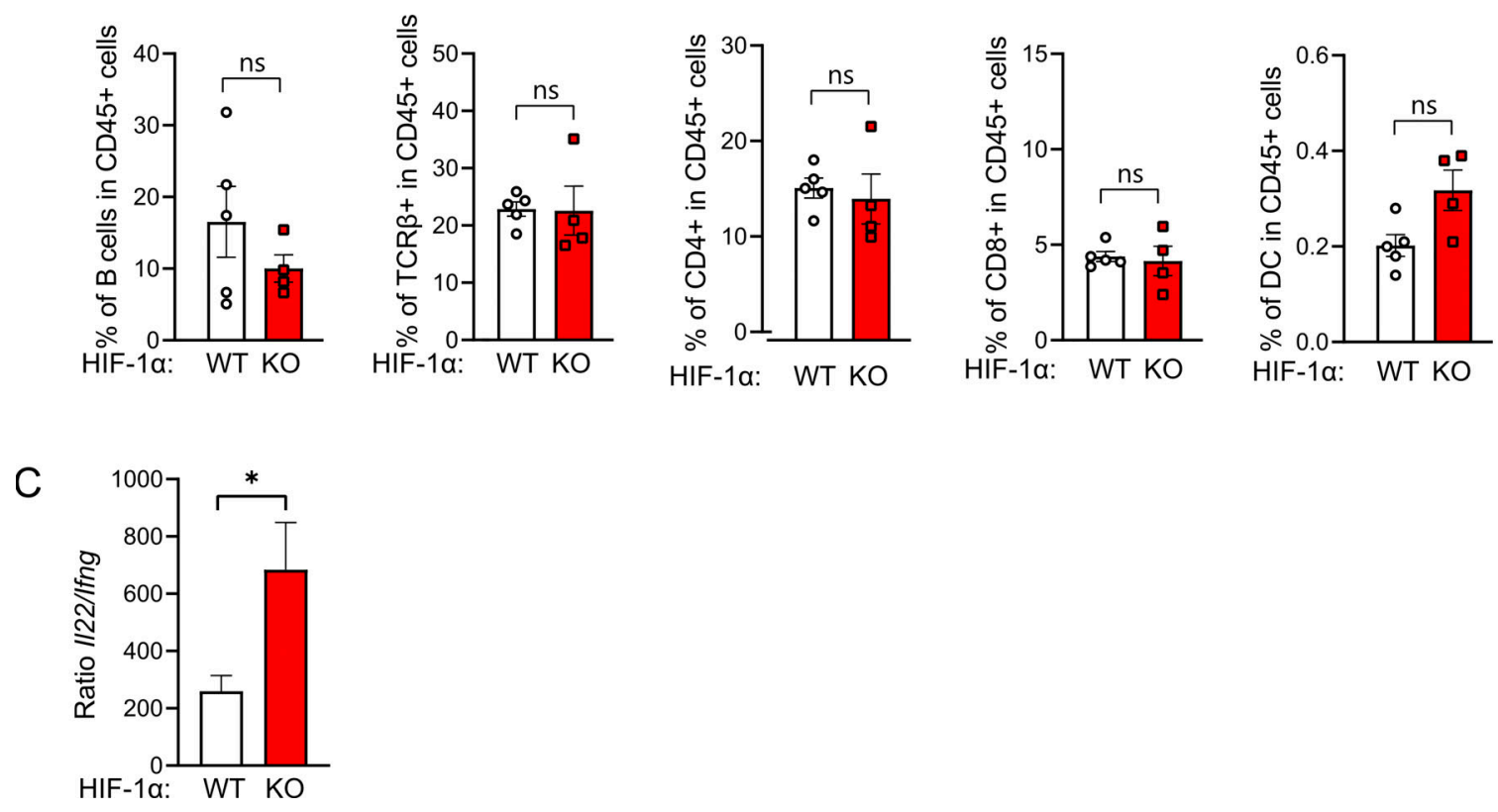

Figure S3. HIF-1a in NKp46+ cells controls susceptibility to the small intestinal damage induced by MTX. (A) NKp46 expression status of EYFP+ ${ }^{+}$cells purified from SI of EYFP-WT and EYFP-HIF-1a KO mice. Top: Gating strategy for EYFP+ cells. Bottom: Representative dot plots of NKp46 ${ }^{+}$expression by EYFP ${ }^{+}$ cells together with no NKp46+ staining control purified from SI of EYFP-WT (WT1, WT2) and EYFP-HIF-1a KO (KO1, KO2) mice with corresponding quantitative analysis. FSC, forward scatter; SSC, side scatter. (B) Flow cytometric analysis of alive CD45+ cells, neutrophils (NPs), macrophages (M $\phi)$, eosinophils (Eos), B cells, total T cells, CD4 cells, CD8 cells, and dendritic cells from small intestinal tissues after MTX treatment on day 1 after treatment from HIF-1a KO and HIFla WT mice $(n \geq 4)$; data are mean values \pm SEM; ${ }^{*}, P<0.05$ by two-tailed Student's $t$ test. (C) Ratio of Il22 expression to Ifng expression in small intestinal tissues after MTX treatment from HIF-la KO and HIF-1a WT mice (pooled data of two independent experiments, $n=6$ ); data are mean values \pm SEM; ${ }^{*}, P<0.05$ by two-tailed Student's $t$ test. 
A

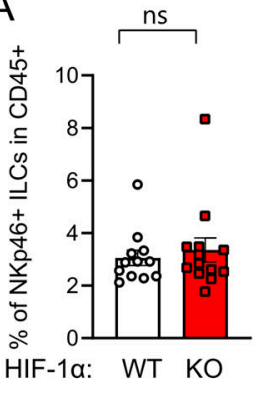

C

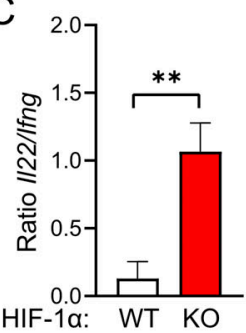

D
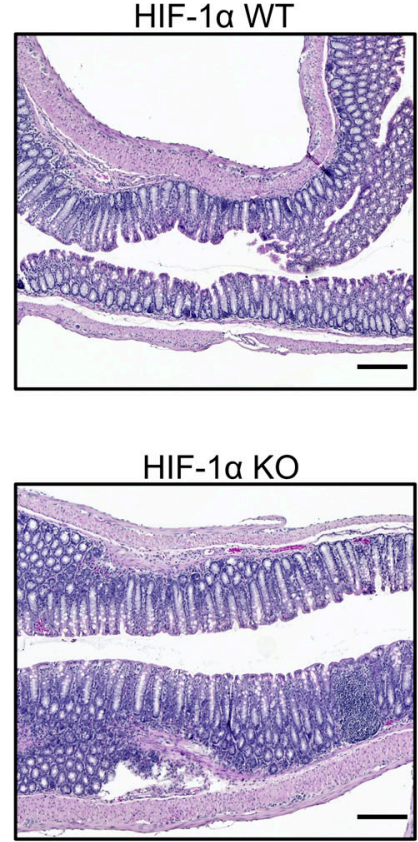

B
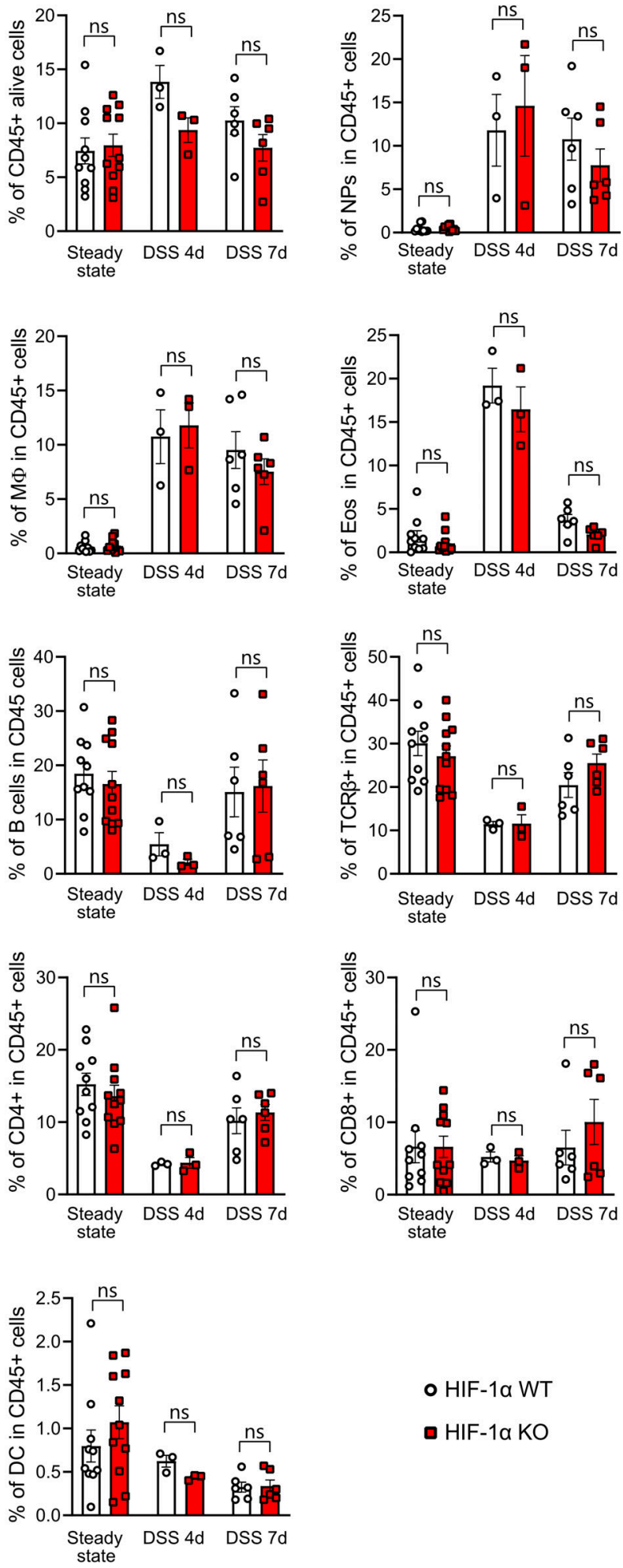

Figure S4. HIF-1a in NKp46+ cells controls the microbiome and susceptibility to colitis. (A) The frequency and absolute number (Nb) of large intestinal NKp46 ILCs in CD45+ population from HIF-1a KO and HIF-1a WT mice (pooled data of four independent experiments, $n \geq 13$ ); data are mean values \pm SEM; two-tailed Student's $t$ test. (B) Flow cytometric analysis of alive CD45 cells, neutrophils (NPs), macrophages (M $\phi$ ), eosinophils (Eos), B cells, total T cells, CD4 cells, CD8 cells, and dendritic cells at the steady state and after DSS treatment on day 4 after treatment and day 7 after treatment from large intestinal tissues from HIF-1a KO and HIF-1a WT mice (pooled data of four independent experiments for steady-state analysis, $n=10$; one experiment for DSS midpoint analysis, $n \geq 3$; two experiments for DSS endpoint analysis, $n=6$ ); data are mean values \pm SEM; two-way ANOVA test. (C) Ratio of Il22 expression to Ifng expression in large intestinal tissues from HIF-la KO and HIF-1a WT mice (pooled data of two independent experiments, $n=6$ ); data are mean values \pm SEM; ${ }^{* *}$, P $<0.01$ by two-tailed Student's $t$ test. (D) Representative H\&E staining of large intestinal tissues from HIF-1a KO and WT mice; scale bar, $100 \mu \mathrm{m}$. 
A

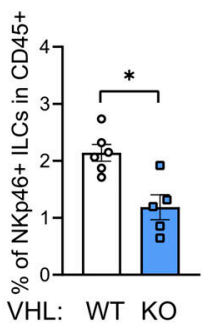

C
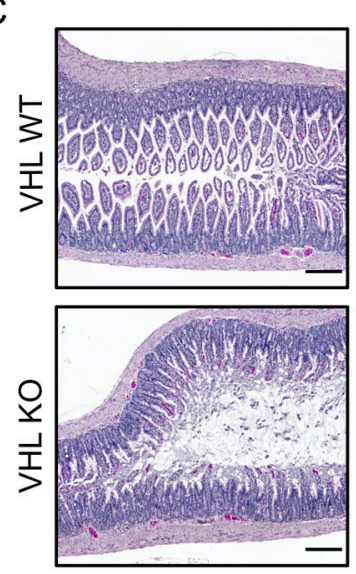

B
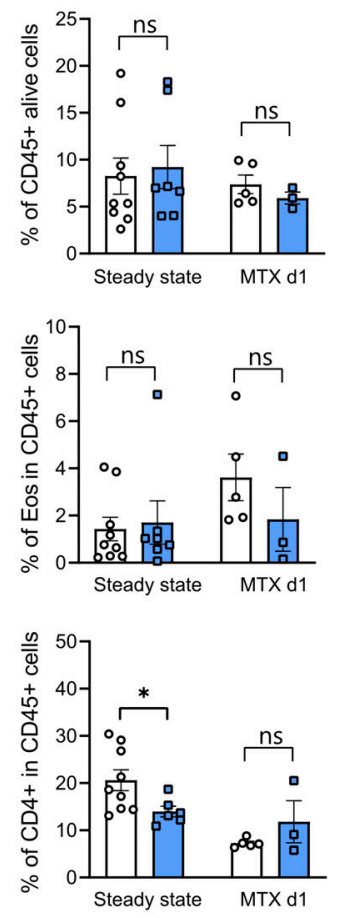
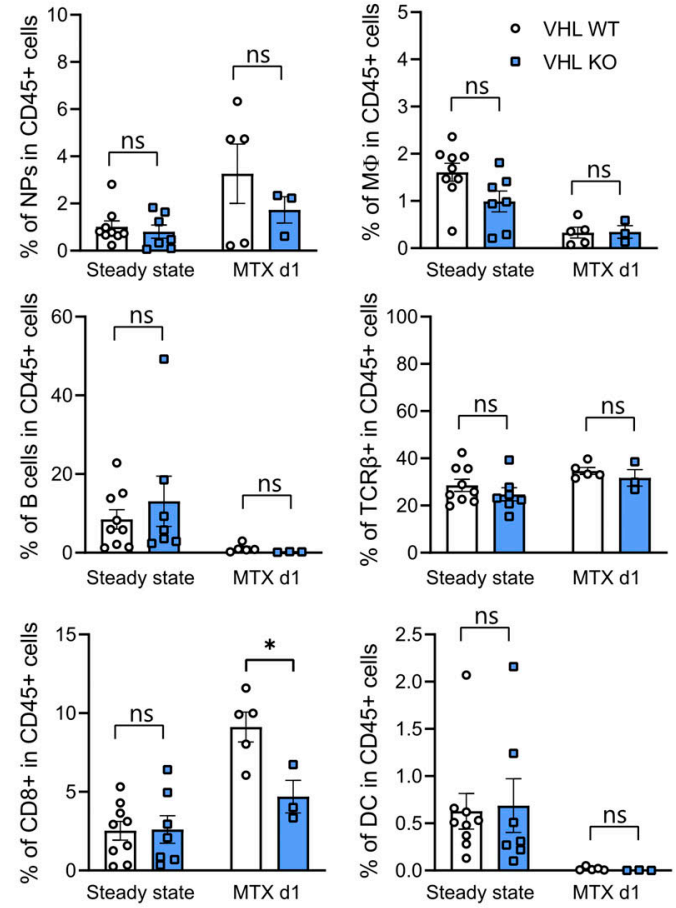

D
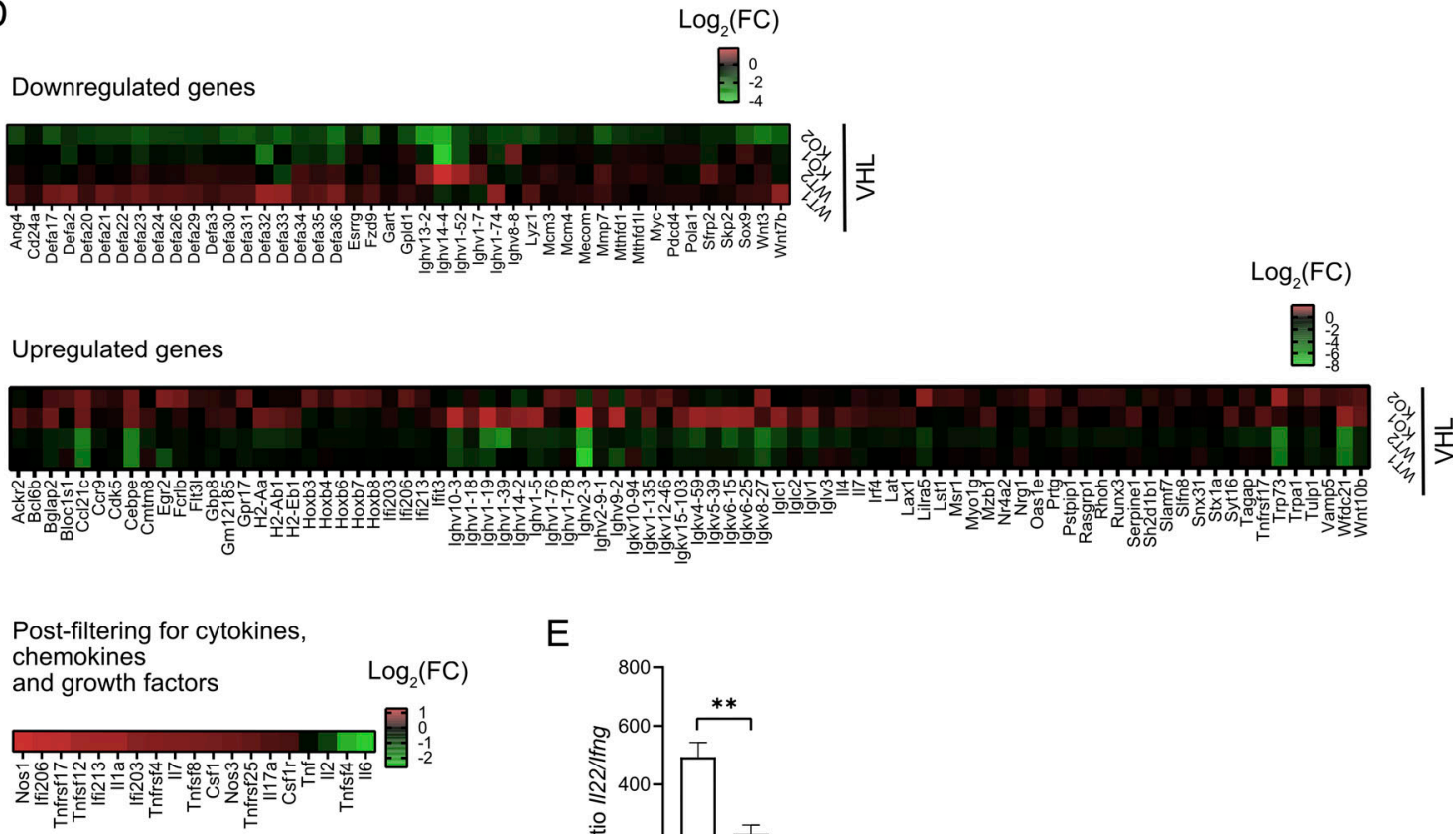

$\mathrm{E}$

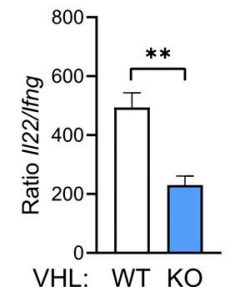

Figure S5. Constitutive expression of HIF-1a in NKp46+ cells reduces ILC numbers in the SI and increases the susceptibility to mucosal damage. (A) The frequency of small intestinal NKp46+ ILCs in CD45 population from VHL KO and VHL WT mice (pooled data of two independent experiments, $n \geq 5$ ); data are mean values \pm SEM; ${ }^{*}, P<0.05$ by two-tailed Student's $t$ test. (B) Flow cytometric analysis of alive CD45 ${ }^{+}$cells, neutrophils (NPs), macrophages (M $\left.\phi\right)$, eosinophils (Eos), B cells, total T cells, CD4 cells, CD8 cells, and dendritic cells at the steady state and after MTX treatment on day 1 after treatment from small intestinal tissues from VHL KO and VHL WT mice $(n \geq 3)$; data are mean values \pm SEM; ${ }^{*}, P<0.05$ by two-way ANOVA. (C) Representative H\&E staining of small intestinal tissues from VHL KO and VHL WT mice; scale bar, $100 \mu \mathrm{m}$. (D) Top: Heatmap of down-regulated gene expression of small intestinal tissues from VHL KO mice significantly associated with identified GO terms. Middle: Heatmap of up-regulated gene expression of small intestinal tissues from VHL KO mice significantly associated with identified GO terms. Bottom: Heatmap of gene expression of small intestinal tissues from VHL KO mice with a significantly differential expression to the small intestinal samples from VHL WT mice from the post-filtered (cytokines, chemokines, growth factors) pool of genes. FC, foldchange. (E) Ratio of II22 expression to Ifng expression in small intestinal tissues from VHL KO and VHL WT mice (pooled data of two independent experiments, $n=6)$; data are mean values \pm SEM; ${ }^{* *}, P<0.01$ by two-tailed Student's $t$ test. 